Facultad de Ciencias Jurídicas y Económicas

Departamento de Finanzas y Contabilidad

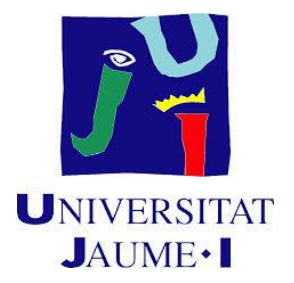

\title{
La Sostenibilidad del Sistema Sanitario en la España
} Descentralizada de las Autonomías.

\section{TESIS DOCTORAL}

\author{
Presentada por: \\ Miguel Ángel Moyano Santiago \\ Dirigida por: \\ Dra. Juana María Rivera Lirio
}

Castellón, septiembre 2015 


\section{La Sostenibilidad del Sistema Sanitario en la España Descentralizada de las Autonomías.}

Doctorando: Miguel Ángel Moyano Santiago Directora: Juana María Rivera Lirio Septiembre, 2015 
A tantas personas que me han acompañado en este camino...

Para Amparo y Gabriel

"El mundo era tan reciente que muchas cosas carecían de nombre, y para mencionarlas había que señalarlas con el dedo"

Cien años de soledad. Gabriel García Márquez. 


\section{RECONOCIMIENTOS}

En algún momento siempre toca cerrar una puerta detrás de la que quizá hemos pasado largos momentos de alegrías y sinsabores, este es uno de ellos. La travesía que supone realizar un trabajo como el presente requiere tiempo, paciencia y el apoyo de muchas personas.

Quiero agradecer especialmente a mi directora de tesis, Juana María Rivera Lirio su confianza y el apoyo recibido a lo largo de estos años, en los que nos ha tocado vivir simultáneamente con la realización de la investigación en sanidad, uno de los períodos de mayores cambios y transformaciones en nuestro país en dicho sector.

También quiero brindar un agradecimiento especial a la Universidad Comillas, por ofrecerme la oportunidad de participar en el IV Taller de Doctorandos en Los Molinos en 2014, fue además de una grata experiencia, una oportunidad inmejorable de recibir feedback de un tribunal de profesores y académicos acreditados acerca de la evolución del trabajo de tesis.

Agradezco a la universidad Jaume I de Castellón los apoyos, medios y servicios puestos a disposición de los doctorandos para la realización de la investigación durante todos estos años. Por último este trabajo no habría sido posible sin la desinteresada y generosa contribución en las diferentes investigaciones realizadas de personas a las que ni siquiera conozco personalmente y a las que por diferentes medios solicité apoyo. Han participado de un modo u otro: administraciones públicas, instituciones sanitarias, universidades, asociaciones de pacientes, empresas privadas, investigadores y un largo etcétera de personas vinculadas a la sanidad. 
ÍNDICE DE CONTENIDOS 


\section{Introducción}

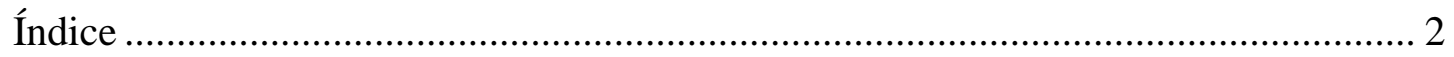

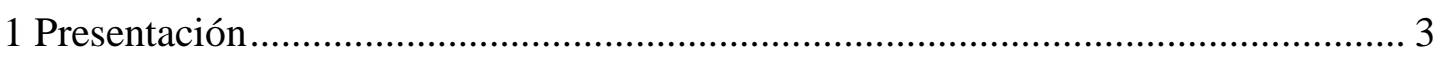

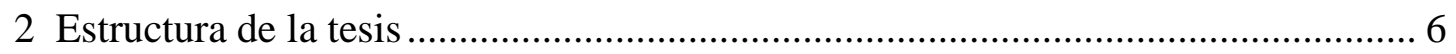

2.1 La sostenibilidad del sistema sanitario español. Una visión desde la gestión

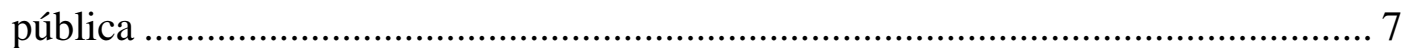

2.2 El enfoque de sostenibilidad en los planes de salud de las comunidades autónomas: el desarrollo sostenible como oportunidad.......................................... 10

2.3 Aspectos relevantes para el diseño de planes de salud sostenibles orientados a los grupos de interés. Una propuesta basada en la guía ISO 26000:2010 .............. 12

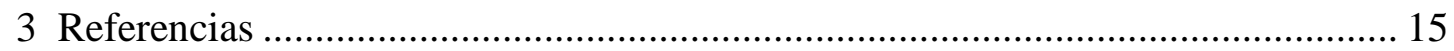

\section{Capítulo 1: La sostenibilidad del sistema sanitario español. Una visión desde la} gestión pública.

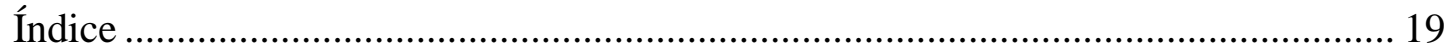

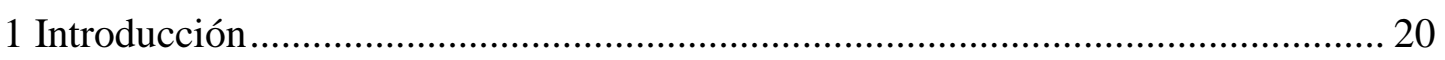

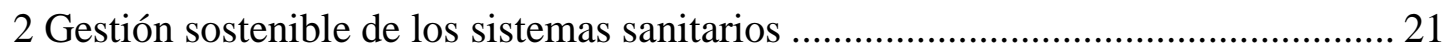

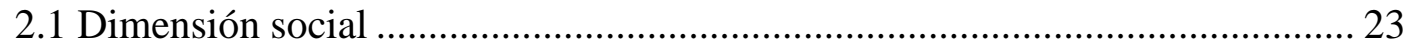

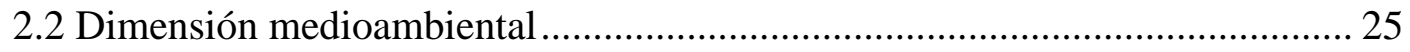

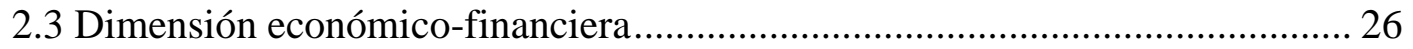

$2.4 \mathrm{El} \mathrm{rol} \mathrm{de} \mathrm{los} \mathrm{gestores} \mathrm{públicos} \mathrm{en} \mathrm{los} \mathrm{sistemas} \mathrm{de} \mathrm{salud} \mathrm{...............................} 27$

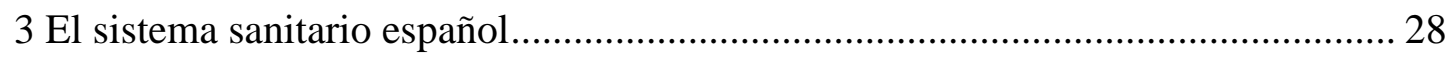

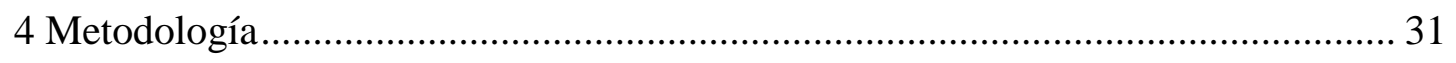

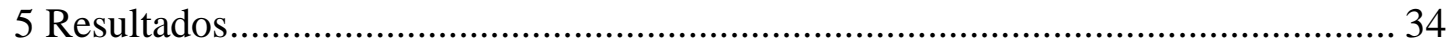

6 Comentarios a la entrevista semi-estructurada al consejero de sanidad de una

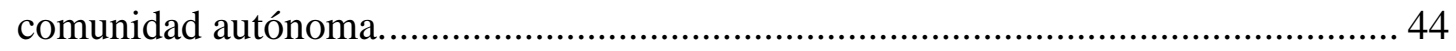

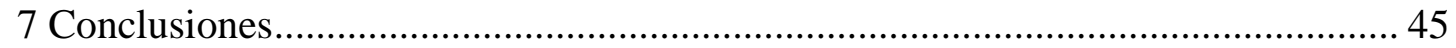

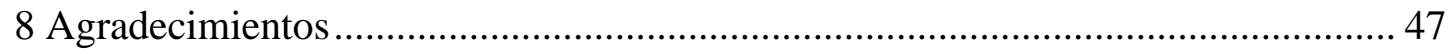

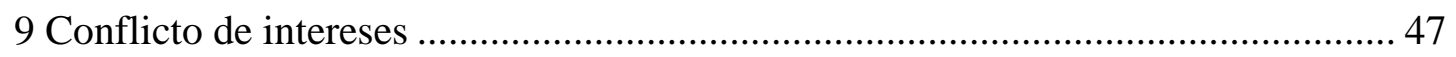

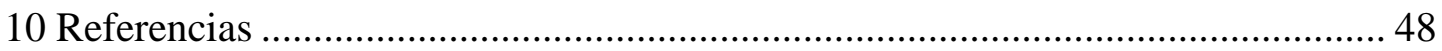


Capítulo 2: El enfoque de sostenibilidad en los planes de salud de las comunidades autónomas: el desarrollo sostenible como oportunidad..........................................56

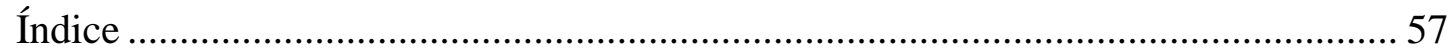

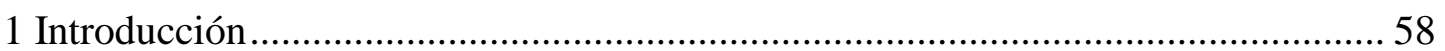

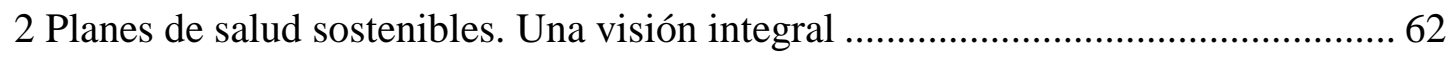

2.1 La cuestión económica en los programas y planes de salud............................... 63

2.2 La vertiente social como driver de las intervenciones en los programas y planes

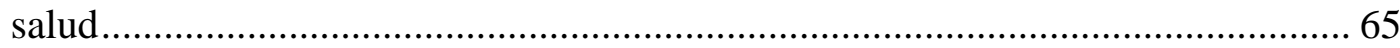

2.3 El contexto y la teoría ecológica en los planes de salud.................................. 68

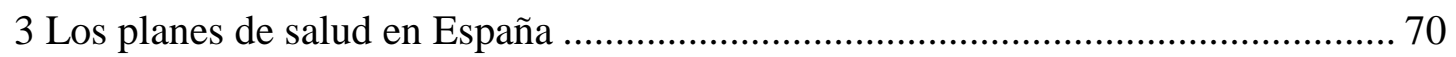

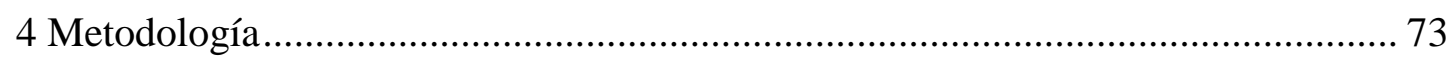

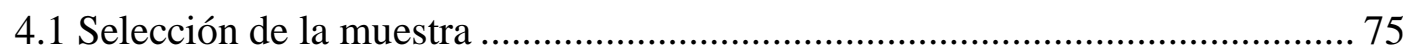

4.2 Sensibilidad simbólica y operativa en las tres dimensiones clásicas del

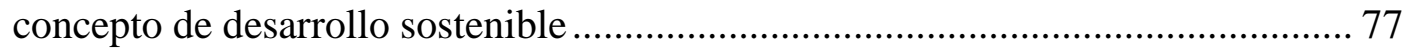

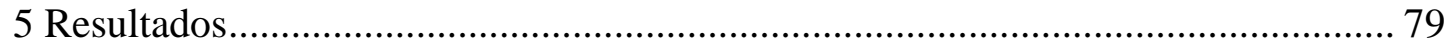

5.1 Índice de Sensibilidad Simbólica (ISS) ........................................................ 80

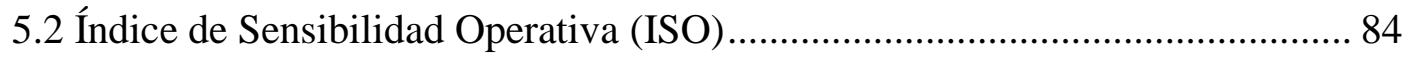

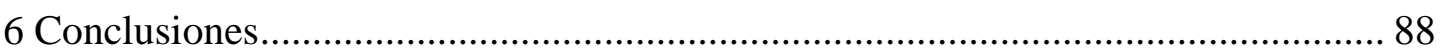

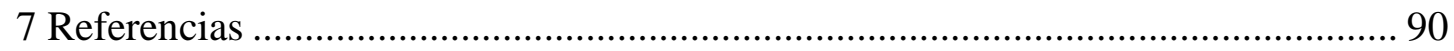

Capítulo 3: Aspectos relevantes para el diseño de planes de salud sostenibles orientados a los grupos de interés. Una propuesta basada en la guía ISO

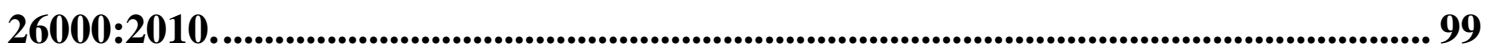

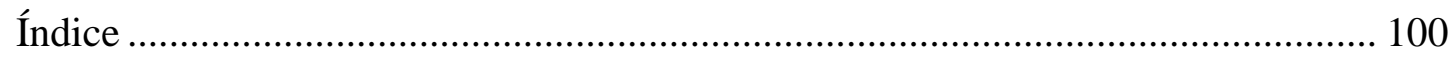

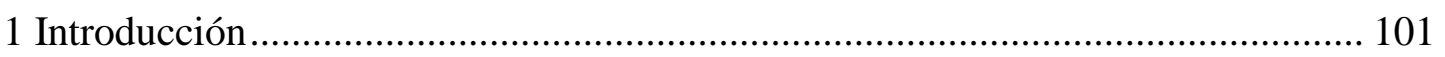

2 De los procesos a la gestión de impactos. .............................................................. 104

2.1 ISO 26000:2010: materias y asuntos en relación con sanidad. ...................... 106

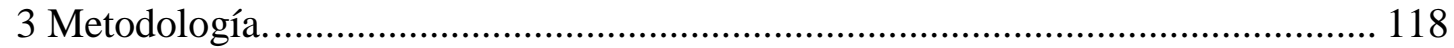

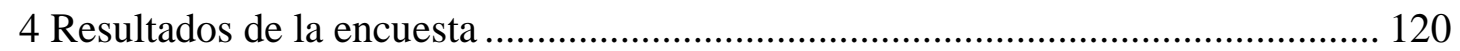

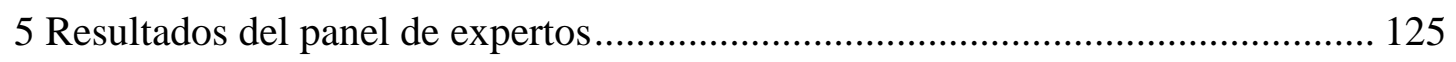

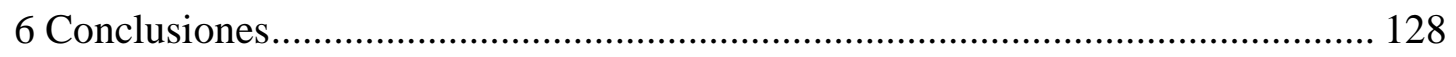

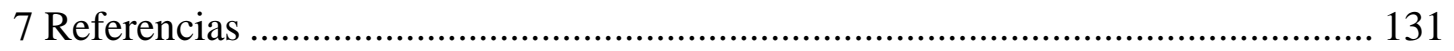


ÍNDICE DE FIGURAS GRÁFICOS Y TABLAS 


\section{Capítulo 1}

Tabla 1 Distribución de la muestra 33

Gráfico I Aspectos relevantes en un sistema sanitario sostenible 35

Gráfico II Afirmaciones sobre cuestiones relacionadas con la sostenibilidad del $\begin{array}{ll}\text { sistema sanitario } & 36\end{array}$

Gráfico III Relevancia de la ley de economía sostenible 37

Gráfico IV Comparación aspectos sociales versus económicos 38

Gráfico V Comparación aspectos medioambientales versus económicos $\quad 39$

Gráfico VI Relevancia de los aspectos económicos para el sistema sanitario $\quad 40$

Gráfico VII Nivel de cumplimiento de los objetivos de la Agenda 21 en sanidad 41

Gráfico VIII Opinión sobre el sistema sanitario español ¿Es sostenible? 42

Gráfico IX Posibilidad de considerar a los grupos de interés en las políticas

públicas en sanidad 43

\section{Capítulo 2}

Cuadro 1 Cronología de los planes de salud publicados a finales de $2013 \quad 72$

$\begin{array}{ll}\text { Tabla } 1 \text { Planes de salud incluidos en la muestra } & 76\end{array}$

$\begin{array}{ll}\text { Tabla } 2 \text { Cuestionario revisión sensibilidad simbólica } & 78\end{array}$

$\begin{array}{ll}\text { Tabla } 3 \text { Cuestionario revisión sensibilidad operativa } & 78\end{array}$

Cuadro 2 Resultados de sensibilidad simbólica en los planes de salud analizados 82

Cuadro 3 Sensibilidad operativa en los planes de salud de la muestra 85

\section{Capítulo 3}

Tabla 1 Materias fundamentales de la guía ISO 26000:2010

Tabla 2 Materias y asuntos relacionados con sanidad en ISO 26000:2010 sometidos a estudio 
Gráfico 1 Distribución gráfica de los grupos de interés incluidos en la muestra $\quad 120$

$\begin{array}{ll}\text { Tabla } 3 \text { Asuntos con bajo nivel de dispersión y claramente relevantes } & 121\end{array}$

Tabla 4 Asuntos relevantes con nivel medio de dispersión 122

Tabla 5 Asuntos relevantes con nivel alto de disenso o dispersión 123

Gráfico 2 Puntuaciones medias y desviaciones típicas por asunto obtenidas en la $\begin{array}{ll}\text { encuesta } & 124\end{array}$

$\begin{array}{ll}\text { Tabla } 6 \text { Participantes en el panel de expertos } & 125\end{array}$

Tabla 7 Puntuaciones del panel de expertos sobre los asuntos con elevado disenso

Tabla 8 Vinculación de materias y asuntos ISO 26000:2010 con indicadores GRI G4 


\section{INTRODUCCIÓN}




\section{Índice}

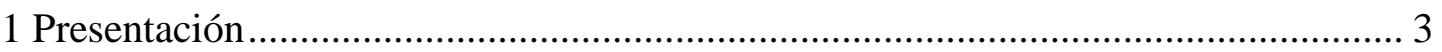

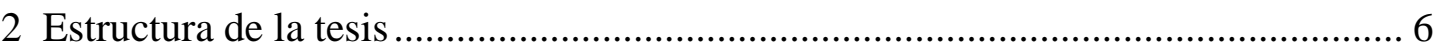

2.1 La sostenibilidad del sistema sanitario español. Una visión desde la gestión pública

2.2 El enfoque de sostenibilidad en los planes de salud de las comunidades autónomas: el desarrollo sostenible como oportunidad

2.3 Aspectos relevantes para el diseño de planes de salud sostenibles orientados a los grupos de interés. Una propuesta basada en la guía ISO 26000:2010.

3 Referencias 


\section{Presentación}

La intensidad del debate político y social acerca de la sostenibilidad del sistema sanitario en España ha evolucionado de forma inversamente proporcional al descenso del crecimiento económico desde el inicio de la crisis global en 2007. En la etapa inmediatamente anterior, es decir, desde principios de siglo y aún más durante los períodos de bonanza económica, gozaba de una merecida fama de ser el "mejor sistema sanitario del mundo", y de ese modo era presentado cotidianamente en foros y eventos del sector por los responsables políticos y gestores sanitarios.

No obstante, y aun con aquella positiva percepción de la situación del sistema sanitario, los retos y dificultades que estarían por llegar no pasaban desapercibidos. En 2007 se celebró la conferencia de ministros de sanidad de la OMS en Tallin (Estonia). Un año más tarde (WHO, 2008), se obtuvo la denominada Carta de Tallin, con el objetivo de fortalecer los sistemas sanitarios de los estados miembros de la OMS en Europa para garantizar la salud de los ciudadanos. En el punto tres del preámbulo del documento se apuntaban algunas de las claves relacionadas con los retos de sostenibilidad: "All countries in the WHO European Region have to address major health challenges in a context of demographic and epidemiological change, widening socioeconomic disparities, limited resources, technological Development and rising expectations. ",

La mayor parte de las amenazas identificadas entonces respondían adecuadamente a un análisis estratégico, sociológico y sectorial. La pirámide de población invertida por el envejecimiento de las cohortes superiores presiona los sistemas sanitarios en el coste de provisión de servicios. El paciente crónico surge como una evolución de las sociedades avanzadas, consolidando el nuevo paradigma sanitario: cuidar, en un modelo que fue creado esencialmente para curar en la segunda mitad del siglo veinte. Por otro lado, las desigualdades socioeconómicas en aumento inciden en la equidad y el acceso a los servicios sanitarios, aumentando la brecha social y acercando en algunos casos el fantasma de la exclusión a la realidad de muchas personas. Todo ello, en un creciente clima de altas expectativas de los ciudadanos sobre su salud y su esperanza de vida en buenas condiciones físicas y mentales.

\footnotetext{
${ }^{1}$ La conferencia ministerial de la OMS sobre sistemas sanitarios, tuvo lugar en el marco del $30^{\text {a }}$ aniversario de la Conferencia de Alma Ata (1978), sobre Atención Primaria, la cual centraba la atención en los ciudadanos. La Carta de Tallin reconoce las contribuciones de otras declaraciones relacionadas (1986 Ottawa, 1997 Yakarta, 2005 Bangkok) entre otras. Y recuerda que el derecho a disfrutar de los mejores estándares posibles en sanidad, está incluido de forma expresa en la Constitución de la OMS, en la Declaración Universal de los Derechos Humanos, en la Convención de los Derechos del Niño y en los Objetivos del Mileno de Naciones Unidas.
} 
Los compromisos recogidos en aquella conferencia hacían mención expresa a la solidaridad como valor compartido, la equidad y la participación ciudadana en materia de salud. Se alentaban las inversiones no solo en el sector sino también en aquellos otros que pudieran impulsarlo, así como el promover la transparencia y la responsabilidad de las decisiones con una clara orientación a la rendición de cuentas. La cooperación intersectorial ha sido señalada en diferentes estudios y documentos públicos como una cuestión crítica a nivel táctico para mejorar la eficacia de los resultados en salud. La colaboración era vista como necesaria en todos los niveles ante el reto de construir un sistema sanitario sostenible. Se hacía necesario desarrollar una estrecha relación entre los gobiernos centrales y autonómicos, las diferentes administraciones de un mismo gobierno, el sector público y privado, y además parecía aconsejable sumar la de todos aquellos sectores que también influyen desde un segundo nivel como universidades, comunidades locales y otras organizaciones (Regan et al., 2014). En el año dos mil seis el Observatorio Europeo de Sistemas y Políticas de Salud junto con el Ministerio de Salud y Asuntos Sociales de Finlandia había publicado "Health in all Policies, Prospects and Potentials", una obra en la que con buen tino se apuntaba a la necesidad de realizar no solo un pacto por la sanidad en el sector, sino una aproximación a ese pacto por la salud de los ciudadanos desde todas las políticas (EU, 2006).

El compromiso de una adecuada estrategia de stakeholder engagement aparece como objetivo en el desarrollo de políticas sanitarias y su implementación. Sin embargo, las metodologías de relación y diálogo con los grupos de interés no parecen haber sido utilizadas regularmente en el sector sanitario. Las políticas públicas de planificación sanitaria tienen una tradición centrada en el sistema, especialmente en su elaboración e implementación. Esta línea de trabajo nos ha inspirado a lo largo de la tesis de manera central y constituye el eje sobre el que giran las tres investigaciones en su conjunto y el tercer trabajo en particular. Por último, el documento pedía a los ministros de los países de la región europea, que aseguraran que los sistemas sanitarios estaban preparados para responder a los retos derivados de la situación de crisis global y sus consecuencias en Europa. En octubre de dos mil doce un documento publicado por la OMS debatía sobre el lugar de la salud en la agenda para el desarrollo después del presente año 2015 (OMS, 2012). Algunos aspectos señalados convergen con nuestro trabajo, cita el documento: "La salud es crucial para el desarrollo: es una condición previa del desarrollo sostenible, y también un indicador y un resultado de los avances logrados en esta 
esfera”. El desarrollo sostenible está en las agendas políticas de todos los países de nuestro entorno, y la salud queda bien reflejada en la resolución tras la cumbre de Rio+20 acerca del futuro que queremos como sociedad (Rio, 2012). Aparecen nuevos conceptos como el de sanimetría que permite evaluar los progresos logrados en las dimensiones económica, social y medioambiental del desarrollo sostenible. El documento incide en la evolución de las prioridades mundiales en materia de salud, dando lugar a una agenda más amplia con enfermedades diferentes y nuevos riesgos.

Una amplia literatura y las evidencias bibliográficas encontradas muestran que los determinantes sociales son una variable ineludible a considerar en las políticas sanitarias y, por otro lado, aparecen como claros precursores de la morbilidad y la mortalidad diferencial de los grupos más vulnerables. Además, el medioambiente juega un papel esencial en la calidad de la salud de las personas. No es frecuente ver en documentos de políticas públicas de salud el abordaje de retos como el cambio climático, la contaminación de las aguas, el ruido (contaminación acústica) en las grandes ciudades o la gestión de residuos y emisiones de gases de efecto invernadero. Todos ellos producen consecuencias y problemas relacionados con la salud que toman una dimensión aún mayor cuando coadyuvan al mismo tiempo en grupos vulnerables y los colectivos menos favorecidos.

El objetivo general de la tesis es innovar en la estrategia de planificación sanitaria al contribuir con un modelo de plan de salud orientado hacia criterios de sostenibilidad. Una guía para considerar aspectos claves desde una perspectiva holística al englobar las dimensiones económica, social y medioambiental. También inclusiva al haber sido seleccionados por consenso un significativo número de asuntos relevantes, señalados por un mapa de partes interesadas amplio y representativo de la sociedad. Y desde una visión de gestión pensamos que supone una oportunidad para elaborar planes de salud estructurados, con indicadores reconocibles y comparables y enfocados hacia el objetivo mayor de construir modelos de salud orientados al desarrollo sostenible. 


\section{Estructura de la tesis}

La tesis se estructura en base a tres artículos, cuyos resultados han sido defendidos en congresos y eventos del sector, o se encuentran en revisión en publicaciones académicas. El conjunto de investigaciones realizadas es secuencial y sigue una lógica lineal en el argumento en el sentido i) pulsión de la opinión de los gestores sanitarios ii) verificación mediante análisis de contenido del nivel de presencia o ausencia de los criterios de desarrollo sostenible en los planes de salud y iii) propuesta de asuntos relevantes en materia de desarrollo sostenible a incluir en un plan de salud. La metodología utilizada es la investigación cualitativa, fenomenológica, con introducción de tratamientos estadísticos para alcanzar las conclusiones con una base empírica de apoyo y el tratamiento gráfico que facilite su comprensión. Cada trabajo comienza con una introducción teórica y una revisión de la bibliografía relacionada que justifica y soporta los objetivos a desarrollar en el mismo. En las tres investigaciones se describe la metodología a utilizar y los instrumentos diseñados y se muestran los resultados previos a las conclusiones finales.

La tesis comienza con un sondeo acerca de la opinión de los gestores públicos sobre la sostenibilidad del sistema sanitario en términos generales, y referidos específicamente a las dimensiones clásicas del desarrollo sostenible: económica, social y medioambiental. Interesaba como punto de partida observar la relevancia de cada una de ellas de forma comparativa, en un contexto de crisis, toda vez que tanto en el discurso político como en el imaginario colectivo (Morin, 1992), comenzaba a incardinar la idea de que el problema de la sostenibilidad del sistema sanitario se debía al hecho central de no existir capacidad económica para pagar la factura del mismo desde las instancias públicas.

Tras comprobar los niveles de relevancia manifestada por los gestores y políticos del sistema sanitario de todas las autonomías en relación a las dimensiones de la sostenibilidad, el segundo trabajo se centra en el análisis documental. Los planes de salud son los documentos públicos de planificación sanitaria por excelencia, desde una perspectiva política y de definición de estrategias para períodos de tiempo variables entre dos años y una década. El trabajo realizado consiste en el análisis de contenido de una muestra de once planes de salud vigentes en el año 2008 o posteriores, hasta el verano de 2013, con objeto de identificar en los contenidos aquellas pautas que pudieran señalar una orientación hacia las diferentes dimensiones de desarrollo sostenible. 
El tercer capítulo constituye la consecuencia lógica del proceso. Para elaborar un plan de salud con criterios de sostenibilidad y responsabilidad social parece necesario utilizar un soporte estratégico. Para ello, hemos elegido la guía ISO 26000:2010 (ISO, 2010) de responsabilidad social. Analizamos en la bibliografía las materias y asuntos relacionados con la sanidad para determinar la base sobre la que realizar una investigación cualitativa basada en la metodología RAND. El análisis de materialidad se desarrolla a través de encuesta y panel de expertos encaminado hacia el logro de una proposición de asuntos a incluir, con sus respectivos indicadores, en la construcción de los planes de salud con criterios de desarrollo sostenible.

\subsection{La sostenibilidad del sistema sanitario español. Una visión desde la gestión pública}

En una primera aproximación al concepto de sostenibilidad del sistema sanitario, la primera pregunta de investigación gira en torno a cuál es la opinión que los propios gestores del sistema público tienen acerca de su viabilidad. Nos planteamos conocer a través de investigación social cualitativa, mediante el empleo de encuesta y entrevista semi-estructurada, la visión de los gestores acerca de si el sistema sanitario español es sostenible desde una perspectiva amplia, es decir más allá de la solvencia para financiarlo.

El reto inicial desde un punto de vista teórico es definir qué entiende - el gestor en

particular y la opinión pública en general - por un sistema sanitario sostenible. Nuestra orientación del concepto se basa en las tres dimensiones relacionadas con los criterios de desarrollo sostenible: económica, social y medioambiental. Sin embargo, el gestor público en una situación de limitaciones presupuestarias, parece primar en orden de preocupación hallar el camino para poder pagar la factura y hacerlo financieramente viable (Kickbusch, 2009 y Thomson, et al., 2009). La emergencia del corto plazo parece dar lugar a decisiones encaminadas no a la sostenibilidad sino a la supervivencia del sistema, a la corrección de efectos derivados de políticas que quizá consideraron el factor tiempo en la formulación de la estrategia sanitaria de un modo diferente. Los gestores de la sanidad pública, a menudo cargos políticos, mueven la agenda en espacios electorales cuyo horizonte suele ser de cuatro años. El rendimiento político en forma de votos y las necesidades ciudadanas de provisión de salud podrían encontrarse, 
en ocasiones, en diferentes entornos de intereses con asimetría de poder a favor de la política frente al paciente.

En este capítulo comenzamos con una revisión bibliográfica acerca de las vinculaciones que existen entre los sistemas sanitarios (y por extensión en la salud) y las cuestiones sociales y medioambientales. Tratamos de encontrar una definición completa y extensa de lo que debe ser entendido como sostenibilidad del sistema sanitario, dado que será sobre este concepto donde situaremos las preguntas en el sondeo de opinión a través de encuesta a una muestra de los gestores públicos de las comunidades autónomas. Para ello entendemos que una comprensión de la evolución del sistema sanitario español actual, desde la ley general de sanidad de 1986 hasta la total descentralización a las comunidades autónomas en el año 2002 es necesaria. No consideramos que la nueva configuración surgida del proceso de descentralización se pueda considerar un factor explicativo de la opinión del gestor, dado que las cuestiones abordadas trascienden la política regional. En este sentido el trabajo no se centra en cuestiones de financiación autonómica o comparativa entre regiones, que podría constituir un diferencial explicativo. Se abordan cuestiones genéricas y objetivos relacionados con la relación entre la sociedad, el sistema sanitario o el medioambiente, así como con los objetivos de la Agenda 21.

La encuesta se lanzó a un total de ochenta y ocho cargos de la Administración Sanitaria, si bien en algún caso incluimos personas con conocimiento experto de otras organizaciones. Además se complementó el sondeo de opinión con una entrevista personal semi-estructurada a un consejero de sanidad de una de las comunidades autónomas, en activo y en el cargo en el momento de la realización del trabajo.

Los resultados obtenidos mediante encuesta muestran un ranking de prioridades claro y sitúa a las cuestiones económicas en primer lugar. No supone un hallazgo importante y formaba parte de las hipótesis que manteníamos respecto de un nivel de comprensión limitado del concepto de sostenibilidad. Una emergencia económica coyuntural y una visión de gestor de organizaciones antes que de planificadores estratégicos es habitual que considere el factor económico como el driver de un sistema sanitario capaz de sobrevivir.

La dimensión social aparece en un segundo plano por detrás del presupuesto. Sin embargo, la sensibilidad sobre los asuntos sociales está presente, como posteriormente comprobaremos en el segundo trabajo. El gestor identifica al paciente y la sociedad en su conjunto como el centro de la acción del sistema, si bien no de una manera inclusiva 
si al menos como sujeto pasivo de la acción. Incluso puede considerarse en determinados casos que esta dimensión es equivalente a la económica en orden de importancia.

La dimensión medioambiental, en el momento de la encuesta, fue relegada a una tercera posición en la percepción de importancia relativa en la mente del gestor sanitario público del momento. La impresión de que hay cosas más importantes en las que fijarse es clara en la encuesta cuando priorizamos, o solicitamos un ranking de relevancia para las tres dimensiones. Quizá las cuestiones relativas a medioambiente son percibidas como colaterales a la salud, o al menos como un asunto no urgente en la agenda sanitaria.

La entrevista personal con el consejero de sanidad, realizada de forma simultánea a la encuesta, confirma el nivel de presión derivado de un presupuesto limitado para satisfacer el gasto corriente en una situación de crisis. Es el ahogo financiero para hacer frente cada mes a la estructura de costes fijos del sistema, en su mayor parte nóminas del propio personal laboral, lo que quizá en buena lógica gestora se considera esencial en la definición de sostenibilidad del sistema sanitario. A ello, hay que añadir una deuda creciente con proveedores, en especial la industria farmacéutica, y una presión constante hacia la incorporación de nuevas tecnologías y terapias más eficaces. El dato concluyente más significativo es que el $56 \%$ de los encuestados considera que el sistema sanitario no es sostenible tal y como lo conocemos. Este dato, tras la presentación de una comunicación oral de los resultados en las XXIV Jornadas de Economía de la Salud en la universidad de Navarra en mayo de 2014, se convirtió en titular en diferentes medios de comunicación del sector.

Los resultados suponen desde nuestra perspectiva una respuesta lógica a las presiones de coyuntura y su influencia en el proceso de toma de decisiones. En la planificación sanitaria, como en otras políticas públicas, no resulta fácil asimilar el significado de sostenibilidad y establecer una definición clara de la misma, lo que probablemente conduce a una visión limitada del concepto (El Ansari y Stibbe, 2009). La conclusión del trabajo gira entorno a una notable prevalencia en las decisiones de los gestores sanitarios basadas en el corto plazo, la gestión económica y la agenda política. Ello supone un reto y una oportunidad, toda vez que el espacio para introducir conceptos e indicadores relacionados con la salud y el desarrollo sostenible, por ejemplo en los planes de salud, es amplio y seguramente recomendable. 


\subsection{El enfoque de sostenibilidad en los planes de salud de las comunidades autónomas: el desarrollo sostenible como oportunidad}

Los planes de salud de las comunidades autónomas son uno de los instrumentos de comunicación en materia de planificación sanitaria utilizado por los responsables políticos, probablemente el más institucional y relevante. En la ley general de sanidad de 1986 (LGS, 1986) se articulaba la necesidad de que cada comunidad autónoma elaborase un plan de salud, el cual debía comprender todas las acciones necesarias para cumplir los objetivos de sus respectivos servicios sanitarios. La implementación de dichos planes desde entonces ha sido desigual en número de documentos publicados, frecuencia, e incluso contenidos y áreas terapéuticas abordadas, si bien en este último punto hay una homogeneidad mucho mayor que en el resto de aspectos mencionados.

En este capítulo el objetivo es determinar si en los planes de salud se incluyen aspectos vinculados a criterios de salud y desarrollo sostenible. Tras un análisis de la bibliografía sobre planes de salud y su vinculación con las dimensiones de desarrollo sostenible, se realiza un recorrido por la historia editorial de estos documentos públicos por comunidades autónomas. Hallamos el mapa de todas las publicaciones conocidas como planes de salud de los diferentes gobiernos y los ordenamos con fechas de publicación, años de vigencia y número de documentos publicados en cada región.

Se analizó una muestra de once planes de salud de diferentes comunidades autónomas. El único criterio de selección fue que la última fecha de vigencia de cada plan no fuera anterior a 2008. El análisis viene marcado por la búsqueda de las dimensiones económicas, sociales y medioambientales en el texto mediante análisis de sensibilidad simbólica y operativa, como ya hicieran Borrel et al., (2005), Peiró et al., (2004) y Briones et al., (2009). Para dicho análisis el conocimiento experto de los investigadores resulta esencial, toda vez que se precisa una visión amplia de la perspectiva política en materia de sanidad. El análisis de contenido es un procedimiento especialmente apropiado para la obtención de información codificando textos escritos con base en un criterio previo de selección (Krippendorff 1980; Unerman 2000). Se desestimó el uso de software y la creación de redes de significado a través de etiquetas y vínculos semánticos dado que no se pretende medir la fuerza o frecuencia con la que aparecen los criterios buscados ni la relación entre ellos, sino simplemente su ausencia o presencia en respuesta a cuestionarios elaborados ad hoc para el análisis. 
El análisis de sensibilidad simbólica trata de hallar elementos escritos y manifestaciones de carácter genérico sobre cada asunto objeto de la investigación. Los documentos expresan la intención de sus autores, y la importancia que le conceden a cada uno de los asuntos. A través de una lectura comprensiva y un cuestionario de tres preguntas cerradas, a responder en función de ausencia o presencia por el propio investigador, determinamos en una escala de uno a tres el nivel de sensibilidad. La misma metodología es usada para la sensibilidad operativa, en este caso con tres cuestionarios para cada área de intervención, uno por dimensión de desarrollo sostenible, y el mismo nivel de puntuación de uno a tres en función de si se aprecia ausencia o presencia por parte del investigador.

Los resultados obtenidos muestran una sensibilidad simbólica media en materia económica de forma genérica. Una característica común en los planes de salud es que no incluyen dotación económica específica para las actuaciones que se describen. La sanidad en su conjunto no dispone de presupuestos finalistas y, los planes de salud en general, no incluyen explícitamente las partidas presupuestarias asignadas a las acciones y objetivos. Que resulte efectiva la implementación de un modo u otro es poco cuestionable, pero que sus resultados sean sostenibles a largo plazo no está demostrado de manera irrefutable (Israr e Islam, 2006). En la mente de los planificadores está presente la necesidad de disponer de presupuesto para llevar a cabo los objetivos, pero la realidad es que no pueden describir la vinculación presupuestaria con las estrategias desplegadas por no disponer de presupuesto asignado. Tradicionalmente los recursos económicos en sanidad no se asignan a procesos concretos, y es este hecho, uno de los factores de complejidad operativa en la financiación de los planes de salud.

Destaca a nivel simbólico la sensibilidad social, la necesidad de implicar a los grupos de interés, en algunos planes incluso se menciona al paciente de forma explícita como parte interesada relevante a considerar. Aparecen con frecuencia los determinantes sociales como factores explicativos de aspectos relacionados con la prevalencia de patologías y los riesgos asociados.

Salvo excepciones es la dimensión medioambiental la que expresa una menor presencia en términos generales, aunque es preciso destacar el esfuerzo de algunas comunidades autónomas en esta materia. Existen planes de salud con capítulos específicos referidos a medioambiente o con fuerte presencia de los aspectos relacionados, probablemente debido a las propias circunstancias geográficas y sociales de la comunidad a la que se refiere. 
Es en las áreas operativas, quizá por estar directamente vinculadas a patologías concretas y objetivos asociados a su prevalencia y las consecuencias sobre la población, donde menos sensibilidades encontramos en el entorno de las dimensiones de desarrollo sostenible. Nos gustaría destacar que un buen número de áreas de intervención tienen planes integrales específicos, o documentos monográficos referidos a dichas áreas, en las que es posible encontrar elementos más concretos de actuaciones sobre ellas.

\subsection{Aspectos relevantes para el diseño de planes de salud sostenibles orientados a los grupos de interés. Una propuesta basada en la guía ISO 26000:2010.}

El objetivo del trabajo final de la tesis es desarrollar y elaborar un marco de asuntos relevantes basados en los criterios de desarrollo sostenible para los planes de salud. Una guía susceptible de ser utilizada por los gobiernos autonómicos, que considere la relación con los grupos de interés como una pilar estratégico en la elaboración de estos documentos de planificación sanitaria. Adicionalmente se proporciona una tabla de vinculación entre los asuntos obtenidos en la investigación y los indicadores que propone el Global Reporting Initiative (GRI, 2013) en su versión G4, lo que facilitaría un posible formato de reporting e informes basados en el modelo seguido en las memorias de sostenibilidad.

Tratar de construir un marco de asuntos relevantes vinculados a la salud y el desarrollo sostenible requiere del soporte documental necesario $\mathrm{y}$, desde nuestra perspectiva una referencia estándar apropiada es la guía de responsabilidad social (ISO 26000, 2010).

El proceso de este trabajo se desarrolla en cuatro fases i) revisión bibliográfica y de contexto para la selección preliminar de asuntos relevantes basados en ISO 26000, ii) selección de grupos de interés y elaboración del cuestionario iii) investigación cualitativa mediante encuesta y panel de expertos iv) obtención de la matriz de materialidad y asuntos relevantes en la elaboración de un plan de salud con criterios de desarrollo sostenible y responsabilidad social.

La primera fase consiste en la justificación teórica de la elección de una guía o modelo estandarizado como referencia con base en la bibliografía. Como destaca Harteloh (2002), los procesos en sanidad, y entendemos la elaboración de un plan de salud como proceso, deben estar referidos a determinadas guías, estándares y protocolos. En este caso, parece además una cuestión crítica toda vez que el análisis de asuntos relevantes requiere de una referencia en materia de responsabilidad social y desarrollo sostenible. 
La guía ISO 26000 contiene siete materias esenciales: gobernanza, derechos humanos, prácticas laborales, medio ambiente, asuntos de consumidores, prácticas justas de operaciones y participación activa y desarrollo de la comunidad. Para cada una de las materias se describen los asuntos vinculados y las posibles acciones a llevar a cabo en una organización. Tras la revisión bibliográfica se determinaron los asuntos previos relacionados con sanidad sobre los que realizar la encuesta a los grupos de interés.

En la segunda fase una revisión de la bibliografía y el análisis realizado mediante el conocimiento experto proporciona un panel de stakeholders que entendemos es apropiado para la consulta. La mayoría de planes de salud publicados también describen los grupos de interés que se tuvieron en consideración durante la fase de elaboración de los mismos, y sirvieron de referencia en este trabajo. En general además del personal vinculado al sistema de salud; facultativos, enfermería, administradores y gestores, también encontramos a la sociedad civil representada por asociaciones de pacientes, universidades y centros de investigación, así como otras instituciones. Para la investigación es crucial implicar a las partes interesadas en la elaboración de políticas públicas de salud, una cuestión que como señalan Grau et al., (2008) sería necesario considerar como parte del proceso.

En la tercera fase con base en la metodología RAND se combinan los resultados de la encuesta con la opinión y puntuaciones del panel de expertos. RAND ha sido utilizada en la elaboración de indicadores de calidad y evaluación de procesos de cuidados de la salud en múltiples estudios. Nuestro trabajo supone una modificación de la propuesta de análisis de González et al., (2009), siguiendo las fases del modelo pero realizando modificaciones en la gestión del panel de expertos.

La última fase del trabajo es la parte central del análisis de materialidad. Una vez obtenidas las puntuaciones de la encuesta en escala Likert (clasificación entre 1 y 5), se determinaron tres agrupaciones de asuntos relevantes divididos en función de la dispersión sobre la media que presentaban sus puntuaciones, esta metodología es apropiada para hallar los niveles de convergencia y divergencia sobre una misma cuestión relacionada con responsabilidad social o desarrollo sostenible como ya publicaran Muñoz-Torres et al., (2012). De este modo, y en función de la desviación típica hallamos aquellos asuntos que presentaban un mayor disenso para someterlo al grupo de discusión formado por el panel de expertos. Los resultados de la encuesta y la metodología realizada junto con documentación adicional sobre el trabajo fue enviada a un grupo de seis expertos que aceptaron participar en una última valoración sobre los 
asuntos cuya relevancia considerábamos no estaba claramente definida. Del resultado de esta última valoración fueron descartados determinados asuntos relacionados con diferentes materias. A partir de este punto construimos el panel de asuntos relevantes basados en la guía ISO 26000 y posteriormente lo relacionamos con sus indicadores en Global Reporting Initiative versión G4.

Para este trabajo se ha contado con la generosidad y participación de una gran número de profesionales del sistema sanitario de toda la geografía española. Este hecho nos hace pensar que existe un crecimiento en la toma de conciencia acerca de la importancia que tiene entender la sostenibilidad del sistema sanitario desde una perspectiva amplia. En una adecuada combinación de presupuesto, inclusión social y consideraciones de medio ambiente quizá no esté toda la solución, pero con un elevado grado de seguridad nos atrevemos a decir que es el camino para construir un mejor sistema de salud con criterios de desarrollo sostenible. 


\section{Referencias}

Borrell, C. Peiró, R. Ramón, N. Pasarín, MI. Colomer, C. Zafra, E. Álvarez-Dardet, C. 2005. Desigualdades socio económicas y planes de salud en las comunidades autónomas del estado español. Gaceta Sanitaria.19 (4), pp. 277-86.

Briones, E. Vives, C. Peiró, R. 2009. Sensibilidad de género de los planes nacionales de salud en el contexto internacional. UNIMAR. CEHEGÍN. Universidad de Murcia.

El Ansari, W y Stibbe, A, 2009. Public Health and the environment: What skills for sustainability Literacy - and Why? Sustainability, 1 pp. 425-40.

EU. 2006. Health in All Policies: prospects and potentials. Ministry of Social Affairs and Health of Finland. European Observatory on Health Systems and Policies. Disponible en:

http://ec.europa.eu/health/ph_information/documents/health_in_all_policies.pdf [Consultado, 17 de marzo de 2015]

Grau, M. Iñiguez-Rueda, L y Subirats, J. 2008. Un enfoque socio-técnico en el análisis de políticas públicas: un estudio de caso. Política y Sociedad, 45 (3), pp. 199217.

GRI, 2013. G4 Sustainability Reporting Guidelines. Global Reporting Initiative. Disponible en: https://www.globalreporting.org/reporting/g4/Pages/default.aspx [Consultado, 2 de abril de 2015]

Harteloh, P.P.M. 2003. Quality systems in health care: a sociotechnical approach. Health Policy. 64, pp. 391-398.

ISO 26000, 2010. Social Responsability. Disponible en: http://www.iso.org/iso/home/standards/iso26000.htm

[Consultado, 17 de marzo de 2015]

Israr, S.M. Islam, A. 2006. Good governance and sustainability: A case study from Pakistan. International Journal of Health Planning and Management, 21, pp. 313-325. 
Kickbusch, I. 2009. Policy Innovation for Health. In: Springer, ed. 2009. Innovation for Health. Geneva. Springer. Ch. 1

Krippendorf, K. 1980. Content analysis. An introduction to its methodology. Beverly Hills: Sage

LGS, 1986. Ley General de Sanidad. Título III, Cap II, Art. 54. Disponible en: https://www.boe.es/boe/dias/1986/04/29/pdfs/A15207-15224.pdf

[Consultado, 30 enero 2013]

Morin, E. 1992. El Método IV: las ideas. Su hábitat, su vida, sus costumbres, su organización. Ed. Cátedra. Madrid.

Muñoz-Torres, MJ. Fernández-Izquierdo, MA. Rivera-Lirio, J. León-Soriano, R. Escrig-Olmedo. E. Ferrero-Ferrero, I. 2012. Materiality Analysis for CSR Reporting in Spanish SMEs. International Journal of Management, Knowledge and Learning, 1 (2), pp. 231-250.

OMS. 2012. El lugar de la salud en la agenda para el desarrollo después de 2015.

Documento de debate de la OMS. Disponible en:

http://www.who.int/topics/millennium_development_goals/post2015/WHOdiscu ssionpaper_October2012_es.pdf

[Consultado, 17 de marzo de 2015]

Peiró, R. Ramón, N. Moyá, C. Borrell, C. 2004. Sensibilidad de género en la formulación de planes de salud en España: lo que pudo ser y no fue. Gaceta Sanitaria, 18 (2), pp. 36-46.

Regan, S. MacDonald, M. Allan, D. Martin, C. Peroff-Johnston, P. 2014. Public health human resources: a comparative analysis of policy documents in two canadian provinces. Human resources for health, 12:13.

Rio, 2012. El Futuro que Queremos. Rio+20. Conferencia de las Naciones Unidas sobre Desarrollo Sostenible. Documento final de la conferencia. Tema 10. Naciones Unidas. Disponible en: https://rio20.un.org/sites/rio20.un.org/files/a-conf.216-11_spanish.pdf.pdf

[Consultado, 17 de marzo de 2015] 
Thomson, S. Foubister, T. Figueras, J, et al, 2009. Addressing financial sustainability in health systems. European observatory on health systems and policies.

Unerman, J. 2000. Methodological Issues. Reflections on quantification in corporate social reporting content analysis, Accounting Auditing \& Accountability Journal, 13 (5), pp. 667-680.

WHO, 2008. WHO European Ministerial Conference on Health Systems: "Health Systems. Health and Wealth". The Tallin Charter: Health Systems for Health and Wealth. 
Capítulo 1: La sostenibilidad del sistema sanitario español. Una visión desde la gestión pública. 


\section{Índice}

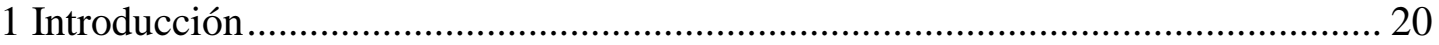

2 Gestión sostenible de los sistemas sanitarios ........................................................ 21

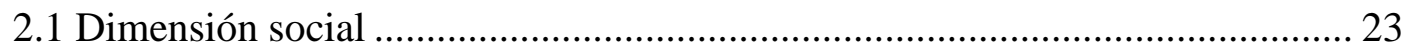

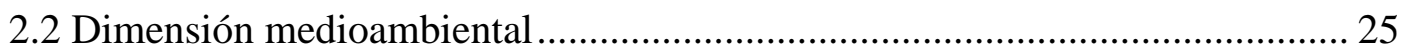

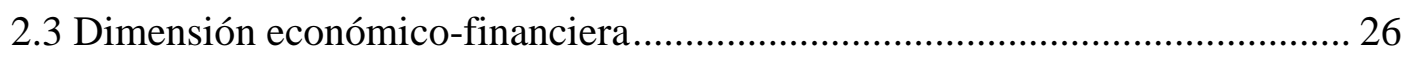

$2.4 \mathrm{El}$ rol de los gestores públicos en los sistemas de salud ................................ 27

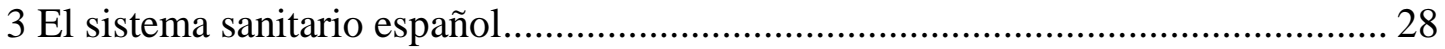

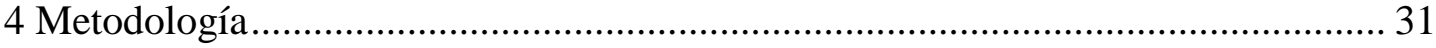

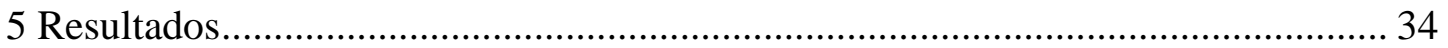

6 Comentarios a la entrevista semi-estructurada al consejero de sanidad de una

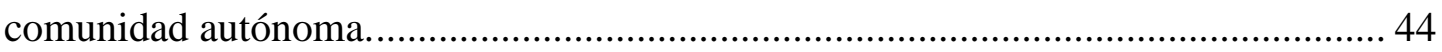

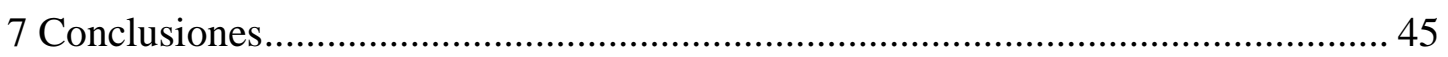

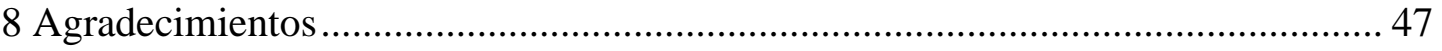

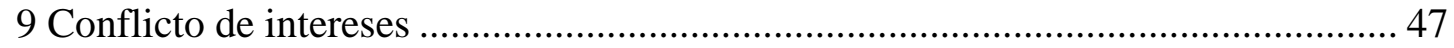

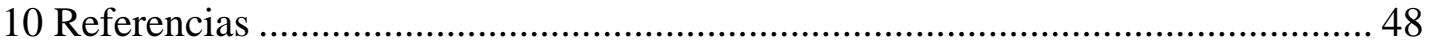




\section{Introducción}

Formular un patrón de desarrollo adecuado para una sociedad sostenible sigue siendo una cuestión crítica (Sumi, 2007), en la medida en que requiere avances en el conocimiento de las dinámicas y funcionamientos de los sistemas sociales y las organizaciones complejas (Jager, 2001). Incluso el término sostenibilidad adquiere diferentes interpretaciones en función del contexto, siendo habitualmente traducido con un marcado sesgo medioambiental o bien interpretado desde una perspectiva estrictamente económica, obviando con ello las estrechas interrelaciones existentes entre la vertiente económica, social y ambiental del desarrollo (Komiyama y Takeuchi 2006). Como destaca Sumi (2007), vivimos en un sistema socioeconómico construido a partir de un sistema natural, e intentar desarrollar el sistema social con la finalidad de maximizar los beneficios económicos puede tener un impacto negativo sobre el sistema natural o sobre el propio sistema humano, pudiendo ocasionar problemas medioambientales o de salud.

Tres de los ocho Objetivos de Desarrollo del Milenio de la ONU están relacionados con la salud: i) reducir la mortalidad infantil, ii) mejorar la salud materna y iii) combatir el VIH/SIDA, el paludismo y otras enfermedades (WHO, 2000). En el inicio del siglo XXI la salud sigue siendo una cuestión fundamental en el debate socio-político. Influenciada además por el actual escenario de crisis, la sostenibilidad del sistema sanitario se ha situado en primera línea de la agenda política europea. Para valorar el alcance del problema, se hace necesario entender el concepto de "sistema sanitario", así como las estrategias a seguir desde una perspectiva tanto pública como privada para que sea sostenible a medio y largo plazo. La duda que surge es si la pregunta cada vez más oída y planteada en foros económicos y sanitarios: “¿Es sostenible la sanidad?”, no está referida en realidad a la cuestión de si es o no asumible desde un punto vista financiero el "pago" de la factura sanitaria del actual modelo (Thomson et al., 2009).

Como recuerda el Informe sobre la Salud en el Mundo del año 2000 (WHO, 2000), “los gobiernos deben ser los "rectores" de los recursos nacionales, manteniéndolos y mejorándolos para beneficio de la población. En materia de salud, esto supone en última instancia hacerse cargo de la gestión cuidadosa del bienestar de los ciudadanos". Autores como Veillard et al., (2011) señalan que la actual crisis 
económica y financiera ha remarcado si cabe aún más la importancia del buen funcionamiento de los sistemas sanitarios, así como de la actuación de los gobiernos para mejorar la salud e incentivar la eficiencia.

Aun considerando que las restricciones financieras actuales son determinantes en la gestión de los fondos públicos, cabe plantearse si abordar la sostenibilidad del sistema considerando también aspectos sociales y medioambientales, pudiera contribuir a su vez a incrementar la eficiencia económica del mismo y por tanto repercutir positivamente en su viabilidad financiera, replicando así el denominado "círculo virtuoso" (Waddock y Graves, 1997) de la gestión de las organizaciones con criterios de sostenibilidad. Los problemas asociados al sistema sanitario nacional son soportados por el conjunto de la sociedad. La dimensión medioambiental se ve igualmente comprometida, puesto que la gestión tanto pública como privada de los recursos económicos y materiales empleados por el sistema tienen también un impacto sobre el entorno natural.

En este contexto, el objetivo del presente trabajo es analizar la visión que los gestores públicos tienen acerca de un sistema sanitario sostenible, comparando dicha visión con un concepto de sostenibilidad entendido desde una perspectiva amplia, es decir, considerando cuestiones económico-financieras e incluyendo dimensiones sociales y medioambientales.

La estructura del artículo es la siguiente. Tras esta breve introducción, los siguientes apartados abordan conceptos de gestión sostenible de los sistemas sanitarios, sentando las bases para el planteamiento de los objetivos de la investigación. Posteriormente se describe la sostenibilidad del sistema sanitario español como objeto de estudio. A continuación, se detalla la metodología empleada y los resultados obtenidos. Para finalizar el trabajo, se exponen las principales conclusiones extraídas del mismo.

\section{Gestión sostenible de los sistemas sanitarios}

La salud y el desarrollo sostenible están íntimamente unidos. La salud además de proporcionar bienestar a los individuos es un poderoso instrumento para el desarrollo social y económico (Brundtland, 2002).

Un sistema sanitario o sistema de salud puede ser entendido como "el conjunto de organizaciones, instituciones y recursos públicos y privados, destinados a mejorar, mantener o restaurar la salud. El sistema sanitario engloba servicios personales y al conjunto de la población, así como actividades encaminadas a influir en las políticas y 
actuaciones de otros sectores con la finalidad de tratar los determinantes económicos, sociales y ambientales de la salud" (WHO Regional Office for Europe, 2008). Por lo tanto, abordar la sostenibilidad del sistema de salud desde un punto de vista estrictamente financiero sin tener en cuenta sus interrelaciones con aspectos sociales y medioambientales, conlleva reducir la dimensión del término sostenibilidad asociado a los sistemas de salud.

A qué llamamos un sistema sanitario sostenible es una cuestión controvertida en los debates sobre política sanitaria, y es, tanto en la percepción pública como en la de la clase política, una preocupación de primer orden encontrar el camino para conseguir que sea a medio y largo plazo financieramente sostenible (Kickbusch, 2009). Por otro lado, no deberíamos pasar por alto que en el caso de que se produjera un hundimiento de un sistema sanitario nacional asequible la carga sería soportada al mismo tiempo por ciudadanos y empresarios (Werbanch, 2009), es decir por el conjunto de la sociedad. La dimensión medioambiental se ve igualmente comprometida dado que la ciencia de la sostenibilidad intenta responder al sustancial pero limitado entendimiento de las interacciones entre naturaleza y sociedad, y el impacto de esas interacciones en el ser humano (Jager, 2001). Parece pues necesario el reconocimiento de la importancia y la inclusión de la triple cuenta de resultados: económica, social y medioambiental en la política sanitaria, y cuestionar al mismo tiempo, la relevancia del factor económico como elemento diferencial.

La falta de reconocimiento de la importancia de las tres dimensiones de la sostenibilidad, puede deberse a una limitada comprensión del concepto (El Ansari y Stibbe, 2009), y por lo tanto de la asimilación de que en la múltiple bottom line las cuestiones ambientales, económicas, sociales y culturales son todas importantes. De hecho, como señalan Jameton y Mcguire (2002), el problema a resolver en la sostenibilidad del sistema sanitario es el balance entre los diferentes aspectos que la componen. Para definir el término sostenibilidad Jameton y Mcguire (2002) citan a Elkington (1998) señalando que: "la sostenibilidad del sistema sanitario se caracteriza por un balance entre las consideraciones en el cuidado del paciente, los costes ambientales de la actividad y la accesibilidad al sistema, además de una adecuada provisión de servicios"(...), "es una aproximación muy similar a la bien establecida triple cuenta de resultados." En la misma línea Pecurul y Peray (2010) defienden que ya ha sido demostrado que las soluciones parciales de cada ámbito de la sostenibilidad 
conducen a acciones descoordinadas que no tienen en cuenta la relación entre las vertientes económica - social - medioambiental.

No cabe duda de que las preocupaciones económicas y de financiación del sistema sanitario están sobre la mesa de los gestores públicos, pero quizá no tanto la apertura a las otras dos dimensiones. Los planes de salud podrían ser una excelente herramienta de difusión estratégica y de medida de intenciones respecto de la importancia otorgada a las diferentes dimensiones de la sostenibilidad en sentido Brundtland.

\subsection{Dimensión social}

La salud y la enfermedad son producto de la acción social, de la forma en que las personas organizan sus vidas y del contexto en el que lo hacen (Potvin et al., 2005). Ante este hecho, cabe plantear que la formulación de programas y planes de salud debería considerar la integración de las teorías sociales, o de sus aportaciones más significativas procedentes del estructuralismo y la racionalidad en la toma de decisiones de los individuos, con la intención de enriquecer el proceso de elaboración de dichos planes estratégicos. Tres líneas teóricas propuestas por los autores podrían reflejar los condicionantes derivados de la influencia social en nuestros días; i) las consecuencias inherentes de la actividad humana en un sistema complejo ii) un planteamiento crítico del modelo burocrático estructural y iii) una reflexión epistemológica que permita superar el dilema objetividad - subjetividad. Esta healthification de las cuestiones sociales, señalan los mismos autores, es un camino importante para incorporar las teorías sociales más avanzadas en la formulación de programas sanitarios.

La conciencia institucional acerca de la relevancia de los determinantes sociales en la salud de las personas es observable en una larga trayectoria de acontecimientos en las últimas décadas. En la Declaración de Alma Ata de 1978, se apuntaba hacia la obligación que los gobiernos tienen de cuidar de la población mediante medidas sociales adecuadas (Alma Ata, 1978). En 1986, se publica la Carta de Ottawa, como resultado de la conferencia global sobre promoción de la salud, en ella se refleja que las sociedades complejas no pueden separar la salud de otros objetivos, y que los lazos que unen al individuo y el medio en el que vive requiere de un acercamiento socioecológico a la salud (Otawa, 1986). En este mismo ciclo de conferencias, en 2005 en Bangkok, se establece como fundamento para el control de los determinantes de la salud un enfoque integrado por parte del gobierno y los organismos internacionales y, 
específicamente, el compromiso de trabajar con la sociedad civil y el sector privado (Bangkok, 2005). El veintidós de mayo de 2009, tuvo lugar la sesenta y dos Asamblea Mundial de la Salud, cuyo título "Reducir las Inequidades sanitarias actuando sobre los determinantes sociales de la salud", señala con claridad la relevancia de esta dimensión. La resolución posterior de la ONU, WHA62.14, insta textualmente a los estados a que: "tengan en cuenta la equidad sanitaria en todas las políticas nacionales relativas a los determinantes sociales" y en este mismo sentido en dicha resolución la Comisión pide a la directora general que "haga de los determinantes sociales de la salud un principio rector para la aplicación de medidas, entre ellas indicadores objetivos para seguir los determinantes sociales de la salud...y en particular en los programas de salud pública" (WHO, 2009). La declaración política de Río de 2011, cita en su segundo punto que: "Reconocemos que los gobiernos son responsables de la salud de su población, y que solo pueden cumplir con esta obligación adoptando las medidas sociales y de salud adecuadas" (WHO, 2011).

Por otro lado, como destaca Jochelson (2006), existen evidencias del papel que el estado puede desempeñar como proveedor de información para una toma de decisiones bien informada por parte de los ciudadanos respecto de la salud. Según el autor, el ejemplo de los anuncios relativos a las consecuencias del consumo de alcohol y tabaco muestran un evidente descenso en el uso por parte de los ciudadanos y sus repercusiones positivas en una menor morbilidad y mortalidad derivadas; estas medidas junto con la presión fiscal tratan de influir en el consumidor a la hora de tomar decisiones. En el año 2004, el departamento de Salud del Gobierno Británico, publicó “Choosing Health, making healthy choices easier" (DOHUK, 2004). Se trata de un resumen de las competencias del gobierno de ese país para motivar cambios en el estilo de vida de la población y reforzar la responsabilidad personal respecto de la propia salud; una apuesta decidida por acercar el papel del estado protector al ámbito de influencia de las decisiones personales. El hecho, no obstante, como señalan algunos autores españoles, de que el estado pueda asumir un papel de guía en las conductas personales también tiene detractores, aunque parece que a los seres humanos nos es más fácil reconocer patrones que pensar a través de secuencias y combinaciones lógicas (Repullo, 2009).

Una cuestión esencial parece ser la comprensión del modelo sostenible desde una perspectiva integradora de los factores que inciden en la salud de la población. (Fiona et $a l ., 2006)$. La salud y el bienestar van de la mano de la prosperidad económica y ambos pueden contribuir a su vez a una mejora medioambiental, haría falta una ruptura en la 
investigación relativa a la planificación sanitaria y salir de los silos tradicionales basados en la provisión de servicios para llevar a cabo una nueva forma de acción desde un punto de vista más holístico, dado que si se pretenden nuevas iniciativas de salud en todas las políticas sería preciso introducir elementos de evaluación del impacto en la salud que aportan las diferentes actividades humanas (Benedicto y Oñorbe, 2010).

Hay por lo tanto evidencia de que los aspectos sociales podrían suponer un apoyo eficiente en cuestiones como la adherencia a los tratamientos, la motivación de los enfermos crónicos o la implicación de la familia que debería ser además enfatizada y apoyada por los programas de salud de cara a tener éxito y conseguir una visión más integradora del sistema en su conjunto (Baxter, 2010).

\subsection{Dimensión Medioambiental}

El clima tiene una gran influencia en diferentes ámbitos de la vida. Las temperaturas extremas, diluvios, olas de calor y otros fenómenos atmosféricos afectan a la biodiversidad y tienen consecuencias sobre la salud de las personas (Haynes et al., 2006). Uno de los ejemplos más recientes fue la ola de calor del año 2003 en el oeste de Europa, donde el número de fallecidos como consecuencia del exceso de temperatura fue de dos mil personas en Inglaterra y Gales y de catorce mil ochocientos en Francia durante ese verano según estos mismos autores. El cambio climático es solo uno de los muchos aspectos que las autoridades sanitarias pueden considerar respecto del medio ambiente y la sanidad, parece relevante determinar qué claves serían necesarias en la planificación para reducir el peso relativo del impacto del clima y el medio ambiente en los resultados de salud de la población (Ebi y Burton. 2008), qué determinantes ambientales son relevantes para la salud y qué resultados producen, cómo se miden, cómo reducir el impacto y adaptar las estructuras. Pero no es solo la incidencia que sobre el índice de mortalidad puede tener el clima o los impactos ambientales, el incremento de la morbilidad también produce una mayor incapacidad laboral y tiene incidencia sobre las economías de los países. La OMS apunta a la importancia del peso global de la enfermedad considerando como variable los años de vida libres de incapacidad (Seuc y Domínguez, 2002). Como es conocido, las cohortes de población más desfavorecidas socio-económicamente padecen con mayor severidad estas consecuencias derivadas de hogares inadecuados desde un punto de vista térmico, higiénico y de salubridad ambiental. El entorno y la vivienda son aspectos claves en la 
salud y el bienestar de las personas e inciden de manera significativa en aspectos como la salud mental (Guite et al., 2006). La percepción de seguridad en las calles o el barrio, la limpieza, el índice de criminalidad y la participación social juegan un papel relevante. El factor contaminación ambiental, formado por el ruido o la emisión de sustancias químicas, tiene un efecto sobre los determinantes socioeconómicos de la salud cuando no directamente sobre la propia salud (Pecurul y Peray, 2010).

Otras acciones más inusuales y relativas al medio ambiente también son posibles y quizá convendría explorar acerca de la viabilidad de implementarlas, como el aprovechamiento de los residuos de los centros sanitarios para producir externalidades positivas. Como describen Heinonen -Tanski et al., (2010), un ejemplo podría ser el reciclado de los desechos biológicos en fertilizantes.

\subsection{Dimensión económico-financiera}

En un entorno de crisis financiera la dimensión económica cobra un protagonismo predominante en las preocupaciones políticas sobre sostenibilidad del sistema sanitario. Las presiones derivadas del envejecimiento de la población, y el aumento de la prevalencia de enfermedades crónicas producen tensiones sobre el presupuesto. Según autores como Gérvas y Meneu (2010), en las sociedades desarrolladas hay a menudo dos culturas visibles en relación a la sanidad, asociadas por un lado a un uso excesivo de los recursos sanitarios y por otro a la búsqueda de la salud permanente en lo sanitario. Además, las presiones derivadas del envejecimiento de la población, y el aumento de la prevalencia de enfermedades crónicas producen tensiones sobre el presupuesto.

Como mencionan Martin y López del Amo (2011), las estrategias básicas del sector sanitario para garantizar la sostenibilidad económica son el incremento de la fiscalidad y el aumento de la eficiencia en la provisión de servicios. Sin embargo, las decisiones políticas acerca de la deseabilidad social del gasto, es decir, la pregunta de si los incrementos y los esfuerzos económicos valen lo que cuestan (Puig-Junoy, 2006) es crítica. Las alternativas, indica el autor, pueden venir a través de una batería de reformas adecuadas, entre ellas, las de priorizar y racionalizar las prestaciones públicas y aumentar la eficiencia en el uso de los recursos. No obstante, la configuración autonómica del estado de las autonomías introduce diferencias en el análisis y quizá en las soluciones y la deseabilidad social. Desde el año 2002, con las transferencias de las competencias en sanidad a las comunidades autónomas que aún no las tenían, el modelo 
de financiación introduce dos factores adicionales como señala Urbanos (2004). En primer lugar, dos variables nuevas en el reparto de los fondos generales para sanidad, la insularidad y la población de más de sesenta y cinco años. En segundo lugar, el incremento de la corresponsabilidad autonómica en el presupuesto. Ambos factores son susceptibles de incidir en las desigualdades en la prestación de servicios.

La fiscalidad finalista es uno de los aspectos más recurrentes en los foros actuales sobre sostenibilidad del sistema sanitario, el destino de los fondos que los ciudadanos aportan entre otros fines de interés público para garantizar la sanidad, padece tensiones de uso por lo que se alzan cada vez más voces en el sentido de la necesidad de proveer con partidas fiscales específicas la financiación sanitaria y evitar trasvases a otras áreas de gasto. Es necesario considerar que, incluso antes de que comenzara la crisis, ya existían serías dudas de que se pudiera financiar la sanidad con cargo a impuestos indirectos (Bernal-Delgado et al., 2014). La financiación selectiva de servicios y tecnologías aparece como una posible solución adicional a los problemas de sostenibilidad económica.

\subsection{El rol de los gestores públicos en los sistemas de salud}

Los objetivos de sostenibilidad del sistema sanitario, sobre todo los financieros, son paralelos a determinados paradigmas ideológicos del gestor, como los niveles de equidad, y son a la vez objetivos pendientes de solucionar en la sanidad en el entorno europeo, como señalan Potvin, et al., (2010). Mejorar la inequidad en la salud producida por las diferencias de clase socio-económica es también una cuestión de liderazgo político, particularmente de las autoridades locales, más cercanas a las comunidades desfavorecidas (Rae, 2006).

Como señalaba Brundtland en el año 2002 en su informe "Salud y Desarrollo Sostenible", el estado de salud de las poblaciones depende entre otros factores de la posibilidad de tener acceso a los servicios sanitarios adecuados. La sostenibilidad del sistema sanitario se enfrenta a la necesidad de mantener la equidad y el acceso al conjunto de la sociedad limando las diferencias regionales o de clase para contribuir a un verdadero desarrollo social y económico. Este aspecto es bien conocido y asimilado por la clase política que destaca la accesibilidad como un elemento clave junto con la cohesión y la universalidad del sistema. Si el objetivo último, como indica Oteo (2010), "es la sostenibilidad financiera y la cohesión social, necesitamos un avance legislativo 
reformista sobre la gobernanza institucional y política para el Sistema Nacional de Salud". El concepto de accesibilidad apunta por otro lado a una necesaria promoción de la equidad en el sentido de a igual necesidad corresponde el acceso a un servicio de igual calidad y competencia (Oteo, 2010). Según afirman autores como Hanlon et al., (2011), algunos de estos paradigmas, herederos de un wellfarestate cada vez más complicado de sostener desde un punto de vista financiero, añaden cuestiones de primer orden ante las abrumadoras circunstancias que retan la sostenibilidad del sistema sanitario, especialmente las relacionadas con encontrar el camino que permita actuar con la mayor efectividad posible. La idea, apuntan, es encontrar un nuevo modelo que permita navegar por la transición de fase en la que nos encontramos, a través de una mayor integración de las diferentes políticas de salud y aspectos relacionados con un cambio cultural. La propuesta de un mix de políticas de equidad orientadas desde todas las instancias de la Administración, no solo desde las políticas de salud, sino desde medioambiente, transportes, mercado de trabajo o políticas de educación es una cuestión pendiente de desarrollo (Muntaner et al., 2011).

\section{El sistema sanitario español}

En el caso español el sistema nacional de salud se creó a finales de los años setenta del siglo veinte, reflejando la intención de los nuevos tiempos en nuestro país de transitar hacia el estado de bienestar, la equidad, la redistribución y la transferencia de competencias a las comunidades autónomas (WHO, 2010). La descentralización en materia de sanidad, culminada en el año 2002, significó de facto la creación de diecisiete sistemas diferenciados de salud y la inexistencia de un sistema de financiación sanitaria al estar este indiferenciado en la propia financiación autonómica (Repullo y Freire, 2008). Por otro lado, según el informe de WHO (2010) el gasto sanitario en España ha seguido la tendencia al alza del resto de países de su entorno. Dicho informe, que aborda los sistemas sanitarios en transición, señala que en el caso de España el porcentaje del PIB dedicado a sanidad era del 8,5\% en 2007, por debajo de la media europea. Así mismo, señala que el $71 \%$ del gasto se pagaba con fondos públicos a través de impuestos, directamente por los ciudadanos el 22,4\% y el 5,5\% restante por seguros privados. Posteriormente, el Real Decreto 16 de 2012, de fecha 20 de abril (RD, 2012) introduce medidas urgentes para garantizar la sostenibilidad del Sistema Nacional 
de Salud y mejorar la calidad y seguridad de sus prestaciones modificando, entre otras medidas, los porcentajes de copago farmacéutico.

El gasto sanitario público se desglosa de la siguiente forma: 54\% atención especializada, $16 \%$ atención primaria, 19,8\% gasto farmacéutico y el 1,4\% salud pública y prevención (WHO, 2010). En relación al porcentaje de gasto sobre PIB dedicado a sanidad se ha debatido ampliamente y son diferentes factores y variables los que pueden incidir en esta cifra, como es el caso de la renta, señala Urbanos (2006), dado que la elasticidad renta del gasto sanitario es superior a la unidad, 1,31\%.

La proporción del gasto sanitario público sobre el gasto sanitario total en España disminuyó un -7.8\% en el período 1990-2004 según datos de la OCDE en 2006. Además y según la misma fuente, el gasto sanitario per cápita en España sigue siendo inferior a la media de la OCDE en términos de paridad del poder adquisitivo.

A primeros de los ochenta se argumentaba que en realidad no existía en España una tradición presupuestaria del sector sanitario público (De Miguel, 1980), y que el sistema había supuesto siempre gastos superiores a los planeados. Treinta años después dicha opinión persiste pese a que el sector privado ha ido cubriendo la falta de inversión en sanidad y mitigando el gap en la accesibilidad cuya manifestación más evidente han sido y continúan siendo las listas de espera que se articulan como mecanismo de gestión de recursos escasos ante una demanda creciente CIREM (2006).

Cada vez hay más voces orientadas en el mismo sentido, y en la sanidad pública es donde esta nueva inquietud toma una forma más evidente: “...el nuevo fantasma que recorre el mundo es el de la sostenibilidad" (Repullo y Segura, 2006). Por un lado, apuntan los autores, la necesaria gestión eficaz de los recursos económicos en su relación con los agentes externos, la pulsión expansionista de la industria farmacéutica y los avances en electromedicina impulsan el crecimiento del gasto. Sería necesaria una sólida base en la toma de decisiones a la hora de incorporar al sistema las innovaciones, particularmente desde una perspectiva de coste-beneficio. Por otro lado, y desde la vertiente interna se pretende una nueva concienciación del papel que desempeñan los trabajadores de la salud pública incluida la dimensión social - la necesidad de "salir de la bata" para dar el necesario apoyo al paciente y su entorno de modo que se consiga el suficiente patient enpowerment que aliente la corresponsabilidad del enfermo con su patología, especialmente en las enfermedades crónicas que en diez años supondrán el $60 \%$ de todas las enfermedades y actualmente significan el $70 \%$ del total del gasto sanitario (Mckinsey y Fedea, 2009). La atención que recibe el ciudadano desde el 
momento de entrada en el sistema sanitario a través de la Atención Primaria debería ir más allá de la asistencia a través de intervenciones dirigidas a la familia y la comunidad (Repullo y Segura, 2006).

En un sistema sanitario descentralizado como el español el enfoque de estudio desde la perspectiva autonómica parece adecuado y aporta elementos de análisis acerca de variables de primer orden como la heterogeneidad, la eficiencia, la equidad y los problemas de financiación en su conjunto. En esta dirección, Segura y Oñorbe (2010) citan a Buades et al., (2009) al indicar que "nos remite a considerar el papel del estado y de las autonomías, porque las relaciones entre las distintas administraciones competentes ( $\sin$ olvidarnos de las administraciones locales) constituyen por ellas mismas una variable de importancia ¿dependiente, independiente o tal vez factor de confusión? Como puntos clave los autores señalan la necesidad de un liderazgo centralizado desde una orientación de mutuo beneficio en la cooperación entre administraciones, partiendo de un análisis en profundidad de la situación actual. Sin embargo, a nuestro entender el papel ideológico podría jugar de barrera en el diálogo y la construcción de un sistema sostenible, quizá más interesados los interlocutores políticos en el beneficio partidista que en el objetivo finalista que sería la salud de la población. La gobernanza y la transparencia aparecen en este contexto como oportunidades de mejora (Israr e Islam, 2006) para unas rutinas administrativas y de procedimientos que podrían estar protegiendo a la partitocracia (Meneu y Ortún, 2011). Como mencionan Arredondo y Orozco (2008), "health governance is related to the way in which civil society and political actors within health system distribute and consume health, taking into account health services demand and health needs; in this context, successful strategies for health policies are considered by these authors as the result of a broad consensus between all political actors. In sustainability terms, it is associated whith the concept of stakeholders management" (Freeman, 1984). En este contexto, herramientas como la Agenda 21 y los planes de acción local que consideran los factores sociales, económicos y medio ambientales, son de utilidad para conseguir la cooperación necesaria para liderar una mejora de la calidad de vida de las personas (Barrutia y Echevarría, 2011). El capítulo seis de la Agenda 21, titulado "Protección y Fomento de la Salud Humana", indica como objetivos "satisfacer las necesidades básicas de salud de las poblaciones urbanas, perturbadas y rurales; proporcionar los servicios especializados necesarios de higienización del medio ambiente y coordinar la participación de los ciudadanos, el sector de la salud, los sectores conexos y los 
sectores no relacionados con la salud (instituciones comerciales, sociales, de educación y religiosas) en la solución de los problemas de salud. Como cuestión de prioridad, debería lograrse la cobertura de los servicios de salud para los grupos de población que más los necesitaran, sobre todo los que viven en zonas rurales” (Agenda 21). La aproximación a estos objetivos debería incluir una perspectiva de salud para todos desde una visión holística y de cooperación, enfocada en la población y el medio ambiente, en consenso con los agentes implicados, con equidad y justicia social y que todo ello se englobe en un formato sostenible (Dooris, 2001). Además, parece imprescindible la implicación de los gobiernos locales o regionales en un diálogo con los ciudadanos, las organizaciones sanitarias si es el caso y las empresas privadas para la adopción de dicha agenda en los diferentes niveles de aplicación (Feichtinger y Pregernig, 2005). Los planes de salud como medio en el que plasmar los objetivos de salud de las CC.AA serían por otro lado, el instrumento adecuado en el que reflejar dichas metas y sus correspondientes indicadores de seguimiento. En España, como señalan Llamas Sánchez et, al., (2011) el esfuerzo de implementación de la Agenda 21 no proviene del gobierno central sino de las comunidades autónomas y la implicación de las autoridades locales. El concepto de enpowerment, la búsqueda de compromiso y la creación de una cultura entorno a la Agenda 21 son factores relevantes para su implementación. La participación ciudadana es esencial en el proceso (Martínez y Rosende, 2010). Sin embargo, citando un estudio de Font y Subirats (2000), los autores destacan que en España la implementación de los programas locales relacionados con los objetivos de la Agenda 21 han tenido escasa repercusión. Un entorno sanitario sostenible requiere de la corresponsabilidad de los individuos, como ciudadanos sanos primero y como pacientes algún día, y del conocimiento y la toma de conciencia necesaria para mejorar la propia circunstancia de vida y contribuir a la sostenibilidad financiera del sistema público de salud.

\section{Metodología}

El enfoque del trabajo realizado es fenomenológico, una de las metodologías de investigación habituales en ciencias de la salud. Como indican March et al., (1999), una investigación cualitativa en la que el investigador se hace con las opiniones, observa las acciones y realiza el análisis de significado de los elementos observados en el proceso. 
Este trabajo de análisis se realiza tras la realización de una encuesta, con el objetivo de ahondar en las razones que motivan los resultados encontrados (Bimbela y Cruz 1996). El análisis no busca representatividad estadística, si bien la validez interna de los resultados ofrece una explicación clara, comprensible y que permite la interpretación y el ajuste a los objetivos del estudio (March et al., 1999 en referencia a Conde, 1990; Conde, 1994; Pope y Mays 1995). No pretende, por lo tanto, obtener inferencias para una población general o más amplia sino capturar las opiniones de un grupo de referencia con un tipo o perfil definido; el del gestor sanitario de diferentes comunidades autónomas españolas. La selección se realiza a través de un sistema de muestreo no probabilístico o intencional, lo que permite el acceso a informantes clave con conocimientos específicos que no posee el resto de población (Prieto, 1997). Para ello a través del conocimiento experto y el acceso a las fuentes necesarias se confecciona un listado de ochenta y ocho altos cargos de las diferentes administraciones autonómicas sanitarias, relacionadas con la elaboración de políticas sectoriales, elaboración de planes y guías de salud, ejecución de proyectos y administración de recursos y presupuestos (tabla 1). 
Tabla 1: Distribución de la muestra

\begin{tabular}{|c|c|c|}
\hline Comunidad Autónoma & Muestra & \% Participación por CA \\
\hline Comunidad Autónoma de la Rioja & 3 & $3,4 \%$ \\
\hline Comunidad Autónoma de Cataluña & 16 & $18,2 \%$ \\
\hline Comunidad Autónoma de Aragón & 3 & $3,4 \%$ \\
\hline Comunidad Valenciana & 6 & $6,8 \%$ \\
\hline Comunidad Autónoma de Castilla La Mancha & 6 & $6,8 \%$ \\
\hline Principado de Asturias & 3 & $3,4 \%$ \\
\hline Comunidad Autónoma de Castilla y León & 6 & $6,8 \%$ \\
\hline Comunidad Autónoma de Aragón & 1 & $1,1 \%$ \\
\hline Comunidad de Madrid & 4 & $4,5 \%$ \\
\hline Comunidad Autónoma de Extremadura & 3 & $3,4 \%$ \\
\hline Región de Murcia & 3 & $3,4 \%$ \\
\hline Comunidad Autónoma de Andalucía & 4 & $4,5 \%$ \\
\hline Comunidad Autónoma de Galicia & 5 & $5,7 \%$ \\
\hline Comunidad Foral de Navarra & 2 & $2,3 \%$ \\
\hline Comunidad Autónoma de Illes Balears & 6 & $6,8 \%$ \\
\hline Comunidad Autónoma de Canarias & 3 & $3,4 \%$ \\
\hline Comunidad Autónoma de Cantabria & 4 & $4,5 \%$ \\
\hline Comunidad Autónoma del País Vasco & 3 & $3,4 \%$ \\
\hline Ministerio de Sanidad & 4 & $4,5 \%$ \\
\hline Instituciones Europeas & 2 & $2,3 \%$ \\
\hline Otros (incluida la industria) & 1 & $1,1 \%$ \\
\hline Total muestra & 88 & $100 \%$ \\
\hline
\end{tabular}

Fuente: elaboración propia

El estudio de modelos de sostenibilidad requiere de herramientas diversas y habilidades combinadas para el análisis de fenómenos sociales (Jager, 2001. p. 641). En el presente trabajo se realiza una encuesta a una base de datos de ochenta y ocho altos cargos de la administración sanitaria de las diferentes comunidades autónomas. Para la recolección 
de datos en este tipo de estudios los métodos más comúnmente utilizados son las encuestas por teléfono y las entrevistas personales, como señalan Scheaffer et al., (1987). A su vez, se realiza una entrevista en profundidad semi-estructurada a un consejero de sanidad de una de las comunidades autónomas. La entrevista como método de investigación es utilizada para profundizar y obtener mayor profundidad sobre aspectos teóricos y globales del discurso especializado (ideológico y profesional) en que este se apoya (Báez, 2007).

La encuesta se lanzó a través de plataforma online, es posible que una parte significativa de las no respuestas se deban a filtros en los sistemas informáticos de las Administraciones Públicas y otras medidas de seguridad. La entrevista personal se realizó "in situ” en la consejería de la comunidad autónoma.

\section{Resultados}

Un número indeterminado de los ochenta y ocho destinatarios no recibieron la encuesta por razones técnicas. Se obtuvieron veinticinco respuestas, un $28.4 \%$.

De los resultados podemos concluir que es frecuente establecer un ranking de importancia en el siguiente orden: económico, social y ambiental. Esta última dimensión no fue elegida en solitario por ninguno de los encuestados como la más relevante mientras que la dimensión económica como única opción fue elegida en un $42 \%$ de los casos, frente a un $31 \%$ la social. No obstante el hecho de que el $27 \%$ de los encuestados señale en igualdad de importancia las tres dimensiones denota una visión, al menos en parte de los gestores, de cierta orientación en el sentido amplio del concepto de sostenibilidad en las organizaciones. 
Gráfico 1. ¿Qué aspectos son relevantes desde su punto de vista para conseguir un sistema sanitario sostenible?

\section{¿Qué aspectos son relevantes desde su punto de vista para conseguir un sistema sanitario sostenible?}

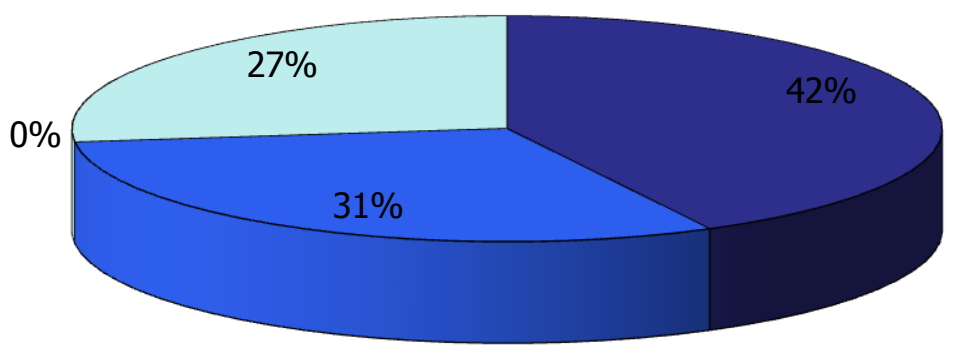

Una idea generalizada a lo largo del estudio es que la sanidad no es sostenible al menos en las circunstancias actuales, de hecho aparecen dos prioridades bien definidas en orden a mejorar la situación. Por un lado, una gestión más eficiente y control del gasto, esta opción aparece en el 56\% de los encuestados como la más necesaria y en segundo lugar, con un $28 \%$ de frecuencia, mantener el actual modelo de prestaciones requiere de más presupuesto en sanidad. Ambos aspectos hacen referencia a dos de las propuestas analizadas por algunos autores. Por una parte la sostenibilidad externa referida a la deseabilidad social, aquello que los políticos y la sociedad en su conjunto esperan de la sanidad y su disponibilidad a pagar el coste (Bernal y Ortún, 2010). Y de otro lado, la sostenibilidad interna, referida al modo de gestionar de forma correcta y llevar a cabo las acciones adecuadas, lo cual debería ser acorde a la generación de expectativas en la población y la oferta de la cartera de servicios (Repullo y Segura, 2006). 
Gráfico 2. ¿Con cuál de estas afirmaciones está usted más de acuerdo?

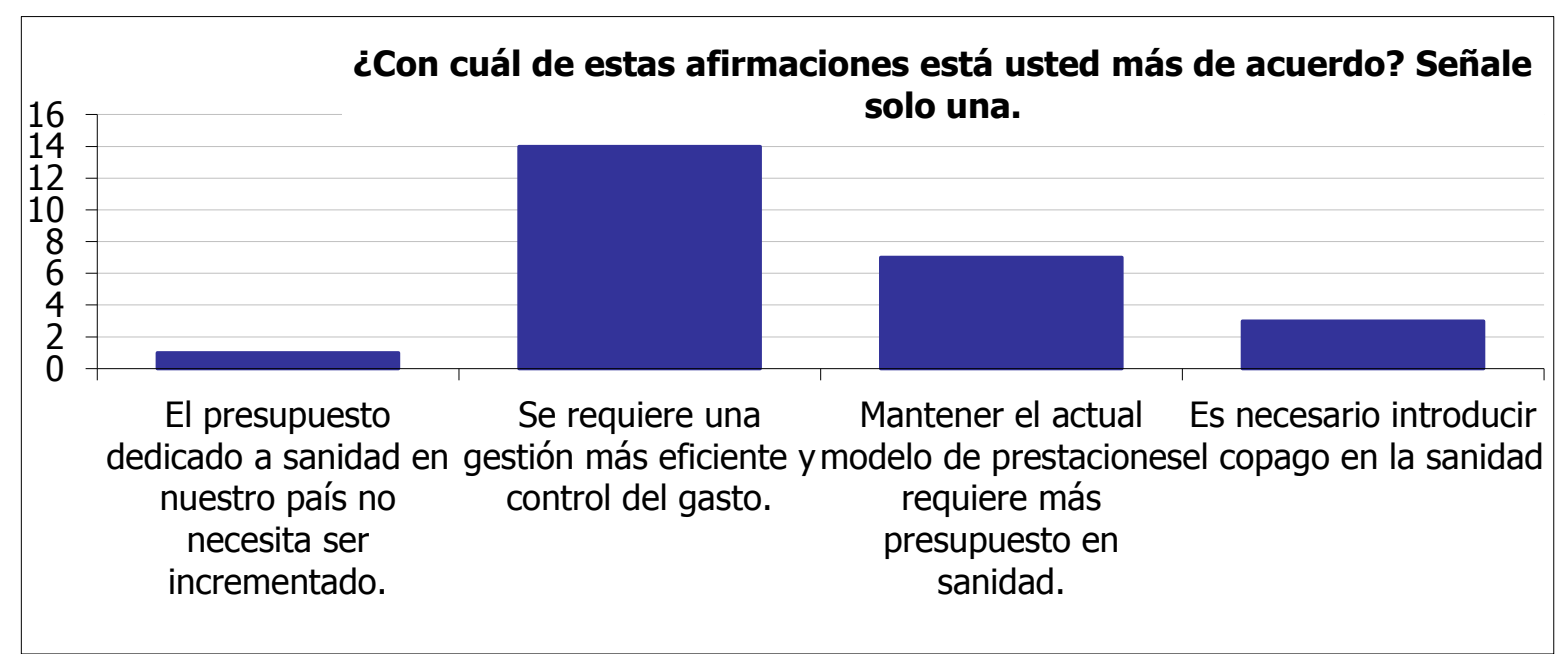

Sobre el grado de acuerdo acerca de si las nuevas iniciativas en la legislación resultaban relevantes para la sostenibilidad del sistema sanitario, los resultados muestran una mayoría en desacuerdo que viene a mostrar un desajuste percibido por los gestores entre el traslado a la legislación de las cuestiones relacionadas con la sostenibilidad y las necesidades reales del sistema. Para en ello en el estudio se pregunta por la controvertida Ley de Economía Sostenible, que venía a situar la sostenibilidad como una prioridad de las administraciones y empresas públicas. 
Gráfico 3. Indique su grado de acuerdo/desacuerdo con la siguiente afirmación: la ley de Economía Sostenible es importante para la sostenibilidad del sistema sanitario. 1 Totalmente en desacuerdo y 5 totalmente de acuerdo.

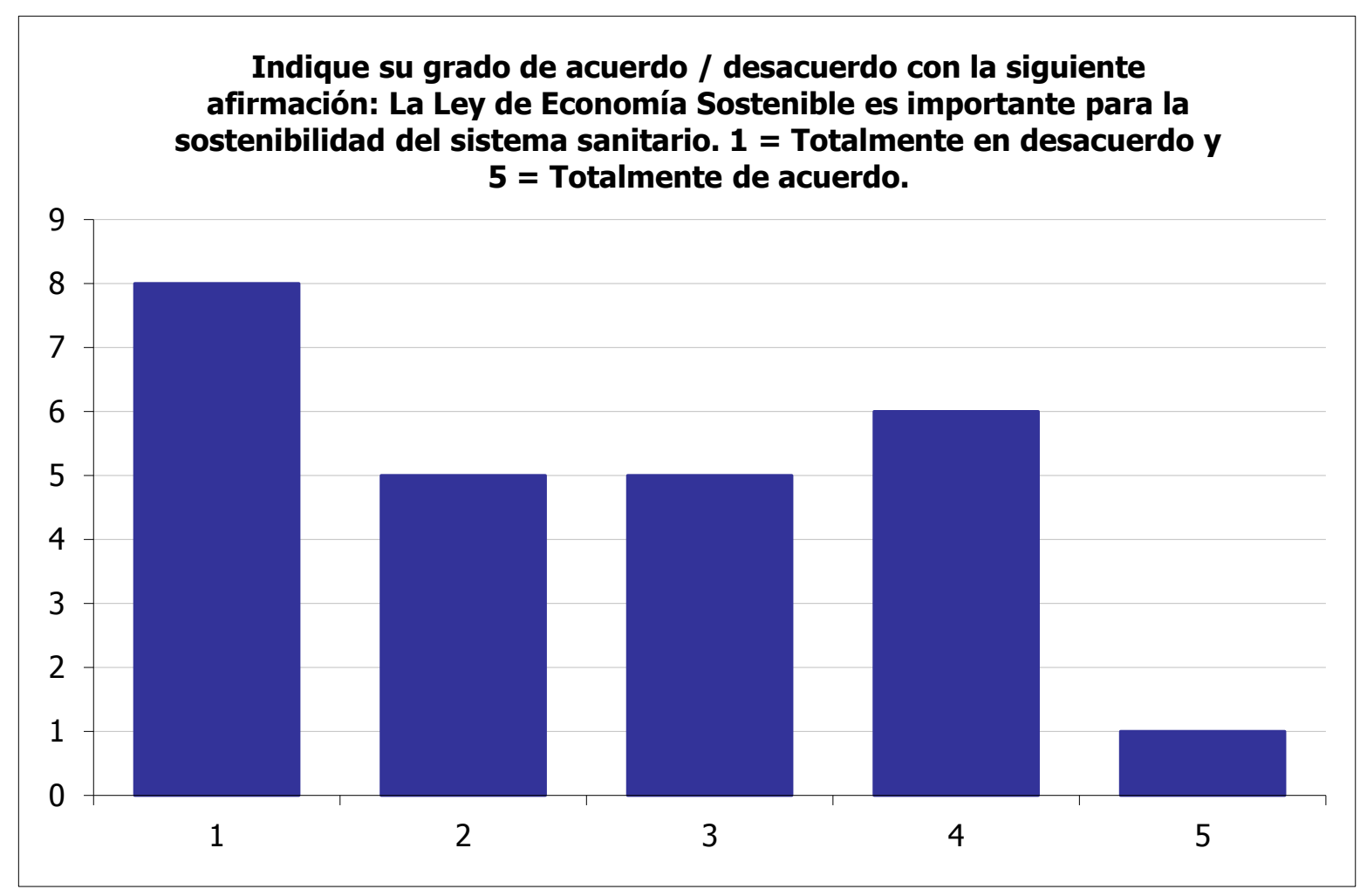

La relevancia entre las diferentes dimensiones de la sostenibilidad se ha analizado de manera bidimensional. Se ha preguntado por la dimensión social frente al factor económico en orden de importancia tratando de situarlas al mismo nivel. En la figura gráfica se aprecia que si bien ninguno de los encuestados está totalmente en desacuerdo con la afirmación relativa a que los aspectos sociales son tan importantes como los económicos, tampoco hay una clara respuesta en el sentido del reconocimiento explícito de que ambas dimensiones son igual de importantes en la sostenibilidad del sistema sanitario. La forma de los histogramas, si trazamos una curva normal imaginaria desde la respuesta una a la cinco, describe una figura ligeramente asimétrica a la derecha, lo que indica que la percepción de que deberían ser igualmente importantes es alta. 
Gráfico 4. ¿Cree usted que los aspectos sociales son tan importantes como los económicos?

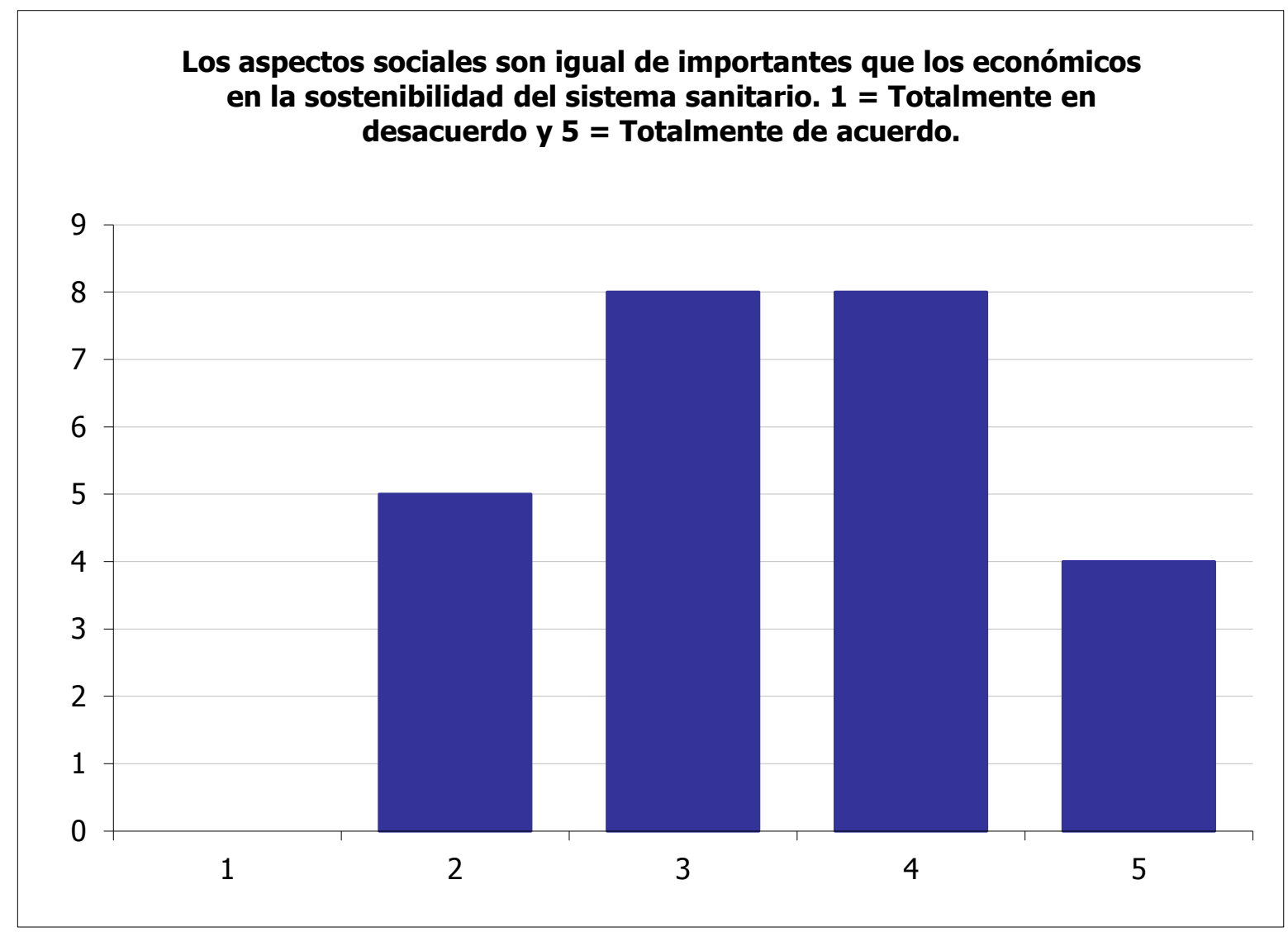

Al realizar el mismo ejercicio con las dimensiones medioambiental y económica hay un claro contraste respecto del análisis de combinaciones anteriores; social - económica. La dimensión medioambiental pierde relevancia en esta comparación de pares en lo que parece configurar una secuencia en orden de importancia que iría en el sentido siguiente: primero el presupuesto, después las personas y por último el medio ambiente. No es fácil determinar si esta percepción de diferentes niveles de importancia de las tres dimensiones de la sostenibilidad, se debe en parte al contexto o coyuntura de crisis, o es una secuencia natural e intrínseca que deriva más de una lógica racional de pensamiento que de un análisis y comprensión rigurosa del concepto de desarrollo sostenible aplicado a los sistemas sanitarios. 
Gráfico 5 ¿Cree usted que los aspectos medioambientales son tan importantes como los económicos?

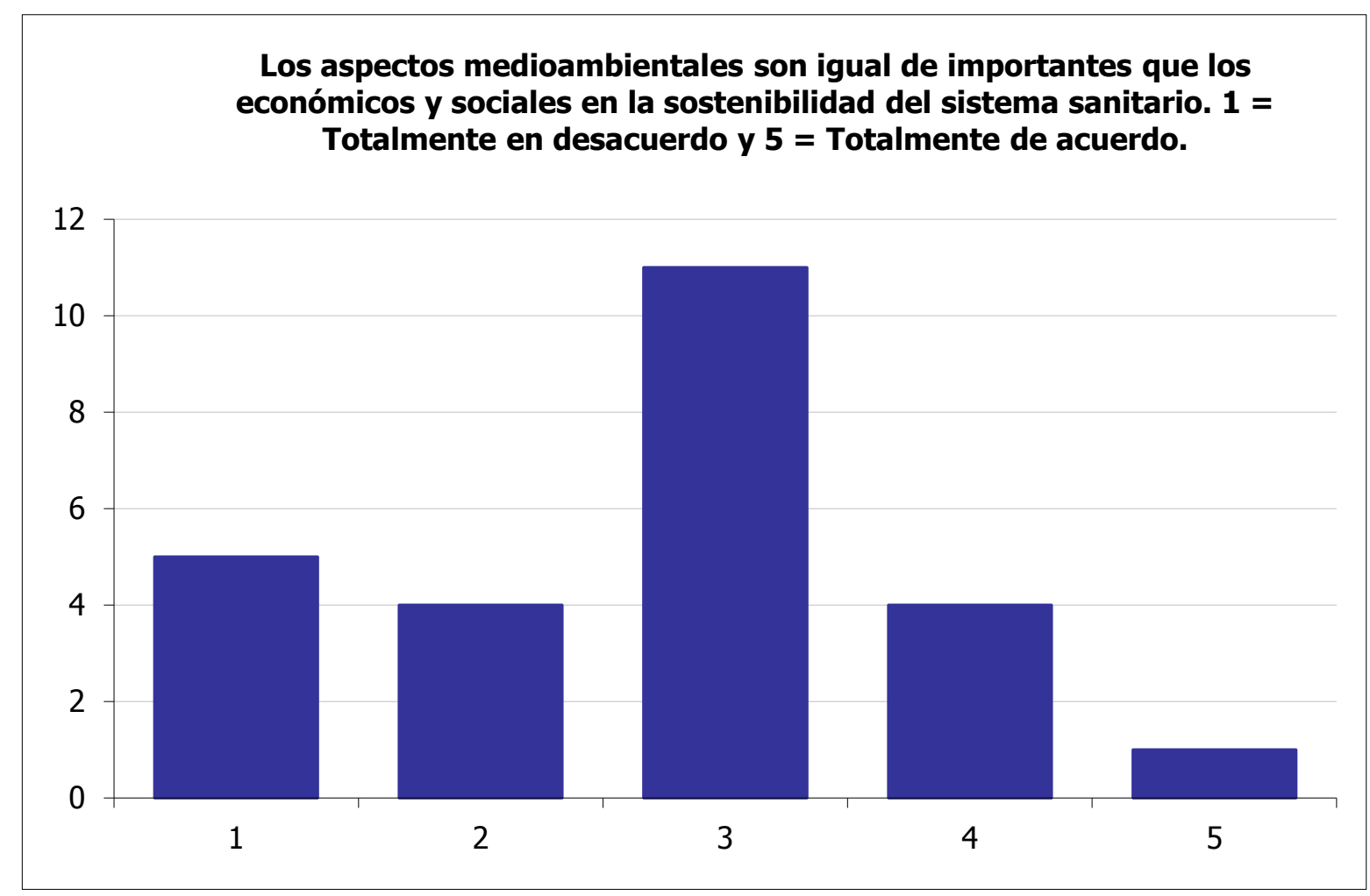

El orden de importancia atribuida a las diferentes dimensiones, y particularmente al factor económico queda expuesto en la siguiente pregunta, en la que directamente se pretende del encuestado un posicionamiento claro respecto del factor económico. Si bien el sesgo afirmativo es apreciable, contrasta el hecho de que también se relativiza cuando la pregunta no se hace de forma comparativa y se refiere específicamente a una dimensión. 
Gráfico 6 ¿Los aspectos económicos son los más importantes en la sostenibilidad del sistema sanitario?

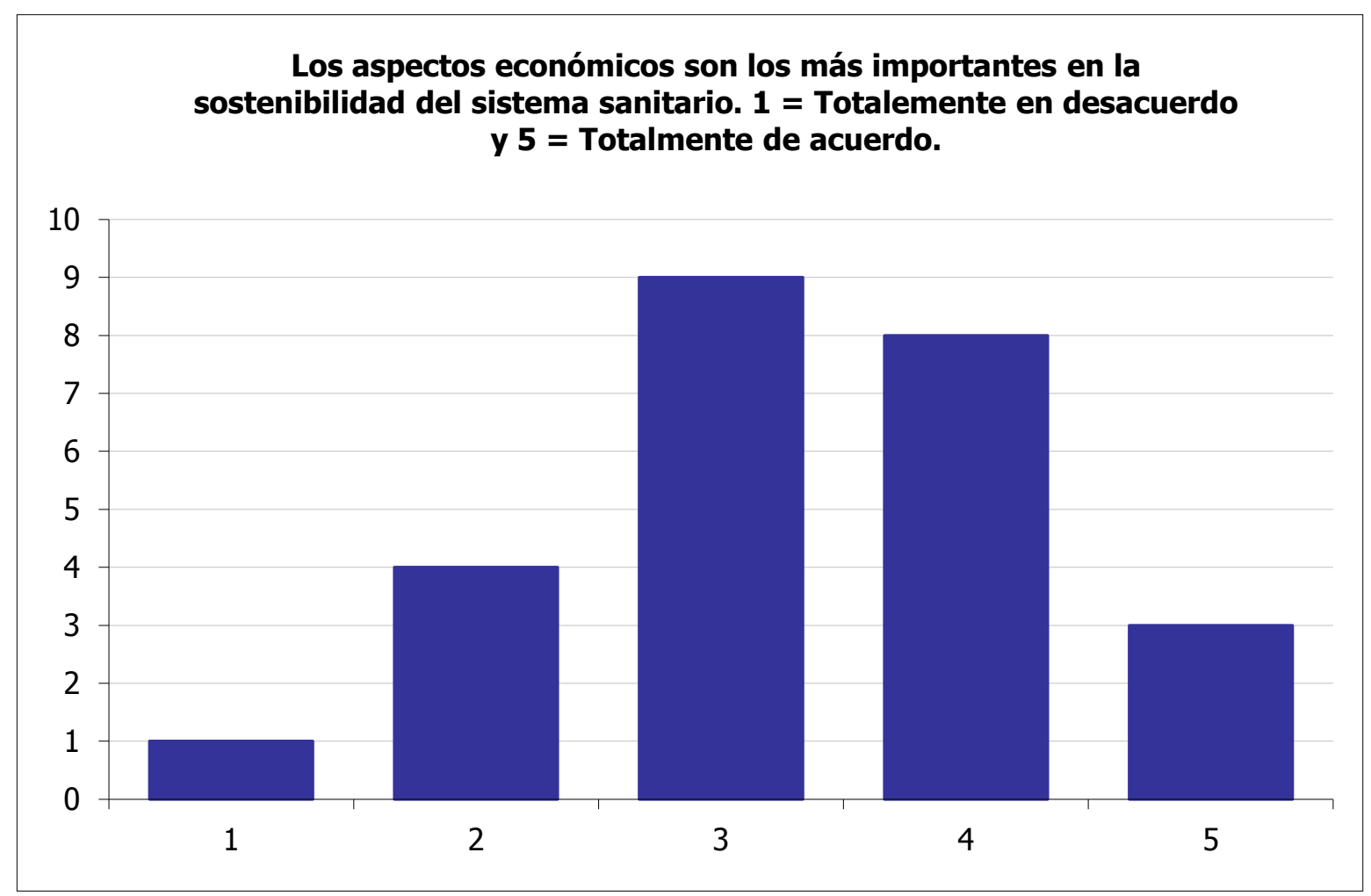

En relación a la cobertura de los objetivos de la Agenda 21 el resultado de la encuesta muestra que en el $52 \%$ de las respuestas no se estima que se estén cumpliendo estos objetivos o al menos que la orientación actual favorezca el que así sea. Es significativo el dato de que el $40 \%$ de los encuestados no lo sabe, lo que puede ser debido a i) el encuestado no ha hecho las comprobaciones pertinentes y le falta información ii) existe un cierto nivel de desconocimiento en relación al contenido de los objetivos de la Agenda 21 por parte de los administradores y gestores de la administración sanitaria. También es posible estimar una combinación de ambos factores. 
Gráfico 7. ¿Cree usted que se aplican los objetivos de la Agenda 21 en los planes de salud de las diferentes CC.AA?

\section{¿Cree usted que se aplican los objetivos de la Agenda 21 en los planes de salud de las diferentes CCAA?}

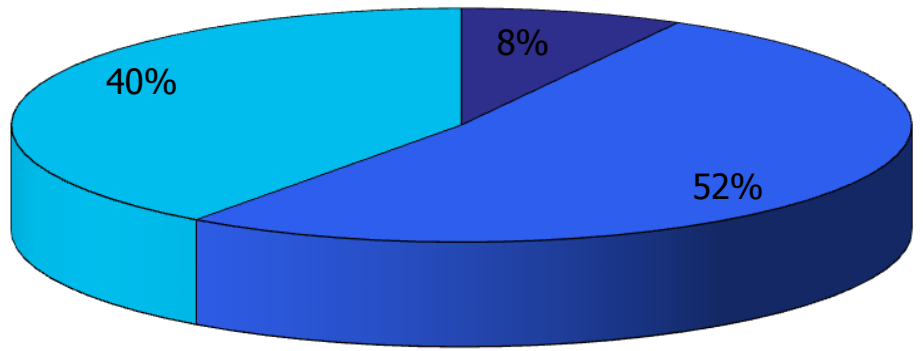

La implementación de dichos objetivos debía ser llevada a cabo mediante la elaboración de agendas locales en función de las necesidades de cumplir con el programa, y quizá este hecho ha podido crear desajustes de calendario y de nivel de relevancia en los diferentes países y regiones. Además la elaboración de dichas agendas requiere de una implicación efectiva de los gestores políticos que debería coincidir con la agenda de objetivos planificada para la legislatura o período de mandato en cada caso. La necesaria diferenciación política quizá no ayude a que se incluyan proyectos similares en agendas de partidos muy alejados en sus posiciones ideológicas.

Por último se han realizado dos preguntas concretas pero genéricas que los ciudadanos pueden estar realizándose a sí mismos dadas las circunstancias, esenciales desde el punto de vista de la percepción que los gestores y políticos tienen acerca de la sostenibilidad del sistema sanitario y la confianza en el mismo. El 56\% de los encuestados cree que el sistema sanitario español no es sostenible, frente a un $40 \%$ que si cree que lo es y un $4 \%$ que manifiesta no saberlo. Este resultado por sí solo mueve a la acción desde los diferentes puntos de actuación posibles para corregir la tendencia, es evidente que el peso de lo "pagable" a corto plazo condiciona la percepción de no 
sostenibilidad del sistema sanitario, pero sería un error estratégico no realizar un diseño global y dejar las medidas tomadas en el recorte presupuestario como solución ideal con la idea de que simplemente con esa "cura de urgencias" el sistema volverá a ser sostenible.

Gráfico 8. ¿Cree usted que el actual sistema de salud español es sostenible.

\section{¿Cree usted que el actual sistema sanitario español es sostenible?}

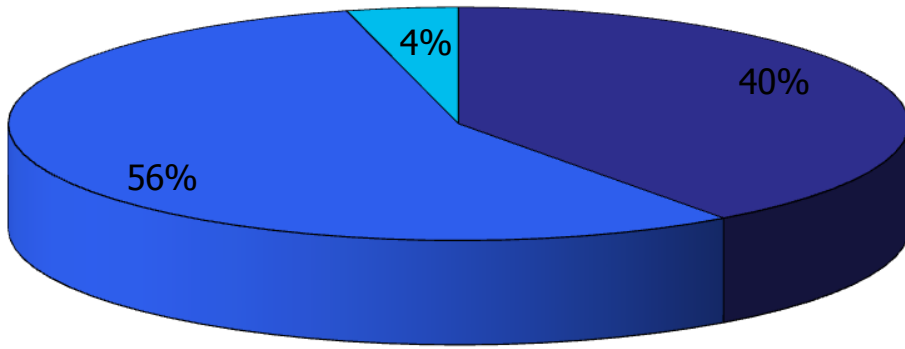

La inclusión de los actores o grupos de interés es fundamental en un aspecto tan importante para los ciudadanos y la sociedad en su conjunto como es la sostenibilidad del sistema sanitario. Sin embargo la voluntad, las posibilidades o la confianza en la utilidad no se reflejan de manera positiva en la encuesta. Podemos considerar que la pregunta está formulada respecto de si puede o no la Administración considerar a los ciudadanos en el diseño de planes de salud, si bien no están presentes las posibles razones que pudieran impedirlo y que sería interesante conocer. 
Gráfico 9 ¿Puede la Administración tener en cuenta a los grupos de interés en el diseño de planes?

\section{En su opinión: ¿Puede la Administración sanitaria en el diseño de sus planes y políticas, tener en cuenta los intereses de todos los grupos de interés?}

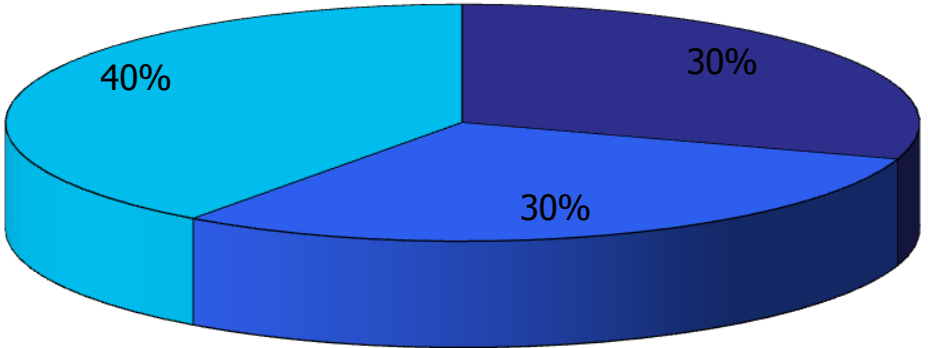




\section{Comentarios a la entrevista semi-estructurada al consejero de sanidad de una comunidad autónoma.}

La sostenibilidad del sistema sanitario tiene prioridades como la financiación y la gestión de los recursos humanos. En cuanto a la primera cuestión, la opinión más generalizada entre los consejeros de sanidad es que la financiación debe ser finalista, es decir, que la partida presupuestaria destinada inicialmente para sanidad desde el estado a las autonomías no pueda ser posteriormente dedicada a otras coberturas del gasto distintas a la prevista. Por otro lado, una vía propuesta para el abordaje de los recursos humanos sería una política común en todo el territorio nacional y dependiente del ministerio. Otros asuntos que quedan pendientes para próximas reuniones del Consejo, pero no menos importantes, son la evaluación de la cartera de servicios que debe ser restrictiva en opinión del consejero así como la utilidad del fondo de cohesión.

La sanidad debe ser universal y gratuita, basada en la tecnología y en la prevención de enfermedades y, sobre todo, es fundamental hacer prevalecer el principio de equidad. Sin embargo, con las premisas de hoy el sistema sanitario español no es sostenible, es esencial controlar el crecimiento del gasto y de la demanda. Las personas cada vez vivirán más y hoy en día ver pacientes de cien años en la consulta no es una anécdota. Este dato, significa que pronto la vida no activa tendrá al menos la misma duración que la vida activa para muchas personas. La proporción del presupuesto de las comunidades autónomas dedicado a sanidad es actualmente del $30 \%$ pero hay estudios que proyectan que en diez años en las condiciones actuales este porcentaje será del $70 \%$ según el consejero. La Ley de Dependencia por otra parte juega un papel fundamental en la atención social y sanitaria, hay que tener en consideración que muchos de estos pacientes no son autónomos y no tienen capacidad para vivir sin el apoyo de una tercera persona. Resolver esta situación que irá en aumento requiere dotación presupuestaria y una planificación específica.

La importancia de los factores medioambientales no pasa desapercibida, muchas de las enfermedades contraídas por los pacientes tienen que ver con el entorno en el que los ciudadanos viven cada día y con los hábitos de vida. Otros indicadores como pueden ser el aumento de las incidencias de las alergias nos llevan a pensar que algo debe modificase en el ambiente que nos proporcionamos. La tecnología y la innovación tienen una importancia decisiva para solucionar muchos de estos problemas. Son los 
países que ahora inviertan en innovación los que saldrán antes de la crisis porque estarán más preparados y no dependerán de otros para volver a crecer.

En relación a la posibilidad de introducir otras medidas como el copago, el consejero opina que en España ya está instaurada dicha herramienta. Los ciudadanos en activo pagan el $40 \%$ del precio de los productos farmacéuticos, pese a ello, es imprescindible una reordenación del copago para que sea más justo. Los criterios de proporcionalidad en el esfuerzo contributivo otorgan la posibilidad de manejar la equidad de manera efectiva, los gestores saben que es una herramienta compleja y que en sanidad puede mejorarse. Además cuando durante la entrevista surgen experiencias en otros países respecto de medidas como el ticket moderador cuyo objetivo es racionalizar la demanda, se reconoce que habría que avanzar en la reflexión pese a que cuenta con muchos detractores y hay que pensarlo bien para evitar que la accesibilidad o la equidad se vean comprometidas.

Los ejes más destacados en los foros de política sanitaria son: financiación, farmacia, recursos humanos y cartera de servicios. La orientación tiende a un pacto que trascienda la mera discusión teórica y que no quede abierto con temas sin concluir y que esté regulado por ley. Es importante, así mismo, que se desarrollen planes específicos a nivel nacional en ese pacto en relación a temas como la dependencia, la diabetes, y otras enfermedades crónicas que son prioritarias. España es uno de los países de la UE que menos presupuesto dedica en términos de PIB a sanidad, con ello se abre espacio a la iniciativa privada cuyo peso relativo es cada vez mayor.

\section{Conclusiones}

La sostenibilidad del sistema sanitario preocupa de manera relevante a la clase política de nuestro país independientemente de la orientación ideológica que se tenga. El factor sobre el que giran una buena parte de las medidas es el económico, el cual aparece además percibido como la clave de la sostenibilidad del sistema. Entendemos que esta orientación tiene un fuerte sesgo derivado de la crisis económica que vive el país en particular, y los países occidentales de manera más genérica, desde la segunda mitad de la primera década de este siglo. Sin embargo, la dimensión económica tiene un fuerte sesgo hacia la gestión del corto plazo, hacia las medidas de ahorro urgente y en ocasiones sin que se haya establecido un consenso con los grupos de interés (tendencia al decretazo). Queda reflejado que la participación ciudadana no aparece como una de 
las consideraciones relevantes por parte de los gestores, ya sea por que estiman falta de criterio de los ciudadanos en las cuestiones públicas, o porque la separación de clase política respecto del resto de individuos crece en tiempos de crisis. Esta línea de actuación urgente y por necesidad se aparta del modelo de desarrollo sostenible, pese a que es conocido en la mayoría de los encuestados y se pone de manifiesto que las dimensiones sociales y ambientales son igualmente relevantes en la sostenibilidad del sistema. Destaca el peso de la gestión del presupuesto y no queda reflejada adecuadamente la importancia de la triple bottom line.

El instrumento de comunicación que nos parece más adecuado y además actúa como soporte estratégico de las políticas de actuación de los gobiernos respecto de la sanidad es el plan de salud, documento que las comunidades autónomas vienen publicando de forma espaciada pero irregular, y en el que se recogen las políticas y actuaciones a llevar a cabo durante el siguiente período, también variable en cada caso. Nos parece que sería deseable aprovechar este medio para enfatizar unas políticas sanitarias que abarcaran las diferentes dimensiones relativas a los criterios de desarrollo sostenible; la vertiente económica, la social especialmente relativa a la participación ciudadana y la medioambiental. La construcción de indicadores de seguimiento en cada aspecto podría facilitar el seguimiento con criterios de mejora continua y resultados de salud de la población. Es más, la extensión a planes específicos relativos a patologías que afectan a una gran parte de la población, como es el caso de las enfermedades crónicas, podría traducirse en un beneficio al orientar de forma más holística el abordaje de las actuaciones.

El discurso político se refiere más a aspectos ideológicos, variables que sean fácilmente trasladables a la población en forma de mensajes rentables desde el punto de vista del retorno en forma de voto: equidad, accesibilidad, universalidad, gratuidad etcétera, que a menudo se ven envueltos en una marea de interpretaciones y variaciones difíciles de ordenar de manera científica. La investigación sobre planes de salud podría aportar luz en el sentido de comparar la heterogeneidad de las diferentes administraciones sanitarias en España y si de ello se desprenden así mismo diferentes modos de afrontar la sanidad desde una perspectiva de sostenibilidad. 


\section{Agradecimientos}

Loa autores desean agradecer al Dr. Lluís Bohigas Santasusagna sus aportaciones especialmente a la hora de suministrar información para la muestra. Y al Excmo. Sr. Consejero de Sanidad, cuya identidad no desvelamos por petición expresa, la concesión de la entrevista.

\section{Conflicto de intereses}

Miguel Ángel Moyano Santiago declara no tener conflicto de intereses a la finalización del presente trabajo, si bien durante el desarrollo del mismo realizó trabajos profesionales para la industria en el sector healthcare. 


\section{Referencias}

Agenda 21. Declaración de Río sobre el medio ambiente y el desarrollo. United Nations. 1992

Disponible en: http://www.un.org/spanish/esa/sustdev/agenda21/index.htm

Alma Ata, 1978. Conferencia Internacional sobre Atención Primaria de Salud. Alma Ata, URSS, 6-12 de septiembre,1978.

Disponible en: http://whqlibdoc.who.int/publications/9243541358.pdf

[Consultado, 2 octubre 2012]

Arredondo, A y Orozco, E. 2008. Equity, governance and financing after health care reform: lessons from Mexico. International journal of health planning and management. 23 , pp. $37-49$

Báez, J, 2007. La entrevista. In: ESIC, ed. 2007. Investigación cualitativa. Madrid.

Bangkok, 2005. Carta de Bangkok para la promoción de la salud en un mundo globalizado.

Disponible en:

http://www.who.int/healthpromotion/conferences/6gchp/BCHP_es.pdf

[Consultado, 15 septiembre 2012]

Barrutia, JM y Echevarría, C. 2011. Explaining and measuring the embrace of local Agenda 21s by local governments. Environment and planning A, 43, pp. 451469.

Baxter, B, 2010. For families, actions speak lauder than words. Evaluation and Program Planning 33, pp. 39-40.

Benedicto, A. y Oñorbe, M, 2010. Cambios en la salud pública: el papel del estado y de las autonomías. Informe SESPAS 2010. Gaceta Sanitaria, 24 (1) pp. 19-22.

Bernal-Delgado, E. Ortún-Rubio, V. 2010. La calidad del sistema nacional de salud: base de su deseabilidad y sostenibilidad. Gaceta Sanitaria, 24 (3), pp. 254-258. 
Bernal-Delgado, E. Campillo-Artero, C. García-Armesto, S. 2014. Oferta sanitaria y crisis: financiamos los bienes y servicios según su valor o caemos en la insolvencia. Informe SESPAS 2014. Gaceta Sanitaria, 28 (1) pp. 69-74.

Bimbela, J.l. Cruz, M.T. 1996. Sida y jóvenes: la prevención por vía sexual. Granada. EASP.

Brundtland, G, 2002. Salud y Desarrollo Sostenible. ICE. Desarrollo Sostenible. Junio Julio 2002. Número 800.

Buades, M. Plasencia, A y Cabeza, E. 2009. La reforma de la salud pública, Gaceta Sanitaria, 23. pp. 462-464

CIREM. Un Sistema Sanitario Sostenible. Ediciones Círculo de Empresarios, 2006. Madrid.

Conferencia de las Naciones Unidas, 1992. Medio ambiente y desarrollo. [Pdf]: http://www.un.org/es/Río de Janeiro

Disponible en: http://www.un.org/depts/dhl/spanish/resguids/specenvsp.htm [Consultado 9 junio 2010]

DECLEY. Anteproyecto de Ley de Economía Sostenible. 27 Noviembre, 2009. (Art.2, pp.1)

De Miguel, J. 1980. Siete tesis erróneas sobre la política sanitaria española y una alternativa sociológica crítica. Reis 9/80 pp. 53-80

DOHUK, 2004. Making Healthy Choosing Easier. NHS, UK Disponible en: http://www.nhs.uk/aboutNHSChoices/professionals/life-checkers/about us/Pages/background.aspx

[Consultado, 25 septiembre 2012]

Dooris, M, 2001. The Health Promoting University: a critical exploration of theory and practice. Health Education. 101 (2), pp. 51-60

Ebi, K. Burton, I, 2008. Identifying practical adaptation options; an approach to address climate change-related health risks. Environmental science \& policy II, pp. 359369.

El Ansari, W y Stibbe, A, 2009. Public Health and the environment: What skills for sustainability Literacy - and Why? Sustainability, 2009 (1) pp. 425-40. 
Feichtinger, J. Pregernig, M, 2005. Imagined Citizens and Participation: Local Agenda 21 in Two Communities in Sweden and Austria. Local Environment.10, (3) pp. $229-42$.

Fiona, A. Thorpe, A. y Rutter, J, 2006. Sustainable development and public health: A national perspective. Public Health, 120 (12), pp. 1102-1105

Freeman, R.E, 1984. Strategic management: a stakeholder approach. Pitman Press, Boston.

Gervás, J. Meneu, R. 2010. La crisis de salud pública en una sociedad desarrollada. Aciertos y limitaciones en España. Informe SESPAS. Gaceta Sanitaria (I) pp. $33-36$

Guite, H, F. Clark, C y Ackrill, G. 2006. The impact of the physical and urban environment on mental well being. Public Health 120, pp. 1117-1126

Hanlon, P. Carlisle, S. Hannah, M. Lyon, A. y Reilly, D, 2011. Learning our way into the future public health; a proposition. Journal of public health. 33, (3), pp. 335342.

Haines, A. Kovats, R.S. Campbell-Lendrum, D. Corvalan, C, 2006. Climate change and human health: Impacts, vulnerability and public health. Journal of public health, 120, pp. 585-596.

Heinonen-Tanski, H. Surendra, K. y Karinen, P, 2010. Sustainable Sanitation. A Cost Effective Tool to Improve Plant Yields and the Environment. Sustainability 2010, 2, pp. 341-53.

Israr, S.M. and Islam, A. (2006). Good governance and sustainability: a case study from Pakistan. The International Journal of Health Planning and Management, 21(4), pp. 313-325.

Jager, J, 2001a. Sustainability Science. In: Kates, R et al. Ed, 2001. Sustainability Science. Science 292. pp. 641- 642.

Jager, J, 2001b. Sustainability Science. In: Kates, R et al. Ed, 2001. Sustainability Science. Science 292. pp. 641-642. 
Jameton, A y McGuire, C, 2002. Toward sustainable Health-care services: Principles, challenges, and a process. International journal of Sustainability in Higher Education. Academic Research Library.

Jochelson, K. 2006. Nanny or steward? The role of government in public Health. Public Health, 120, 1149-1155.

Kickbusch, I. 2009. Policy Innovation for Health. In: Springer, ed. 2009. Innovation for Health. Geneva. Springer. Ch. 1

Komiyama, H. \& Takeuchi, K, 2006. Sustainability science: building a new discipline. Sustainability Science, 1(1) pp. 1-6.

Llamas-Sánchez, R. Muñoz-Fernández, A y Maraver-Tarifa, G. The local agenda 21 in Andalusia, Spain: a model for sustainable innovation. 2011. African journal of business management. 5 (32) pp. 12653-12663

LES, 2009. Ley de Economía Sostenible. Cap. 2.

March, JC. Prieto, M. Hernán, M. Solas, O. 1999. Técnicas cualitativas para la investigación en salud pública y gestión des servicios de salud: algo más que otro tipo de técnicas. Gaceta Sanitaria. 4, pp. 312-319

Martín, J y López del Amo, M.P, 2011. La sostenibilidad del Sistema Nacional de Salud en España. Departamento de Economía Aplicada, Facultad de Ciencias Económicas y Empresariales. Campus Universitario de Cartuja S/N. Artigo Article, n 2773. Granada.

Martínez, M y Rosende, S. Participación ciudadana en las agendas 21 locales: cuestiones críticas de las gobernanza urbana. 2010. Scripta Nova. Revista electrónica de geografía y ciencias sociales. XV. 355.

McKinsey \& Fedea, 2009. Impulsar un cambio posible en el sistema sanitario. Fundación de estudios de economía aplicada.

Disponible en :

http://www.cambioposible.es/documentos/sanidad_cambio_posible.pdf [Consultado 25 Febrero 2013]

Meneu, R. Ortún, V. 2001. Transparencia y buen gobierno en sanidad. También para salir de la crisis. Gaceta Sanitaria; 25 (4) pp. 333-338. 
MINISAN. Ministerio de Sanidad, 2010. Desarrollo sostenible. Salud ambiental y laboral.

Disponible en:

http://www.msps.es/ciudadanos/saludAmbLaboral/medioAmbiente/desarroSoste nible.htm

[Consultado 22 Junio 2010]

Muntaner, C. Benach, J. Tarafa, G. y Chung, H, 2011. The welfare state and global Health; Latin America, the Arab world and the politics of social class. Gaceta Sanitaria, 25 (6) pp. 445-447

NUAG. Cumbre para la Tierra 21, 1992. Naciones Unidas. Rio de Janeiro.

Disponible en: http://www.un.org/esa/dsd/agenda21_spanish/

[Consultado 27 mayo 2010]

OECD. Health data, 2006

Otawa, 1986. Carta de Otawa para la Promoción de la Salud.

Disponible en:

http://www.famp.es/racs/intranet/otras_secciones/documentos/CARTA\%20DE \%20OTTAWA.pdf

[Consultado, 10 septiembre 2012]

Oteo, L A, 2010. La sostenibilidad del Sistema Nacional de Salud: los profesionales sanitarios y la ciudadanía. Revista Administración Sanitaria, 8 (1) pp. 5-32.

Pecurul, M. Peray, J.L. 2010, Trabajando hacia una salud pública sostenible mediante la interrelación de lo ambiental y lo social. Informe SESPAS. Gaceta Sanitaria, (I) pp. 74-77

Potvin, L. Gendron, S. Bilodeau, A. Chabot, P, 2005. Integrating Social Theory into Public Health Practice. American Journal of Public Health, 95 (4), pp. 591-595.

Potvin, L. Mantoura, P. Ridde, V, 2010. Evaluating equity in health promotion.

Prieto, L. 1997. Más allá de los métodos cuantitativos y cualitativos: el método científico. Revisiones en Salud Pública, 5, pp. 195-199

PROMOSALUD. La evidencia de la eficacia de la promoción de la salud. ECSC 
Puig-Junoy, J. 2006. ¿Es la financiación sanitaria suficiente y adecuada? Gaceta Sanitaria, 20 (1), pp. 96-102.

EC-EAEC, 1999. [Pdf] Bruselas - Luxemburgo.

Disponible en:

www.msps.es/profesionales/saludPublica/prevPromocion/docs/Parte_2.pdf

[Consultado 8 Julio 2010]

Rae, M. 2006. Health Inequalities - a sustainable Development issue. Public Health, 120, pp. 1106-1109.

Real Decreto Ley 4/2010. de 26 de marzo, de racionalización del gasto farmacéutico con cargo al Sistema Nacional de Salud. Disposición 5030. BOE, Núm. 75, 27 marzo 2010. Sec. I. p. 28989.

Repullo, J y Freire J, 2008. Gobernabilidad del Sistema Nacional de Salud: mejorando el balance entre los beneficios y los costes de la descentralización. Informe SESPAS. Gaceta Sanitaria, 22 (1) pp. 118-25.

Repullo, J y Segura. A, 2006. Rev. Salud Pública y Sostenibilidad de los sistemas públicos de salud. Española de Salud Pública; 80 pp. 475-82.

Repullo J, 2009. Identificación y modulación del comportamiento sistemáticamente irracional en medicina y salud pública. Revista Española de Salud Pública, 83 pp. 43-57.

Río, 2011. Conferencia Mundial sobre los Determinantes Sociales de la Salud. OMS, Río de janeiro, 19-21 octubre 2011.

Disponible en:

http://www.who.int/sdhconference/declaration/Rio_political_declaration_Spanis h.pdf

[Consultado, 19 septiembre 2012]

Scheaffer, R. Mendenhall, W. Ott, L, 1987. Elementos de muestreo. Versión española de la obra Elementary survey sampling. $3^{\mathrm{a}}$ ed. México D.F. Grupo Editorial Iberoamérica.

Segura, A. Oñorbe, M. 2010. Cambios en la salud pública: el papel del estado y de las autonomías. Gaceta Sanitaria, 24. (I) pp. 19-22 
Seuc, H.A. Domínguez, E. 2002. Introducción al cálculo de esperanza de vida ajustada por discapacidad. Instituto Nacional de Angiología y Cirugía Vascular. Rev. cubana de Hig Epidemiol, 40 (2), pp.95-102.

Sumi, A. 2007. On several issues regarding efforts toward a sustainable society. Sustainability Science 2, (1), pp.67-76.

Thomson, S. Foubister, T. Figueras, J, et al, 2009. Addressing financial sustainability in health systems. European observatory on health systems and policies.

Urbanos, R. 2004. El impacto de la financiación de la asistencia sanitaria en las desigualdades. Gaceta Sanitaria, 18 (1), pp. 90-5.

Urbanos, R. 2006. El gasto sanitario y su financiación: evolución, tendencias y reflexiones para el futuro. Revista Asturiana de Economía. RAE, nº 35 .

Veillard, J.H.M. Brown, A.D. Barıs, E. Permanand, G. Klazinga, N.S. 2011. Health system stewardship of National Health Ministries in the WHO European region: Concepts, functions and assessment framework. Health Policy, 103, pp. 191199.

Waddock, S.A. y Graves, S.B., 1997. The corporate social performance-financial performance link. Strategic Management Review. 10, pp. 758-769.

Werbanch, A. 2009. Estrategias sostenibles: un manifiesto para la empresa del siglo XXI. Barcelona. Ediciones Urano.

WHO Regional Office for Europe, 2008. The Tallin Charter: health systems for health and wealth. WHO, Regional Office for Europe, Copenhagen. http://www.euro.who.int/document/E91438.pdf

WHO, 2008. Carta de Ottawa para la promoción de la salud.

Disponible en: www.paho.org/spanish/hpp/ottawachartersp.pdf

[Consultado 3 de septiembre de 2012]

Who, 2009. Reducir las inequidades sanitarias actuando sobre los determinantes sociales de la salud. 62 ${ }^{\mathrm{a}}$ Asamblea Mundial de la Salud. WHA62.14, punto 12.5 orden del día, 22 de mayo 2009.

Disponible en: http://apps.who.int/gb/ebwha/pdf_files/A62/A62_R14-sp.pdf [Consultado, 16 septiembre 2012] 
Who Europe, 2010. European Observatory on Health System and Policies. Spain.

Disponible en: http://www.euro.who.int/en/who-we-

are/partners/observatory/health-system-reviews-hits/full-list-of-hits/spain-hit2010

[Consultado 7 de mayo de 2012]

Who, 2000. Objetivos de desarrollo del milenio. Naciones Unidas.

Disponible en: http://www.un.org/spanish/milenio/ares552.pdf

[Consultado 7 de mayo de 2012] 
Capítulo 2: El enfoque de sostenibilidad en los planes de salud de las comunidades autónomas: el desarrollo sostenible como oportunidad. 


\section{Índice}

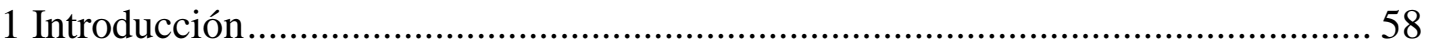

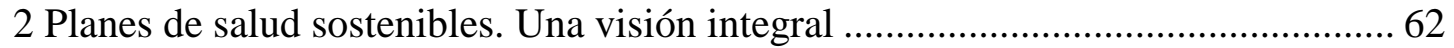

2.1 La cuestión económica en los programas y planes de salud............................. 63

2.2 La vertiente social como driver de las intervenciones en los programas y planes

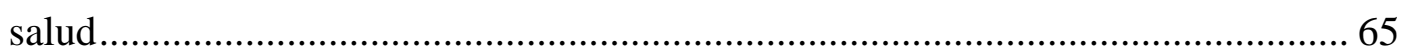

$2.3 \mathrm{El}$ contexto y la teoría ecológica en los planes de salud................................. 68

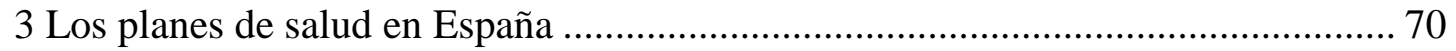

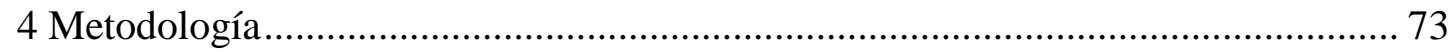

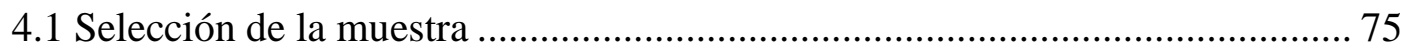

4.2 Sensibilidad simbólica y operativa en las tres dimensiones clásicas del

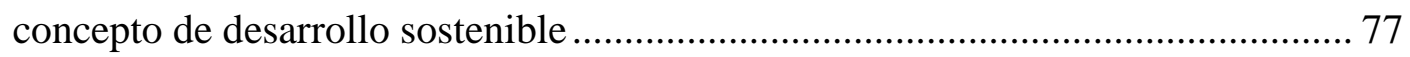

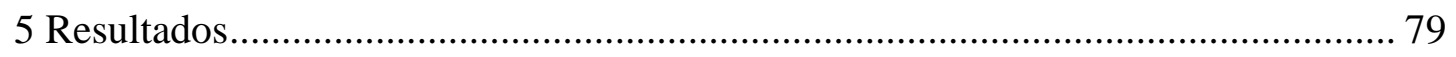

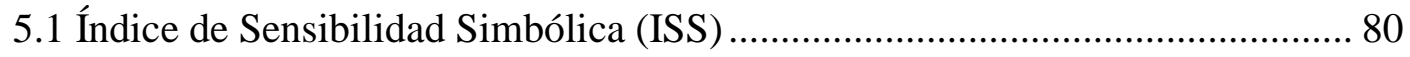

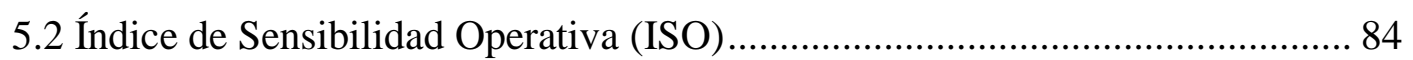

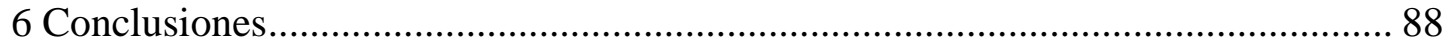

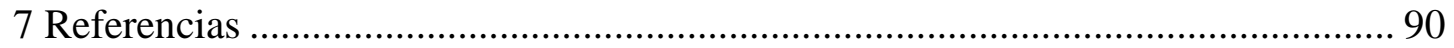




\section{1.- Introducción}

La idea de un plan de salud con base en criterios de desarrollo sostenible es particularmente apropiada para los servicios de provisión de cuidados de la salud, ya que sitúa el foco de la acción en la promoción, el bienestar social y la equidad además de ser una cuestión de justicia social (Evans et al., 2012). Los programas y planes de salud de iniciativa pública pretenden proporcionar el liderazgo y la dirección necesarios para impulsar el desarrollo de un sistema de salud con el que mejorar la sanidad y el bienestar de las poblaciones de una forma eficiente y eficaz (Beuregards, 1995; Marshall et al., 2014; Nancholas, 1998 y Pluye et al., 2004a). Sin embargo, cuestiones relativas a la sostenibilidad de los instrumentos de planificación en salud no están del todo resueltas pese a que se suele considerar una prioridad (Altman et al., 1991). Aspectos como su definición en términos operativos y procedimentales o la forma de medir la sostenibilidad de los programas continúan en desarrollo (Scheirer y Dearing, 2011).

Por un lado, el término sostenibilidad asociado a los programas de salud suele traducirse en relación con su duración en el tiempo (Scheirer y Dearing, 2011; Schell et al., 2013). No obstante, como afirman Pluye et al., (2004b) esta concepción de la sostenibilidad aplicada a la promoción de la salud requiere ser matizada. De acuerdo con Pluye et al., (2004a), hay cuatro razones en la literatura por las cuales la sostenibilidad interesa a los profesionales de la salud pública i) porque se pueden mantener los efectos del plan por un extenso período de tiempo y permite estudiarlos a largo plazo ii) porque existe un período de latencia entre la puesta en marcha del plan y sus efectos en la salud de la población dado que los resultados suelen ser apreciados en un rango temporal de tres a diez años después de su implementación iii) porque en programas que resultan beneficiosos para la salud de la población objetivo, la ausencia de sostenibilidad puede provocar que se pierdan inversiones adicionales en el plan y se desvinculen personas involucradas en el mismo y iv) porque descontinuar los programas comunitarios desmotiva a la población y dificulta la movilización social en este tipo de asuntos.

Por otro lado, relacionado con la medición y evaluación de la sostenibilidad de los programas de salud, no es posible hallar un método consensuado con el que llevar a 
cabo tal evaluación (Pluye et al., 2004a; Schell et al., 2013; Scheirer, 2005). Como destacan Pluye et al., (2004a), "poco se conoce acerca del proceso de sostenibilidad, por consiguiente es difícil para los profesionales de salud pública cómo y cuándo influir en la sostenibilidad de sus programas, para los decisores cómo y cuándo evaluar dichos programas y para los investigadores cómo estudiarlos".

Es posible identificar diferentes tipos de programas y planes de salud a los que aplicar criterios de sostenibilidad en función de las estructuras sociales en las que se sustentan dichos programas. La literatura identifica dos enfoques diferentes, una propuesta de programas de promoción de la salud dentro de las organizaciones por un lado, y otro basado en aquellos que se llevan a cabo en colaboración con grupos de la comunidad, es decir, con un enfoque más centrado en intervención comunitaria (Scheirer, 2005). Si bien las herramientas del análisis organizacional pueden ser utilizadas igualmente en los estudios comunitarios (Boulte, 1991), la sostenibilidad de los programas de salud parece que funciona mejor en el entorno de una organización donde es factible un mayor control e influencia sobre las tareas y objetivos a realizar. En el razonamiento de la sociología organizacional encontramos el establecimiento de tareas concretas o rutinas como telón de fondo (Weber, 1995; Scheirer, 2013), es decir, un conjunto de actividades a nivel de operaciones normalizadas en los programas que propenden a ser sostenibles y reconocibles en el tiempo (Pluye et al., 2004b). Este sistema debería encontrar indicadores adecuados en cada objetivo y sus correspondientes tareas o rutinas asignadas. Algunos ensayos realizados en España se han visto condicionados por la asignación de presupuestos y sus rutinas de trabajo interrumpidas por la falta del mismo, especialmente en situaciones de crisis económicas. Ausencia de recursos que en ocasiones debían dar cumplimiento a leyes aprobadas o permitir continuar con acciones sobre el terreno de las que cabría esperar resultados en el medio largo plazo, pero que al no existir, han terminado con las actividades y tareas establecidas. Tal fue el caso de la Llei de Barris de la Generalitat de Catalunya (LBAR, 2004), una ley enfocada en el desarrollo de las comunidades con mayores necesidades socioeconómicas y en riesgo de vulnerabilidad. Por otro lado, la estandarización de los procesos, según Pluye et al., (2004a) basa las actividades y rutinas en estándares reconocibles y facilita la sostenibilidad de los programas de forma más efectiva que la mera asignación de tareas institucionalizadas. Establecer un marco de trabajo orientado al desarrollo sostenible de los planes de salud y el análisis de los indicadores correspondientes de forma comparable y comprensible, con aspectos de materialidad adecuados, que incluya a los 
grupos de interés y situado en el contexto pertinente es un enfoque que podría contribuir al desarrollo de dichos documentos estratégicos. Sin embargo, es preciso señalar como contrapunto, la dificultad de estandarizar procesos en las estructuras sociales complejas. Un plan, señala Uribe (2011) en referencia a Matus (1993), es una de las posibilidades de acción. Que el plan sea más o menos consistente dependerá de la potencia de sus argumentos y los sistemas de análisis entre otros factores. En relación a los planes de salud, el enfoque de una tercera generación podría aprovechar lo aprendido a lo largo de los primeros veinte años de elaboración de documentos. Avanzar en propuestas más holísticas que incidan en cambios culturales, de hábitos de vida a través de una mejor promoción, incentivar a pacientes y profesionales y actuar con perspectiva social amplia e inclusiva además de la visión interna y organizativa del propio sistema sanitario.

Los programas de salud no son iniciativas aisladas sino que forman parte de una estructura mayor. Con frecuencia la pregunta relativa a cuándo podemos decir que un sistema de salud es sostenible encuentra respuestas ambiguas. Existen marcos teóricos de visión amplia, por ejemplo (Olsen, 1998) lo define de este modo; "Un servicio de salud es considerado sostenible cuando opera a través de una organización o sistema con la capacidad a largo plazo de conseguir y ubicar los recursos necesarios para las necesidades individuales o de salud pública”. La definición, a priori, podría señalar una orientación de corte economicista en relación con las dimensiones sociales o medioambientales así como en materia de inclusión de grupos de interés, dado que sitúa el foco en la eficacia en la captación de medios económicos y la gestión posterior de los mismos. Sin embargo, al investigar el modelo propuesto observamos que los tres clusters en lo que se basa: -capacidad de la organización, perfil de la actividad y factores del contexto-, dotan al modelo de un perfil más amplio y al menos apunta a una visión más holística.

Como señalan Themba et al., (2008), la construcción de alternativas políticas y las decisiones sobre las actuaciones a seguir en aspectos relacionados con programas o planes de provisión de servicios públicos como la sanidad, requiere de una exploración en profundidad del contexto en el que se enmarca la acción. Los factores del contexto cobran una relevancia evidente, dado que al no ser controlables deberían ser monitorizados y sus efectos sobre la salud de la población considerados a un nivel de estimación adecuados. Minkler et al., (2010) mencionan una serie de factores de contexto, entre los cuales encontramos, entre otros, los modelos de construcción urbanística, las emisiones de gases de efecto invernadero de entornos industriales 
cercanos o la situación socioeconómica y política de la comunidad en concreto. Es importante observar, siquiera de forma colateral, si estos factores inciden en el modelo sanitario y hasta qué punto fueron previstos. Es más, la tendencia a efectuar recortes en el gasto sanitario a corto plazo puede agravar eventualidades no previstas en los planes de salud y por consiguiente afectar a la estrategia sanitaria.

La presión sobre los presupuestos es incremental y aumenta tanto por situaciones de coyuntura económica desfavorable como por factores demográficos. En la situación actual los recortes se basan en la creencia de que los servicios públicos no cumplen adecuadamente con sus objetivos y se promueve la privatización y la entrada del mercado con resultados negativos (Evans et al., 2012). En España, las tendencias y las acciones privatizadoras de la sanidad son dispares ya que su incidencia difiere por cuestiones ideológicas en cada comunidad autónoma según el partido gobernante, sin embargo, encontramos en el recorte de los presupuestos en sanidad un elemento común en todas ellas, ya sea de forma nominal o por vía de reducción en la provisión de servicios, horarios de atención, prestación farmacéutica y otras medidas urgentes adoptadas por real decreto con objeto de garantizar la sostenibilidad del sistema sanitario.

Como mencionan Evans et al., (2012), una de las claves del desarrollo sostenible es la relación entre la justicia social, la salud y el bienestar, traducido en términos prácticos en cuatro elementos: i) enfoque en el sistema global para evitar compensaciones o contradicciones de objetivos y resultados, es decir, estar alineados con objetivos comunes en todas las áreas relacionadas, ii) prevenir mejor que curar, iii) participación ciudadana y todo ello considerando iv) resultados a largo plazo con objetivos que integren las tres dimensiones: económica, social y medioambiental.

El análisis en materia coste económica y asignación de recursos es esencial, así como la participación de los agentes sociales y otros grupos de interés en aspectos como los determinantes sociales o la salud ambiental. Por otro lado, como queda reflejado en el artículo de Minkler et al., (2010) en la voz de los propios participantes en la investigación sobre la promoción de la equidad social en una comunidad latina en el estado americano de California, las personas implicadas aprendieron el modo de mejorar la educación en salud, a mantener un entorno saludable y fomentar la comunicación entre ellos implicando a buena parte de los ciudadanos. Una visión y comprensión común de los objetivos y las actividades a realizar es fundamental, especialmente entre los pacientes y su experiencia de relación con el sistema de salud 
(Kepros y Opreanu, 2009). Como destacan Arredondo y Orozco (2008), las oportunidades de colaboración de los diferentes grupos de interés contribuyen además a desarrollar las capacidades de los gobiernos locales, los líderes comunitarios, la sociedad civil, los proveedores de salud y el gobierno central. Parece claro según los autores, que entre los objetivos y las cuestiones clave que podrían ser incluidas en los planes de salud o en aquellos instrumentos políticos de provisión de servicios sanitarios, estarían la equidad, la gobernanza y la eficiencia de los recursos económicos, y que una mejora en la efectividad de la descentralización puede contribuir a una mejora en la asignación de los recursos.

El objetivo del presente trabajo es conocer si los planes de salud en España están orientados hacia la sostenibilidad en términos financieros, sociales y medio ambientales, y especialmente si esa orientación sigue un modelo integrador de estos factores y dimensiones. Para ello, se analiza una muestra de planes de salud publicados en España en las diferentes comunidades autónomas y se determina el nivel de orientación a los criterios de sostenibilidad en sentido amplio que podemos hallar en los mismos, sensibilidades que deben venir mostradas en el ámbito económico, social y medioambiental. En primer lugar, se realiza una revisión de conceptos y justificación teórica de cada una de las dimensiones de la sostenibilidad en relación con los sistemas sanitarios y planes de salud para entrar, posteriormente, en un breve repaso de la historia y situación de estos documentos estratégicos en España. A continuación describimos el modelo metodológico propuesto con base en experiencias anteriores en diferentes investigaciones en planes de salud y se muestran las evidencias en la bibliografía respecto del método. Se realiza la construcción de los materiales necesarios para la realización del estudio a través de formularios con las cuestiones clave para la lectura de los documentos. El criterio de selección de muestra se basa en un período histórico de cinco años, ligeramente superior al intervalo medio temporal que dichos planes tienen de vigencia. Una vez analizados los planes de la muestra, se describen los hallazgos y conclusiones.

\section{Planes de salud sostenibles. Una visión integral}

En el caso español el plan de salud es el instrumento de comunicación de las diferentes comunidades autónomas en materia de planificación y definición de políticas sanitarias. Dependiente de las consejerías autonómicas debe ser aprobado por el parlamento 
regional cada cierto tiempo tras las revisiones y propuestas para el siguiente período. El documento comprende por lo general un apartado de seguimiento del plan anterior, una descripción del contexto de salud y población en el momento en el que se han elaborado las políticas sanitarias, y un nivel de desagregación a patologías o áreas concretas de intervención.

La idea de planificar la salud de la población parece cada vez más cerca de la necesidad de una visión holística y, en los planes de salud como documentos de definición de política sanitaria, el reflejo de esa visión debería ser observado por los ciudadanos y partes interesadas en general.

El documento de la Comisión Europea (2013) “Invertir en salud”, refleja la importancia de la salud para alcanzar los objetivos fijados en la estrategia general Europa 2020 y conseguir un desarrollo integrador, inteligente y sostenible de la Unión Europea. Dicha inversión implica: i) invertir en sistemas de salud sostenibles ii) invertir en la salud de las personas mediante programas nacionales iii) invertir en cobertura sanitaria como medio para reducir las desigualdades e incrementar la cohesión social. La estrategia de la UE "Juntos por la salud", adoptada en 2007, ya reconocía que la salud de la población no es una cuestión exclusivamente de política sanitaria y recogía entre sus principios el documento denominado "Salud en todas las políticas" (COM630). Este concepto, publicado por Stahl et al., (2006) nos remite hacia una aproximación cercana al criterio de elaboración de planes de salud con base en principios de desarrollo sostenible, vinculados a múltiples stakeholders involucrados en cuestiones relativas a la vertiente económica, social y medioambiental en relación con la salud de las personas.

\section{1.- La cuestión económica en los programas y planes de salud}

Quizá una de las necesidades más obvias de los planes de salud es la de disponer de un presupuesto finalista asignado al desarrollo del instrumento político encargado de guiar las actuaciones en salud para un período de tiempo determinado, pero la mayoría de los

países se enfrentan actualmente a la necesidad de acometer reformas de sus sistemas de salud como respuesta a una variedad de retos políticos, tecnológicos, económicos, demográficos y sociales (Beyer et al,. 2000), y como es lógico a presiones económicas de diversa índole y dureza. En la comunidad internacional la sostenibilidad es una preocupación para los responsables de la asignación de presupuestos dedicados a los 
programas sanitarios, así como para las entidades u organismos que asignan diferentes partidas económicas y que, de hecho, en algunos casos planean descontinuarlas (Stefanini, 1995) o directamente esperar a que lleguen mejores tiempos para considerar la conveniencia. La efectividad de la implementación de planes y programas de salud es poco cuestionable, pero que sus resultados sean sostenibles a largo plazo no está demostrado de manera irrefutable (Israr e Islam, 2006). Hay experiencias documentadas, especialmente en los países en desarrollo, que apuntan a la relación entre la sostenibilidad de un proyecto en concreto y los factores económicos sociales y políticos, así como de gobernanza en el sector público de la salud (Berman 1995; Olsen 1998; Sarriot et al., 2004).

Las consecuencias de la situación económica en el espacio europeo desde mediados de la primera década de este siglo son claras. La propia Comisión Europea, en el mencionado documento "Juntos por la Salud: una aproximación estratégica para la UE 2008-2013" (Comisión Europea, 2007), establece una serie de mecanismos orientados a la inclusión de los grupos de interés y la cooperación con todos los organismos que pudieran estar implicados o relacionados con las cuestiones relativas a la salud de los ciudadanos. Sin embargo, en el apartado denominado instrumentos financieros se indica: “Las acciones en esta estrategia serán financiadas con los presupuestos actuales hasta la finalización del período previsto para el programa, sin consecuencias adicionales para los presupuestos”. El documento señala la dirección y apunta buenas voluntades y teoriza sobre las dinámicas más adecuadas pero no asigna ni señala necesidad alguna de dotación económica con una partida ad hoc para dichas estrategias. Los planes de salud más recientes incorporan elementos de priorización con base en el análisis coste efectividad a través de guías clínicas que incorporan no solo costes sino evidencias acerca de los resultados relacionados (Sánchez et al., 2008), persiguiendo el paradigma de los resultados en salud como indicadores prioritarios en la asignación de recursos y relacionados con el coste de oportunidad. En sanidad, como en otras disciplinas, la elección es crítica cuando se combina con la escasez, y en situaciones de crisis profundas como la actual en el entorno europeo en general y español en particular cabe esperar algún tipo de estrategia de contención del gasto. Peiró et al., (2011) apuntan en este contexto a posibles acciones como la reducción de servicios o prestaciones, la reducción de la calidad de las mismas manteniéndolas en número y diversidad, mejorar la eficiencia interna haciendo más con menos o una combinación de todas las opciones. La experiencia empírica que nos proporciona el tiempo transcurrido 
durante el actual período de crisis nos demuestra que en efecto algunas de las citadas estrategias se han llevado a cabo en el conjunto de las comunidades autónomas. En el estudio realizado por Peiró et al., (2011), para el que se utilizaron técnicas de braimstorming, grupo nominal y método de consenso RAND, se concluyó entre otros aspectos que el impacto económico de las medidas legislativas tomadas por el gobierno era elevado y orientado a corto plazo además de carente de reformas estructurales y visión estratégica. La necesidad de inmediatez en las decisiones propiciada por la coyuntura podría introducir acciones al margen de las estrategias establecidas a priori con el consiguiente riesgo. Interesaría conocer los efectos derivados a largo plazo y si podrían suponer un agravamiento de las condiciones de determinados grupos de pacientes, o si dichos efectos podrían producir eventos y complicaciones mayores provocando un incremento del gasto sanitario necesario para intervenciones más complejas y graves.

\section{2.- La vertiente social como driver de las intervenciones en los programas y planes salud}

La idea de incluir a los pacientes de manera activa a la hora de realizar planes de salud no es nueva y ya fue introducida en Estados Unidos en la obra The Urban Condition (Duhl, 1963). Otros autores, inciden en el hecho de que esta inclusión supondría una orientación más holística relacionada con el reto de elaborar planes de salud y sus correspondientes acciones encaminadas a construir indicadores y objetivos, y quizá la adopción de nuevos conceptos sanitarios que afectan a la salud física y el bienestar de las personas (Hoffman, 2009). En otros países el proceso de decisiones compartidas entre pacientes y sistema sanitario ha sido estudiado en los diferentes niveles de aplicación. En primer lugar a nivel macro o nivel de utilización de los recursos del sistema, en segundo lugar a nivel meso o relativo a las decisiones clínicas y políticas de intervención terapéutica y por último a nivel micro o relacionado con situaciones individuales del paciente (Goss y Renzi, 2007). El concepto de decisiones compartidas tiene significados muy diferentes según el nivel al que se refiere, especialmente en el macro nivel. Los grupos de interés implicados varían en función de si nos referimos a organización y asignación de recursos del sistema, o nos situamos en el punto meso y micro, donde los aspectos concretos se refieren a situaciones particulares de pacientes y profesionales. En el caso de Italia, los autores señalan que es el Instituto Superior de 
Sanidad el que indica la necesidad de atender especialmente a los grupos más vulnerables e implicar a las organizaciones de pacientes en la educación y provisión de los instrumentos adecuados para que el paciente tenga un rol activo en las decisiones del cuidado de la salud. Por otro lado, en el caso español, el propio Plan Nacional de Salud y autoridades regionales reconocen explícitamente la importancia de la participación de los pacientes en los tres niveles.

El modelo paternalista de actuaciones de arriba hacia abajo donde el paciente es en buena medida sujeto pasivo o receptor, debería ir dando paso a un modelo participativo y de decisiones compartidas, sin embargo el camino a recorrer aún es largo. Según Nguyen et al., (2014), el modelo de decisiones compartidas se caracteriza por tres aspectos fundamentales i) un intercambio de información relevante bidireccional entre pacientes y clínicos ii) la deliberación entre ambos acerca de la mejor decisión entre las opciones existentes y iii) la toma conjunta de las decisiones pertinentes. En el estudio realizado por los mencionados autores, como parte de una investigación colaborativa entre la McMaster University de Ontario (Canadá) y el GATE-LSE Research Unit de Lyon (Francia), se analizaron las percepciones que tenían tanto pacientes como especialistas clínicos acerca de los roles que habían asumido durante las decisiones de tratamiento. Doscientos treinta y ocho pacientes contestaron al instrumento de medición, una encuesta, de un total de trescientos cuarenta y siete. Los resultados mostraron que el $86 \%$ declaró haber participado de forma limitada en la toma de decisiones. El $40 \%$ identificó el proceso como paternalista y el $48 \%$ como moderadamente compartido. Es posible que la implementación de las políticas inclusivas de los pacientes en los procesos de construcción de estrategias sanitarias estén descritas en diferentes países y aceptadas como convenientes, sin embargo, la factibilidad y la forma de llevarlas a cabo, sigue siendo un reto. El sistema sanitario debe tener al paciente como centro de las actuaciones. Sin embargo, como mencionan Gagliardi et al., (2008), no podemos pasar por alto que ello implica proveer al ciudadano, y en particular al paciente o a las asociaciones que les representan, de las oportunidades para influenciar no solo en el modo en que se organiza la provisión de servicios, sino más allá, en la planificación y la evaluación de los planes. Estos autores, en un estudio exploratorio llevado a cabo en Canadá con treinta pacientes de cáncer y los especialistas implicados en su tratamiento, tenían como objetivo determinar las actitudes de ambos grupos en la selección de indicadores de seguimiento. Mostraron en sus conclusiones una actitud de los especialistas sensiblemente contraria a compartir la 
toma de decisiones. Los autores concluyen que existe la necesidad de crear políticas de gobierno y de las agencias de salud para promocionar la implicación de los pacientes en los programas y planes de salud así como en sus indicadores de seguimiento.

En el caso español existen experiencias y estudios basados en acciones orientadas a reducir las inequidades en salud como factor diferencial. Precedentes como en el caso de Cataluña, de estrategias y legislaciones que han favorecido el avance en los modelos de acción comunitaria. La ley de Barrios de 2004 (LBAR, 2004) incidía en los determinantes sociales de la salud, en el desarrollo de proyectos colaborativos entre diferentes sectores centrándolos en las causas de las inequidades y tomaba como uno de los primeros pasos a dar el fomento de la participación de la comunidad en los procesos que se debían llevar a cabo (SBARRIS, 2004). El esquema de trabajo consistía en un análisis previo cualitativo de los grupos y propuesta de acciones específicas, una planificación de dichas actuaciones y la acción correspondiente. Este diseño nos remite a un esquema APA (Análisis, Planificación y Acción) susceptible de ser ampliado al modelo PDCA (Plan, Do, Check, Act) de mejora continua según el ciclo de Deming (1982), ampliando así las actuaciones a un círculo virtuoso de búsqueda de excelencia y evitando los fallos debidos a implementaciones parciales de los objetivos o a la implicación de solo determinados grupos aislados (Deming, 1986; Saunders, 1994). La introducción de revisiones a la implementación a través de indicadores ayudaría a corregir aquellas actuaciones que no estén alcanzando los niveles objetivo en las intervenciones comunitarias.

La experiencia llevada a cabo por el departamento de salud de Cataluña en 2007, fue realizada por el grupo Salud en los Barrios (Fuertes et al., 2012) y se realizó con un modelo sistemático de acción basado en tres puntos iniciales: i) alianza con los stakeholders ii) análisis de las necesidades de salud y planificación iii) intervención y evaluación de las actuaciones. Dos poblaciones, Poble Sec y Roquetes, fueron elegidas por sus condiciones socio-económicas y demográficas y que presentaban además un fuerte componente de población inmigrante. Se evaluaron dieciocho indicadores, entre ellos la disponibilidad de los implicados y el número de reuniones realizadas que se fijó en ocho al año para los grupos de trabajo. Se tomaron medidas del nivel de satisfacción a través del cuestionario Community Group Member diseñado por la Universidad de Wisconsin (WISCO, 2002). En ambas comunidades el porcentaje de viabilidad de los programas llevados a efecto y medidos a través de los indicadores excedió el 75\%. Los autores concluyen en el estudio que la implementación de planes adaptados a la 
comunidad orientados a reducir las inequidades con participación de los grupos de interés es viable (Fuertes et al., 2012).

Como se ha señalado con anterioridad, prestar una atención especial a los grupos desfavorecidos es de vital importancia. Una menor visibilidad en situaciones de

vulnerabilidad podría aumentar los efectos negativos en las tasas de morbilidad y mortalidad inducida por una menor capacidad de acceso y exposición de necesidades. Numerosos estudios señalan que existe una fuerte correlación entre ingresos económicos y esperanza de vida medida por la prevalencia de las patologías más comunes, entre las cuales, encontramos desordenes mentales, diabetes o incluso una mayor incidencia de la tasa de suicidios y utilización de los servicios sanitarios (Lemstra et al., 2006). Hay evidencias de que las comunidades más desfavorecidas también tienen más dificultades para acceder a servicios relacionados con la salud incluso en países desarrollados como Nueva Zelanda (Pearce et al., 2006), especialmente si se activan barreras de entrada al sistema como el copago en atención primaria. En situaciones de pobreza, incluso las diferencias de miseria pueden tener incidencia negativa sobre indicadores como el índice de masa corporal o la presión arterial, tal y como destacan Merlo et al., (2004). La experiencia práctica demuestra que las comunidades empobrecidas comparten características similares en cuestiones de salud y parece relevante que en los planes a realizar con dichos grupos haya la mayor representatividad posible en los procesos de decisión (Tranquada, 1973).

\section{3.- El contexto y la teoría ecológica en los planes de salud}

Como señalan Ballester et al. (2014), más allá de los determinantes sociales que a menudo vienen marcados por el lugar en el que las personas nacen y viven, las condiciones socio-sanitarias del entorno y el acceso a servicios de salud adecuados, interesa analizar las estrategias y las medidas incluidas en los instrumentos de planificación sanitaria respecto de factores más globales como las condiciones sociales, económicas, ambientales y culturales y su influencia en los servicios sanitarios. Se mencionan a modo de ejemplo los referidos al entorno de trabajo, la vivienda o a la incidencia del medioambiente en la salud. Respecto de este último factor ambiental, Pruss-Ustun et al,. (2008) destacan que según la OMS entre el trece y el veintisiete por 
ciento de la carga de enfermedad mundial podría prevenirse mejorando el medio ambiente.

Los modelos ecológicos de interacción pueden ser incluidos en la complejidad de los problemas relacionados con la salud y la equidad (Reifsnider et al,. 2005). Desde la perspectiva de la presente investigación, a priori cabe preguntarse qué podrían aportar las teorías ecológicas a una investigación en planes de salud. Y desde un punto de vista más teórico, si dichas teorías tendrían un sentido justificado en los planes de salud en el caso de ser consideradas. La teoría ecológica del desarrollo humano (Bronfenbrenner, 1977) se centra fundamentalmente en aspectos relacionados con la interacción individuo-ambiente, en una estructura de "capas de cebolla" que van desde el corazón o núcleo representado por la relación inicial del individuo con la madre a nivel micro sistema, a una relación más extensa o nivel meso sistema con intervención de actores e influencias del entorno más cercano. Ambas fases pueden influir en hábitos que determinen los niveles futuros de salud del individuo, el micro contexto representado por el hábitat más cercano, puede ejercer una influencia en los comportamientos relacionados con los hábitos de salud. Desde una perspectiva de planificación de las intervenciones sanitarias estaríamos en el ámbito de la promoción de la salud. Los siguientes niveles son igualmente relevantes, en el exosistema los individuos pueden llegar a ser agentes pasivos y recibir los inputs del entorno, si bien Bronfenbrenner (1977) se mantiene en el ámbito de las interacciones directas: repercusiones laborales de los padres o actuaciones de las asociaciones comunitarias. Consideramos que en este nivel las externalidades medioambientales que afecten a los individuos podrían tener hueco en el modelo. Una fábrica altamente contaminante en el lugar de residencia tiene una clara influencia sobre la salud de los habitantes del entorno, por citar una circunstancia habitual en muchas ciudades industriales. Finalmente, en la capa más externa, el autor sitúa el macro sistema, determinado por factores culturales de creencias e ideologías que influyen en las decisiones que toman las personas respecto de sus hábitos e incluso prácticas sanitarias. Así, la teoría ecológica aporta una clasificación paralela, en tres niveles, a las del propio sistema sanitario aportando una posible línea de diseño de estrategias para integrar a los actores sociales en la construcción de planes de salud.

Los condicionantes de la situación ambiental de la población, entendida esta en su sentido más amplio, favorecen o sirven de freno en la aparición de determinadas patologías, como señala Reifsnider et al,. (2005) citando a Valanis (1992). Parece que la 
enfermedad tiene un cierto componente oportunista y florece con mayor éxito allí donde el contexto le resulta más favorable. Este factor resalta la importancia de mantener un nivel de equidad adecuado y actuar sobre los determinantes sociales en los nichos de población más desfavorecidos. Como concluyen Gruen et al., (2008), es el ecosistema el que debería ser considerado de forma amplia y la sostenibilidad de los programas de salud podría contemplar las complejas interrelaciones en ese contexto: objetivos de salud, grupos de interés, recursos y acciones a llevar a cabo.

\section{3.- Los planes de salud en España}

La necesidad de elaboración e implementación de instrumentos de planificación de salud en las diferentes comunidades autónomas españolas viene marcada por la Ley General de Sanidad de 1986 (LGS), en la que se articula que "Cada comunidad autónoma elaborará un plan de salud que comprenderá todas las acciones sanitarias necesarias para cumplir los objetivos de sus servicios de salud. El plan de salud de cada comunidad autónoma, que se ajustará a los criterios generales de coordinación aprobados por el gobierno, deberá englobar el conjunto de planes de las diferentes áreas de salud".

Por otro lado, las diferentes leyes de ordenación sanitaria, amplían este marco legislativo de referencia, entre otras la de Cataluña de 1990 (Tresserras, 2008), o la ley 1/1993 de 6 de abril, de Ordenación del Sistema Sanitario de Castilla y León, que dedica un capítulo completo a tratar del plan de salud (LSSCL), o la Ley 4/2005 de Salud Pública de la Comunidad Valenciana (LSPCV) unida igualmente a un plan estratégico de salud. Cierto es que no hubo un ajuste temporal definido en cuanto a la realización de dichos planes de salud por parte de las comunidades autónomas a partir de la publicación de la Ley General de Sanidad, que de hecho, dejaba en su artículo setenta abierta la posibilidad de que se realizaran anual o plurianualmente sin mayor especificación. En diferentes regiones españolas los primeros planes de salud se elaboran y publican a principios de los años noventa, con anterioridad al plan integrado de salud según lo previsto en la LGS. A lo largo de las siguientes décadas y hasta la fecha actual, no existe una secuencia o patrón temporal definido para la elaboración de los planes de salud y la duración o vigencia de los mismos varía por comunidades autónomas. Los intervalos de publicación oscilan con frecuencia entre los dos y los 
cuatro años y existe un rango temporal en el conjunto de las publicaciones de uno a nueve años.

La Sociedad Española de Salud Pública y Administración Sanitaria (SESPAS), creó un grupo en 1998 denominado "Plan de Salud" que viene contribuyendo desde entonces al debate sanitario sobre estos instrumentos de planificación sanitaria en España (Fiuza et $a l ., 2010)$. Según publica el grupo en su página web a primeros de 2013 (WPSALUD), se pueden contabilizar treinta y cinco planes de salud en el conjunto de las diferentes comunidades autónomas, además de un plan de salud inicial en Asturias no fechado y de otros planes relacionados o vinculados a los propios planes de salud.

Como destacan Fiuza et al., (2010) la actividad del grupo de trabajo sobre planes de salud centró su debate en tres aspectos fundamentales: i) la formulación de políticas y objetivos, ii) el proceso de planificación y iii) el desarrollo y la implantación social del plan de salud. Durante el primer taller nacional, celebrado en el año 2000 en las Palmas de Gran Canaria, se consensuó la denominada "declaración” de Las Palmas de Gran Canaria sobre planes de salud, entre cuyas conclusiones destacamos las siguientes: i) los planes de salud tienen un valor estratégico en las políticas de salud, ii) es necesario definir las políticas de salud desde una perspectiva coherente suprarregional y local, iii) evaluar los planes de salud debe ser una cuestión de transparencia social, iv) es necesario dotar de órganos de participación social que expliquen la participación ciudadana en todas las fases de elaboración para garantizar su eficacia y efectividad y v) es imprescindible que exista un liderazgo político y técnico de las organizaciones de salud pública para la correcta implementación de los planes de salud. La pregunta del evento ¿Son una herramienta útil los planes de salud?, quedó contestada según los autores: "los planes de salud eran una herramienta útil pero debían adaptarse al nuevo siglo" (Fiuza et al., 2010). 
Cuadro 1: cronología de los planes de salud publicados a finales de 2013

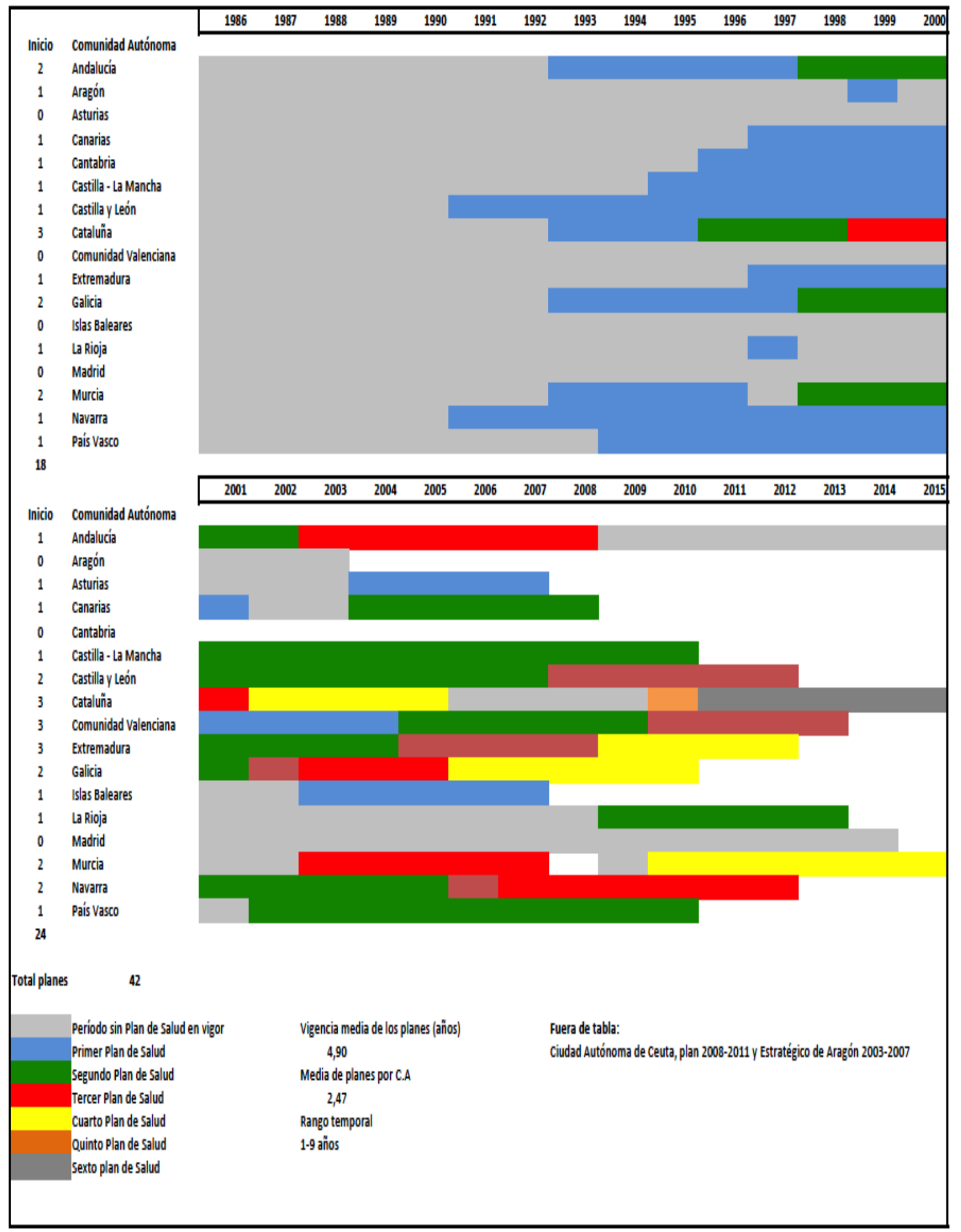

Fuente: elaboración propia desde datos publicados por las CCAA 
El (Cuadro 1) muestra la cronología de publicaciones de los planes de salud aparecidos en España, obtenida a partir de la información públicamente disponible en las páginas web institucionales de las diferentes comunidades autónomas. Los planes de salud identificados presentan una media de publicaciones de dos planes y medio por comunidad autónoma y una vigencia con un promedio cercano a los cinco años. El rango temporal comprende desde los planes de un año hasta los de larga duración y que abarcan prácticamente una década.

Esta larga experiencia en publicaciones de documentos estratégicos de las políticas de salud continúa con las nuevas apariciones de planes que tratan de adaptarse a las necesidades y tendencias más recientes. Los objetivos de salud deben ser realistas e integradores y estar recogidos en un plan que parta de la experiencia acumulada de las comunidades autónomas (Gispert et al., 2000). Estudios previos sobre planes de salud en España han abordado cuestiones como la consideración de aspectos ligados a desigualdades socioeconómicas (Borrel et al., 2005) o aspectos de género (Peiró et al., 2004 y Briones et al., 2009). No obstante, hasta donde llega nuestro conocimiento, no existen estudios que analicen los planes de salud desde una perspectiva económica, social y medioambiental con carácter integral.

\section{4.- Metodología}

El objetivo del presente trabajo es determinar si los planes de salud en nuestro país se orientan en sus propuestas hacia criterios de desarrollo sostenible e incluyen aspectos como diálogo con los grupos de interés, atención a los determinantes sociales o medio ambientales. Para ello analizamos una muestra de planes de salud publicados en España en las diferentes comunidades autónomas mediante análisis de contenido y cuestionarios que evidencien las sensibilidades que deben venir mostradas en el ámbito económico, social y medioambiental.

El análisis de contenido es un procedimiento especialmente apropiado para la obtención de información codificando textos escritos con base en un criterio previo de selección (Krippendorff 1980; Unerman 2000). Posteriormente se realiza un análisis de sensibilidad en los planes de salud de las comunidades autónomas seleccionadas respecto de las dimensiones clásicas y postulados de la teoría de desarrollo sostenible en 
cada plan. Para ello se analizan los contenidos relacionados con el desarrollo de aspectos, políticas e indicadores económicos, sociales y medioambientales en estos instrumentos de política sanitaria.

El análisis de contenido ha sido utilizado en multitud de investigaciones sobre documentación, textos escritos y medios de comunicación (entre otros, Alazzani et al., 2013; Delai y Takahashi, 2013; Lee et al., 2013). Autores como Piñuel (2002), entienden dicho análisis como procedimiento de interpretación de productos comunicativos que procede de procesos singulares de comunicación previamente registrados. Como mencionan Delai y Takahashi (2013), el análisis de contenido cuenta con tres pasos fundamentales: i) pre-análisis (establecimiento del propósito y categorías de estudio) ii) análisis (codificación y categorización) iii) interpretación (obtención de las principales conclusiones).

La experiencia metodológica comparativa respecto de planes de salud fue utilizada para determinar el nivel de sensibilidad en desigualdades socioeconómicas (NSE) en los planes de salud de las comunidades autónomas del estado español por Borrel et al., (2005). Para ello realizaron una revisión sistemática de catorce planes utilizando siempre los más recientes. Emplearon dos niveles de sensibilidad, a los contenidos introductorios se les denominó contenidos simbólicos y a las propuestas de acción contenidos operativos. Otorgaron rangos de cero a tres para el cálculo de los niveles desagregados en cada área de salud o intervención. Esta metodología también fue empleada por Peiró et al., (2004) y Briones et al., (2009) para el análisis de sensibilidad de género en los planes de salud de las comunidades autónomas en el primer caso, y en una visión comparativa internacional sobre género en el segundo con una muestra de treinta y siete planes de salud. Siguiendo a Borrel et al., (2005), Briones et al. (2009) y Peiró et al. (2004), se analizará la sensibilidad simbólica y la sensibilidad operativa de los planes de salud en España con respecto a las dimensiones económicas, sociales y medioambientales.

Como afirman Grimmer y Stewart (2011), los textos de naturaleza política utilizan un lenguaje complejo, hecho que dificulta la realización de un análisis de contenido automatizado como sustituto de una cuidadosa lectura del texto. Consideramos que tal circunstancia es especialmente aplicable en el caso del análisis de aspectos relacionados con la sostenibilidad, dada su naturaleza compleja y polimorfa (White, 2013). Por ello, de igual modo que autores como Campopiano y de Massis (2014), el análisis de contenido se llevó a cabo mediante una lectura comprensiva de las unidades 
hermenéuticas por parte de los investigadores, e igualmente se siguió un proceso de identificación de categorías previas para el esquema de codificación de acuerdo con (Philips 1994; Short y Palmer 2003). Para el análisis de contenido se consideraron palabras clave, frases y las estructuras cuya semántica remitieran al significado de los conceptos y las dimensiones objeto de estudio (Weber, 1985). En concreto significados y estructuras relacionadas con las dimensiones económica, social y medioambiental. Coincidimos con la opinión expresada por Steckler et al., (1992) en el sentido de que tanto el estudio de las intervenciones sociales como la promoción de planes de salud son un fenómeno complejo que precisan de una combinación de métodos de aproximación e investigación. Este método de revisión de textos en investigación cualitativa llamada de terceras partes, implica que el análisis de contenido no es realizado por la fuente de información ni por el receptor de los resultados o informes derivados del mismo (Gamerschlag et al., 2011).

\section{1.- Selección de la muestra}

La selección de los planes de salud para ser analizados se llevó a cabo entre los meses de julio y agosto de 2013, a partir de la información publicada disponible en páginas web de las diferentes consejerías de salud de las comunidades autónomas, del portal de planificación sanitaria y políticas de salud, y de la realización de llamadas telefónicas a los organismos implicados. Como condición incluyente en la elaboración de la muestra de planes de salud se estableció que el plan debía estar en vigor en el momento de la selección de la muestra o haber estado vigente en enero de 2008 como límite temporal anterior. Se seleccionaron once planes de salud de las comunidades autónomas de: Andalucía, Canarias, Cataluña, Castilla La Mancha, Castilla y León, Extremadura, Murcia, Navarra, Rioja, País Vasco y Valencia (Tabla 1). Según datos del último informe anual del sistema nacional de salud (Ministerio de Sanidad, Servicios Sociales e Igualdad, 2014), dichas comunidades autónomas representaban el $71 \%$ del gasto sanitario público español en 2012.

La estructura y metodología de elaboración de los planes de salud no es homogénea entre los seleccionados para la muestra, toda vez que algunos de los que cumplen los criterios de inclusión son planes de segunda generación y, en otros casos, se trata de 
experiencias muy avanzadas como el sexto plan de salud de Cataluña, o apuestan por metodologías combinadas entre el modelo clásico y otros modelos de gestión como en la Comunidad Valenciana. Hemos mantenido, no obstante la heterogeneidad, primando el número de planes que entraban en las fechas indicadas lo que ha supuesto un reto adicional en el análisis, aunque sin duda nos ha aportado un enriquecimiento para la investigación al observar el modo en que estos instrumentos estratégicos de la política sanitaria de las comunidades autónomas van evolucionando en el tiempo.

Tabla 1: Planes de salud incluidos en la muestra

\begin{tabular}{|c|c|c|}
\hline III Plan de Salud Andalucía & 2004-2008 & www.juntadeandalucia.es \\
\hline Plan de Salud de Cataluña & 2011-2015 & www.gencat.cat \\
\hline Plan de Salud Castilla y León & 2008-2012 & www.saludcastillayleon.es \\
\hline Plan de Salud de Extremadura & 2009-2012 & www.gobex.es \\
\hline Plan de Salud de Murcia & $2010-2015$ & www.murciasalud.es \\
\hline Plan de Salud de Navarra & 2006-2012 & www.navarra.es \\
\hline Plan de Salud del País Vasco & 2002-2010 & www.osakidetza.euskadi.net \\
\hline Plan de Salud de La Rioja & 2009-2013 & www.riojasalud.es \\
\hline \multicolumn{3}{|l|}{ Plan de Salud de la Comunidad } \\
\hline Valenciana & 2010-2013 & www.san.gva.es \\
\hline
\end{tabular}

Fuente: elaboración propia a partir de la muestra seleccionada de planes de salud 


\section{2.- Sensibilidad simbólica y operativa en las tres dimensiones clásicas del concepto de desarrollo sostenible}

Para determinar la sensibilidad simbólica utilizamos un cuestionario ad hoc que servirá de guía de lectura a la parte introductoria de los planes de salud en la muestra analizada (Tabla 2). Dicha guía contiene tres preguntas dicotómicas que se responden con si o no en cada caso, aunque hemos querido recurrir a una codificación mixta adicional cuando encontramos respuesta a la primera parte de la pregunta pero no a la segunda. Las preguntas ponen el foco en los siguientes asuntos y dimensiones i) la existencia de presupuestos específicos para el plan de salud y los resultados que se esperan obtener en materia económica ii) la inclusión de grupos de interés en la elaboración del plan de salud así como la consideración de los determinantes sociales y iii) aborda el hecho de si los aspectos medioambientales son considerados en el plan de salud mediante herramientas o instrumentos reconocibles internacionalmente a modo de guía y uso de indicadores. Para cada plan de salud obtendremos resultados de sensibilidad simbólica separados por dimensión y por lo tanto una visión comparativa.

Para la sensibilidad operativa utilizaremos un nuevo cuestionario específico. En este caso con tres preguntas por dimensión de desarrollo sostenible para cada área de intervención, resultando de este modo un cuestionario de nueve preguntas. Medimos la sensibilidad operativa mediante una escala de cero a tres para cada pregunta y en cada dimensión. Posteriormente aplicamos una media aritmética para determinar la puntuación por dimensión y área de intervención (Tabla 3).

En el área económica las cuestiones abordadas en el cuestionario son: i) si cada área de intervención operativa contiene un presupuesto dedicado a la mejora y consecución de objetivos ii) si se relaciona el gasto con el resultado en salud en términos económicos y iii) si existen indicadores económicos de seguimiento por área de intervención. En la dimensión social las cuestiones preguntadas son: i) si se incluye a los grupos de interés en la elaboración del plan de intervención en cada área ii) si se consideran los determinantes sociales y iii) si se prevén acciones específicas para los grupos más desfavorecidos. En la dimensión medioambiental las cuestiones son: i) en primer lugar si se ha analizado el contexto medioambiental en la enfermedad o asunto relativo al área de intervención ii) si se plantean medidas de acción activas o preventivas respecto de la influencia del medio ambiente en las mismas y iii) relativo al uso de estándares o 
herramientas internacionalmente reconocibles con relación al medio ambiente en cada área de intervención operativa.

Tabla 2: Cuestionario revisión sensibilidad simbólica.

1 ¿Se especifican presupuestos dedicados al plan de salud de forma concreta y los resultados que se espera obtener en términos económicos?

2 ¿Se han incluido grupos de interés en el proceso de elaboración del plan de salud y considerado los factores relativos a determinantes sociales de la salud?

3 ¿Se han tenido en consideración los factores medioambientales a través del uso de guías o herramientas reconocidas internacionalmente y el uso de indicadores?

*Preguntas auto-formuladas al analizar los documentos (planes de salud)

Tabla 3: Cuestionario revisión sensibilidad operativa

1 ¿Dispone el área de intervención de un presupuesto específico dedicado a la mejora de los resultados de salud y objetivos?

2 ¿Se relaciona para el área de intervención el presupuesto económico o dotación asignada con los resultados en salud en términos económicos?

3 ¿Se han elaborado y se dispone de indicadores económicos de seguimiento para el área de intervención?

4 ¿Se tuvieron en consideración y participaron en la elaboración del plan en el área de intervención los diferentes grupos de interés, incluidos los pacientes?

5 ¿Se consideraron los determinantes sociales en el plan de intervención del área tratada?

6 ¿Se consideraron los grupos desfavorecidos en el plan de intervención del área tratada?

7 ¿Se ha analizado el medio ambiente y su influencia en el área de intervención?

8 ¿Se han incluido medidas preventivas en relación a la influencia del medioambiente en el área de intervención?

9 ¿Se propone el uso de herramientas, estándares internacionales e indicadores de seguimiento relacionados con la influencia del medioambiente en el área de intervención?

\footnotetext{
* Preguntas auto-formuladas al analizar los documentos (planes de salud)
} 


\section{5.- Resultados}

Un primer resultado del estudio es la ausencia de una respuesta nítida en todos los casos a las preguntas planteadas. Por ello, se ha recurrido al conocimiento experto para extraer conclusiones de los textos analizados. Los planes de salud seleccionados muestran diferencias y similitudes entre ellos, con introducción de variaciones en los más recientes que nos permiten apreciar la evolución que van incorporando en el diseño y las estrategias.

La semejanza más evidente es la falta de dotación económica específica para el plan de salud, aspecto mencionado explícitamente en algún caso y quizá que todos ellos manifiestan una clara orientación social e inclusiva. La dimensión social es la más señalada en los aspectos introductorios donde hemos buscado la sensibilidad simbólica y en varios planes de salud se incorporan de manera adicional apartados específicos relativos a determinantes sociales, entorno y medio ambiente, si bien no es genérica la orientación a incluir cuestiones medioambientales como factores influyentes en la salud de las personas. Hallamos una ausencia generalizada de herramientas o estándares reconocidos en materias sociales y medioambientales, aunque con notables excepciones al respecto.

En el análisis de sensibilidad operativa no hemos considerado las alusiones genéricas sobre las diferentes dimensiones como válidas para la investigación. Es frecuente en los planes que se argumente que el presupuesto de sanidad de la comunidad autónoma en su conjunto está dedicado al plan de salud o que todos los ciudadanos están implicados en todas las áreas de intervención elaboradas, sin embargo, y aunque a nivel simbólico lo hemos considerado como respuesta positiva, al no quedar evidencia de dichas afirmaciones en el plano operativo de cada intervención se ha puntuado sobre ellas en este nivel como ausencia. Cabe señalar que existen planes integrales específicos para las diferentes áreas de intervención en los que, aunque trasciende a esta investigación, podemos suponer una mayor especificidad respecto de las acciones y los actores. 


\section{1.- Índice de Sensibilidad Simbólica (ISS)}

Presentamos a continuación un análisis individualizado de los resultados obtenidos en términos de sensibilidad simbólica organizados por plan de salud (Cuadro 2).

El plan de salud de Andalucía, en el análisis de sensibilidad simbólica, no presenta mención específica de presupuesto asociado al mismo, sin embargo muestra un elevado componente social y fuerte orientación integradora y presenta un balance positivo en la inclusión de grupos de interés. Destacamos un capítulo concreto para las desigualdades y los determinantes sociales, algo que veremos es común en otras comunidades. A nivel medioambiental no apreciamos referencias que coincidan con los criterios establecidos en la investigación (PAND, 2003).

En el caso del plan de salud de Canarias, a diferencia de otros planes, hallamos una clara preocupación por la dimensión económica y mención de la necesidad de que se le asigne un presupuesto (PCAN, 2004) de financiación. Además se señala una evaluación previa de coste eficiencia por cada área de intervención, así como del impacto que suponen las incidencias y prevalencias en términos de PIB para la comunidad. Cuenta con una ficha técnica económica de cada área y aparece como uno de los planes más enfocados en la dimensión económica. La vertiente social cuenta con el diálogo con los grupos de interés incluidos los pacientes en las diferentes áreas, sin embargo no hay mención equivalente relativa a las cuestiones medioambientales desde la perspectiva de la investigación que hemos realizado.

El caso del plan de salud de Cataluña 2011-2015, presenta una estructura diferente e innovadora, incluyendo las áreas de intervención en un trío de ejes de transformación que derivan en treinta y dos objetivos o proyectos estratégicos (PCAT, 2012). En la parte introductoria apunta a la relevancia de los factores económicos, sin embargo, no existe un presupuesto asignado. La sostenibilidad es el macro objetivo del plan catalán, entendida en dos direcciones: la moderación de la demanda y el uso eficiente de los recursos del sistema e introduce al menos dos estrategias diferenciadoras. Asignación territorial de recursos en función de la necesidad y tamaño de la población y eficiencia como meta irrenunciable. Por otro lado, la incorporación de un modelo de excelencia en calidad certificado como EFQM, ampliamente extendido en el sistema de salud catalán, es una ventaja competitiva respecto de otras propuestas e introduce el concepto de riesgos compartidos y resultados en salud con la industria farmacéutica marcando objetivos de firma de acuerdos. Es un plan socialmente orientado a la participación pero 
no apreciamos estrategia o foco en cuestiones medioambientales. La propuesta del plan es de cambio estructural y el objetivo declarado garantizar la sostenibilidad desde las perspectivas descritas en el documento.

Castilla la Mancha (PCLM, 2001) publicó un extenso plan de salud previsto para nueve años de duración del cual se desprende una cierta pulsión de exhaustividad (Repullo y Otero, 1999). Presenta un extenso análisis sociodemográfico descriptivo y con amplia información gráfica con mención específica medioambiental y acciones relacionadas con el tratamiento de residuos sanitarios y atención a los riesgos contaminantes o calidad del aire. La dimensión social a nivel simbólico queda bien acreditada si bien no podemos decir lo mismo de la económica al no disponer de presupuesto específico.

Castilla y León presenta un plan de salud (PCYL, 2008) bien balanceado en aspectos sociales y económicos, se muestra el presupuesto y desgloses o asignaciones de partidas económicas y es explícito en la inclusión de grupos de interés, como otros planes la dimensión medioambiental queda en un plano más secundario.

Volvemos a encontrar una cierta pulsión de exhaustividad en el plan de salud de Extremadura (PEXT, 2009), el cual desarrolla a lo largo de más de trescientas páginas una descripción de la sociedad y la demografía extremeñas además de las cuestiones relativas a salud. El plan contempla la participación ciudadana por diferentes vías incluyendo encuestas e intervenciones en grupos desfavorecidos, así mismo hay un apartado específico para medio ambiente, residuos y actividades relacionadas. Capítulos concretos dedicados a educación para la salud o zoonosis resultan innovadores o cuando menos singulares. La cuestión económica, como en otras ocasiones, queda en segundo plano, si bien se especifican los presupuestos transferidos no existe una dotación ad hoc asignada al plan, aunque los autores mencionan el hecho de que las intervenciones han sido evaluadas en términos económicos por otras instancias de la administración autonómica (CAE). 
Cuadro 2. Resultados de sensibilidad simbólica en los planes de salud analizados.

\begin{tabular}{|c|c|c|c|c|c|c|c|c|c|c|c|}
\hline ISS & Andalucía & Canarias & Cataluña & CLM & CYL & Extremadura & Murcia & Navarra & P.V & Rioja & Valencia \\
\hline Económica & 1 & $\mathbf{0}$ & I & $0 /$ & 0 & $\mathbf{0}$ & 1 & 1 & $0 /$ & $0 /$ & 0 \\
\hline Social & $\mathbf{0}$ & $\mathbf{0}$ & 0 & 0 & 0 & 0 & 0 & 0 & o & $\mathbf{0}$ & 0 \\
\hline Ambiental & 0/ & I & 0/ & I & $0 /$ & $\mathbf{0}$ & 0 & I & o & I & I \\
\hline \multicolumn{12}{|l|}{$\mathbf{0}=\mathbf{S i}$} \\
\hline \multicolumn{12}{|l|}{$I=$ No } \\
\hline \multicolumn{12}{|l|}{$0 /=\mathrm{Si}$ una } \\
\hline \multicolumn{12}{|l|}{ cuestión al } \\
\hline \multicolumn{12}{|l|}{ menos } \\
\hline \multicolumn{12}{|l|}{$\mathrm{n}=\mathbf{1 1}$} \\
\hline Dimensión & $\mathbf{F r}$ & $\%$ & & & & & & & & & \\
\hline Económica & 5,5 & $\mathbf{5 0 \%}$ & & & & & & & & & \\
\hline Social & 11 & $100 \%$ & & & & & & & & & \\
\hline Ambiental & 4,5 & $41 \%$ & & & & & & & & & \\
\hline
\end{tabular}

Fuente: elaboración propia a partir del análisis de los planes de salud de la muestra

En el caso de la comunidad autónoma de Murcia, encontramos un plan de salud moderno, transversal y en el que observamos un capítulo específico dedicado a medio ambiente al que hemos prestado especial atención. En dicho capítulo se cita textualmente respecto del menor reparto de recursos en esta dimensión: "En el extremo opuesto se sitúa el estilo de vida y el medio ambiente a los que se destina una parte minoritaria de los recursos contradiciendo su potencialidad en la contribución a la salud del conjunto de la ciudadanía" (PMUR, 2010). También se hace eco en este plan de los datos presentados por la OMS (Prus-Ustum y Corvalan, 2006) donde señalan que el medio ambiente influye en el ochenta por ciento de las enfermedades estudiadas. Además se estima que a nivel global el $24 \%$ de la carga de morbilidad medida en APVP (años perdidos de vida prematuramente) y el 23\% de las defunciones en términos de mortalidad prematura son atribuibles a factores medioambientales. Es por lo tanto un plan orientado en el sentido de sensibilidad simbólica a la dimensión medioambiental e igualmente podemos concluir de la dimensión social, al incluir un amplio capítulo sobre estilos de vida. No obstante, la carencia de presupuesto hace que la dimensión económica no quede adecuadamente reflejada desde la perspectiva de esta investigación.

El plan de salud de Navarra (PNAV, 2006) es un plan corto en comparación con la mayoría de planes de salud y sin dotación presupuestaria como indica el mismo documento en su parte final. Destacamos la tendencia a establecer en este caso 
declaraciones de intenciones mediante el uso de términos como: establecerá, estudiará, fomentará, creará etc. Estos enfoques de intención en forma de objetivos constituyen la línea general del plan, que menciona la vertiente social y los determinantes sociales como importantes. Las cuestiones medioambientales no aparecen con el nivel de relevancia requerido.

Por su parte, el País Vasco diseñó un plan de salud con clara orientación social, inclusivo y participativo en el que se presta especial interés a los determinantes sociales y las cuestiones relativas al estilo de vida de las personas. Contiene a nivel simbólico una evaluación previa del contexto medioambiental y en parte asumimos una asignación económica a las actuaciones.

La Rioja presenta un plan de salud (PSR, 2009) con alto nivel de sensibilidad simbólica en la dimensión social y baja en términos de medio ambiente. Como en otros planes previamente analizados la dimensión económica es parcialmente mencionada. Se percibe la necesidad de dotación presupuestaria pero no se incluye la misma de manera explícita en el documento. La sensibilidad operativa presentada por áreas de intervención, muestra niveles altos en respuesta a las preguntas relacionadas con aspectos sociales y baja con relación a cuestiones medioambientales y no hay evidencias de dotación de presupuestos en dichas áreas.

El último plan de salud de la muestra es el de la Comunidad Valenciana (PVAL, 2010) construido mediante una combinación de metodología clásica y el uso del Balanced Scorecard (Kaplan y Norton, 1992), incluye creación de foros de participación ciudadana e identifica las áreas de intervención con el concepto problemas de salud. La identificación de las áreas de intervención en este plan, debido a la metodología, se realiza a lo largo de las diferentes propuestas de líneas estratégicas que engloban treinta y cinco objetivos generales, ciento sesenta y tres objetivos específicos, trescientas sesenta y una líneas de actuación y doscientos treinta y dos indicadores. Encontramos dotación económica a nivel simbólico aunque no está desagregada por áreas a nivel operativo. No apreciamos foco medioambiental. 


\section{2.- Índice de Sensibilidad Operativa (ISO)}

Para la investigación fueron elegidas catorce áreas de intervención prioritarias clásicas en los planes de salud e incluidas en el análisis allí donde aparecían claramente diferenciadas, si bien dada la tendencia a la transversalidad en la metodología de los planes más recientes, no siempre resulta evidente la diferenciación o es posible localizar con claridad las propuestas para cada una de ellas. En estos casos hemos optado por no incluirlas en el análisis. Como resultado, se han obtenido catorce áreas de intervención recogidas en el Cuadro 3.

El hecho de que los planes de salud no sigan un estándar o marco común en su diseño dificulta en parte la comparabilidad, si bien hay que añadir que las áreas de intervención relativas a patologías suelen ser comunes a todos ellos. Hay en estos documentos innovaciones por una parte como se ha señalado y derivaciones que, cabe suponer, reflejan problemas o retos de salud puntuales en el tiempo o que por alguna circunstancia tienen una mayor relevancia en unas comunidades autónomas concretas. 


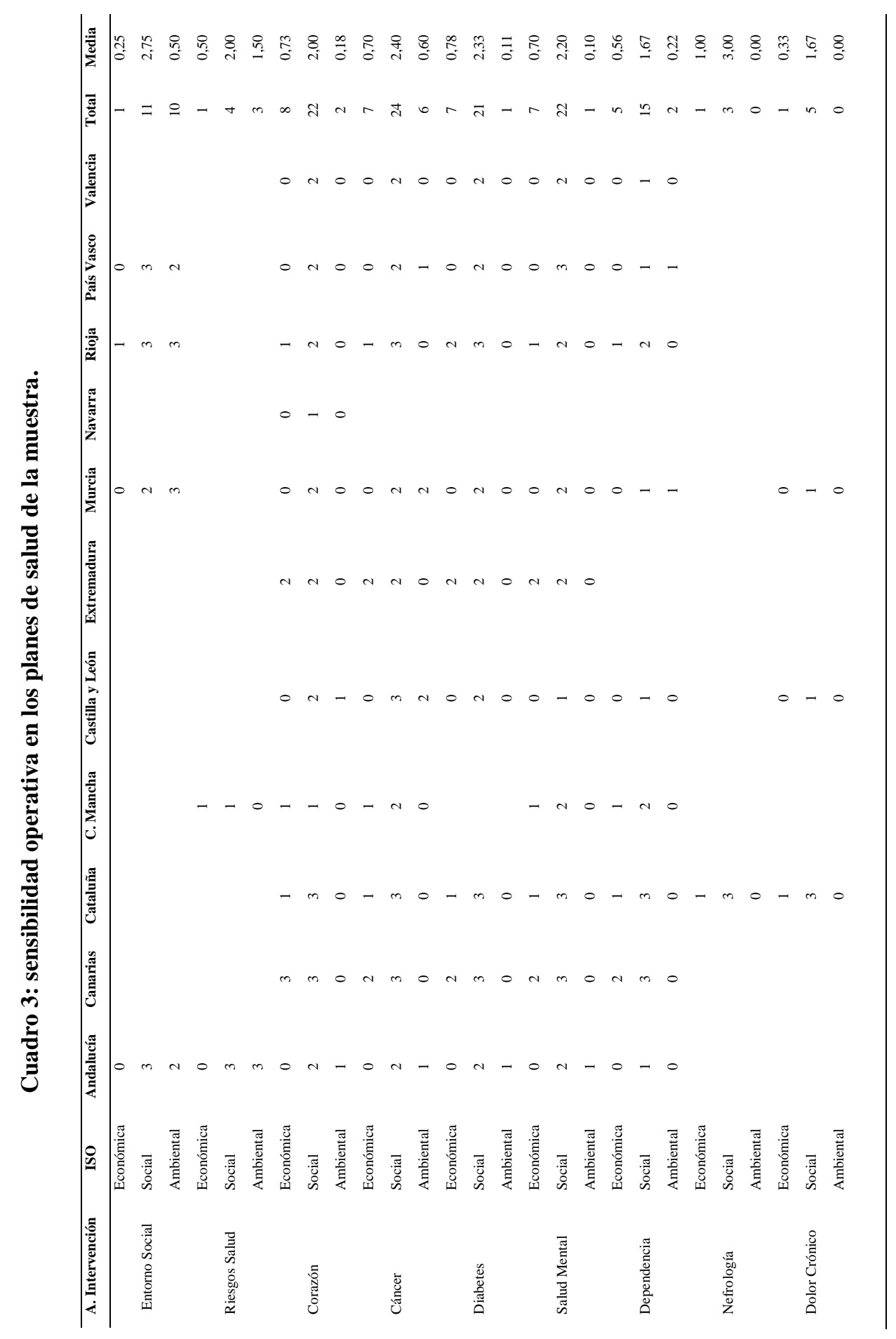




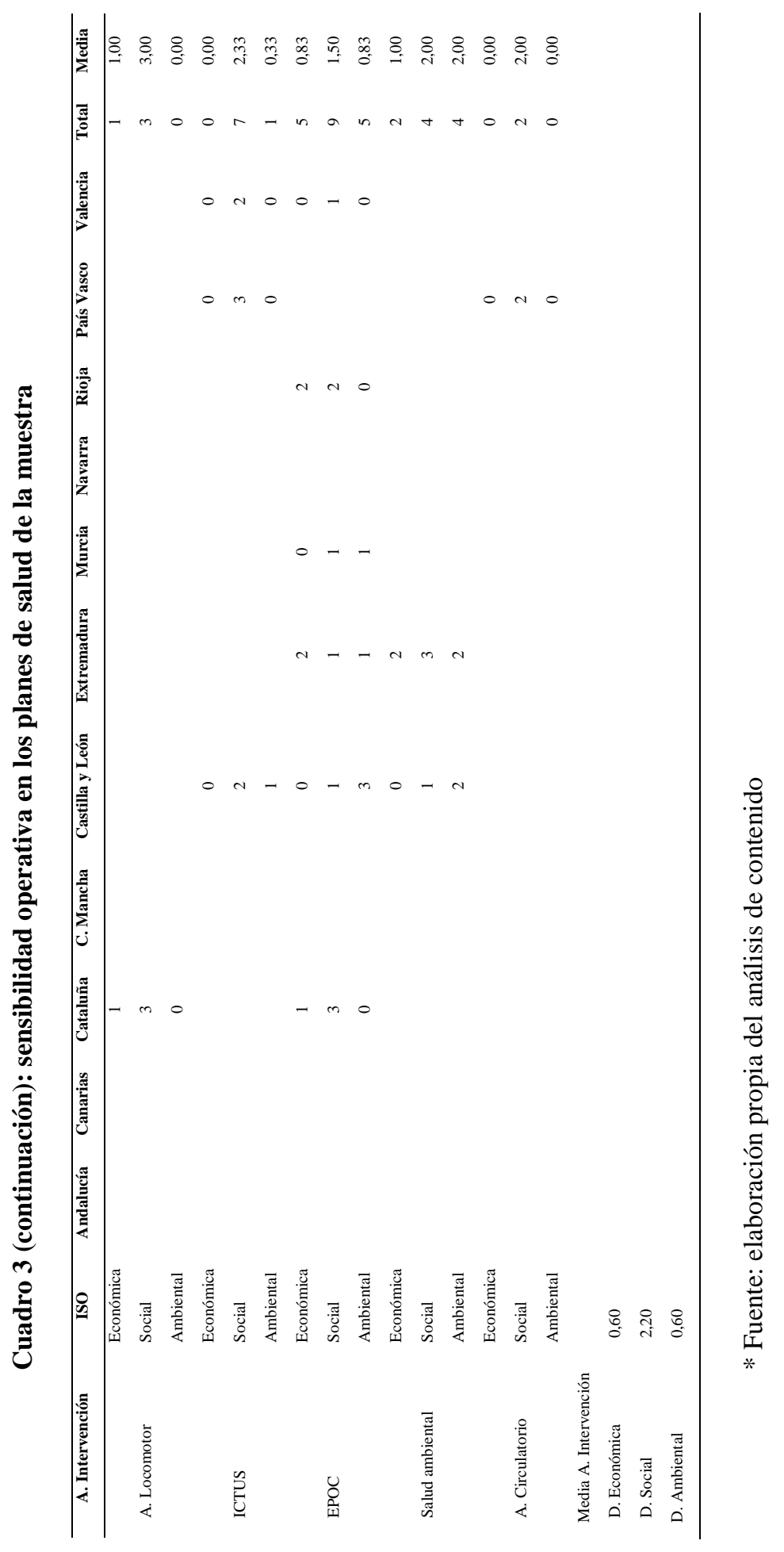


La elección de las áreas de intervención no indica dirección alguna en el sentido de relevancia. En los planes de salud encontramos otras propuestas que pueden ser situadas al mismo nivel de importancia que las elegidas en esta investigación y que, a los efectos perseguidos, son una muestra significativa y mayoritaria de todas ellas.

La dimensión económica junto con la medioambiental aparecen débilmente en el análisis de sensibilidad operativa con medias de cero sesenta sobre tres en ambos casos, y si bien existen frecuentes menciones a los planes integrales para encontrar desarrollos más específicos sobre las diferentes áreas de intervención, no podemos soslayar el hecho de que el plan de salud como instrumento base de las actuaciones a nivel operativo no incluye, o raramente lo hace, desagregados económicos por área que permitan una evaluación posterior. En este sentido, Canarias y Extremadura presentan los planes con mayor esfuerzo de acercamiento al análisis económico para cada área, marcando en este punto una clara diferencia y una tendencia al resultado económico de las actuaciones.

La dimensión social obtiene dos con veinte puntos de media y muestra, a nuestro entender, que los planes de salud en su mayoría tienen en consideración a los diferentes grupos de interés -incluyendo a los pacientes-, ya sea en las fases de elaboración del plan o posteriormente como receptores de la comunicación por parte de las autoridades sanitarias respecto de lo que se proyecta realizar. Los determinantes sociales son considerados por lo general en todos los documentos analizados en especial las cuestiones relativas a género o grupos de edad. En algunos casos, los grupos más desfavorecidos son además observados desde un prisma diferencial y se proponen actuaciones específicas para ellos.

En la dimensión medioambiental, quizá porque en algunos planes existen capítulos o apartados y menciones muy específicas sobre la materia (PCLM 2001; PEXT 2009; PMUR 2010), no es frecuente ver menciones a nivel operativo. Esta dimensión obtiene al igual que la económica una valoración media de cero sesenta sobre tres, mostrando una débil inclusión de factores ambientales en cada área. Destacamos el plan de salud de Andalucía (PAND 2003) como el más orientado en materia medioambiental a nivel operativo y la alta frecuencia con la que este factor es obviado en otros planes de otras comunidades autónomas. 


\section{6.- Conclusiones}

La tradición sobre los planes de salud en España se ha ido afianzando de forma paulatina, reflejando en distintas etapas de la historia reciente del sistema sanitario español las directrices maestras de los diferentes gobiernos autonómicos. En treinta años de trayectoria de planes de salud, con épocas de mayor visibilidad seguidas de otras de menor seguimiento por parte de las autoridades, estos instrumentos de planificación de políticas de salud han llegado al momento actual con un elevado grado de relevancia sectorial. Una mayor inclusividad de las partes interesadas en el diseño y desarrollo y una adecuada implementación a nivel local podría contribuir a que se consiguieran objetivos relacionados con la agenda 21. Los planes de salud supondrían así un compromiso no exclusivo de organización del sistema, y tendrían la posibilidad de convertirse en instrumento de diálogo social con aquellos a quienes van dirigidas las acciones descritas en los documentos.

Los planes de salud han ido evolucionando de manera desigual por comunidades autónomas como muestra el hecho de las variaciones que se aprecian en el número de publicaciones, la extensión de los documentos o el período de cobertura que abarcan. Una de las apreciaciones más significativas es la referida a las diferencias de metodología, sobre todo en los planes más recientes, donde la transversalidad y la inclusión de modelos procedentes de la gestión de la calidad o el mundo empresarial han tenido una influencia apreciable.

Los planes presentan en general y a nivel introductorio o simbólico una visión bien estructurada de las tres dimensiones de desarrollo sostenible, quizá con la carencia generalizada y reconocida de no introducir el análisis económico salvo de forma excepcional y poco desagregada. En nuestra opinión son altamente inclusivos por el número de grupos de interés y actores involucrados en la elaboración y muestran un contenido social fuerte tanto en relación a determinantes sociales como a desigualdades. La dimensión medioambiental es con frecuencia considerada e incluso en determinados casos es tratada de forma específica y recogida en capítulo diferenciado. No obstante, existe un recorrido evidente en el uso de estándares internacionales, indicadores y sistemas de medición de la influencia ambiental en la salud de las personas.

El análisis realizado evidencia el estado incipiente en el que se sitúan los planes de salud como documentos de planificación estratégica que integren aspectos económicos, sociales y ambientales con los que contribuir a la sostenibilidad de los diferentes 
sistemas sanitarios del país. La transversalidad introducida en algunos planes hace a nuestro entender que las áreas de intervención queden en ocasiones un punto más difusas. Observamos una cierta orientación a dar por bueno para todas las áreas lo que en un capítulo determinado se establece a priori en materia de medio ambiente o en relación a determinantes sociales, y estimamos que pudiera existir un riesgo de generalización que dificultara la concreción en objetivos y resultados para cada una de las áreas. En la operatividad de las áreas de intervención queda abierta una línea de continuidad para futuras investigaciones que sería interesante explorar. Situar la acción en el terreno de la patología y el grupo de pacientes en concreto, determinar indicadores de desarrollo sostenible relacionados con diabetes o cáncer por citar dos ejemplos, podría aportar un complemento a las estrategias específicas de alto valor. La relación de una enfermedad concreta y el medio ambiente o el retorno social de las inversiones en acciones comunitarias en programas de salud, son a nuestro entender acciones susceptibles de mostrar nuevas eficiencias en la sostenibilidad de los sistemas sanitarios.

La pluralidad y el hecho de que cada autonomía establezca, proponga y publique el modelo que estima más adecuado en cada momento aporta heterogeneidad. Sin duda algunos de los avances e innovaciones observadas en los planes de salud provienen de esta circunstancia. Sin embargo, este hecho, que suele ser indicativo de riqueza productiva, podría dificultar el análisis comparativo. En este sentido, un modelo de consenso estandarizado y respetuoso con las diferencias y variables endógenas de cada comunidad quizá aportaría valor desde un punto de vista del análisis de sostenibilidad reflejado en los planes de salud. Actualmente existen marcos y estándares basados en criterios de desarrollo sostenible que nos parecen capaces de dar soporte a documentos públicos de planificación, como es el caso de los planes de salud. La guía ISO 26000:2010 de responsabilidad social engloba materias y asuntos relacionados con las dimensiones clásicas: económica, social y medioambiental y se puede referenciar con indicadores recogidos en sistemas de reporte de informes internacionales como Global Reporting Initiative. La especificidad de las materias que se tratan en un plan de salud, particularmente a nivel operativo, hacen necesario el uso de indicadores de salud concretos y definidos en la bibliografía relacionada con cada área de intervención y así los encontramos en los documentos analizados. Más allá, hayamos no obstante espacio para envolver las actuaciones concretas en un amplio marco de integración e inclusión de los asuntos relativos a la salud y el desarrollo sostenible. 


\section{Referencias}

Alazzani, A., y Wan-Hussin, W. N. 2013. Global Reporting Initiative's environmental reporting: A study of oil and gas companies. Ecological Indicators, 32, pp. 1924.

Altman, D.G. Endres, J. Linzer, J. Lorig, K. Howard-Pitney, B. Rogers, T. 1991. Obstacles to and future goals of ten comprehensive community health promotion Project. Journal of Community Health, 16. pp. 299-314.

Arredondo, A. Orozco, E. 2008. Equity, governance and financing after health care reform: lessons from Mexico. International Journal of Health Planning and Management. Publicado on line, 14 Noviembre 2007.

Disponible en: $\underline{w w w . i n t e r s c i e n c e . w i l e y . c o m ~}$

[Consultado, 15 enero 2015]

Ballester, F. Llop, S. Querol, X. Esplugues, A. Evolución de los riesgos ambientales en el contexto de la crisis económica. Informe SESPAS 2014. Gaceta Sanitaria; 28 (1) pp. 51-57

Berman, P. 1995. Health sector reforms: Making health Development Sustainable. Health Policy 32, pp. 13-28

Beuregard, R.A. 1995. Institutional Constraints and subnational planning: economic Development in the United States. Evaluation and program planning, 18, pp. 295-300.

Beyer de JA. Preker AS. Feachem RGA. 2000. The role of the World Bank in international health: renewed commitment and partnership. Soc Sci Med 50, pp. 169-176.

Borrell, C. Peiró, R. Ramón, N. Pasarín, MI. Colomer, C. Zafra, E. Álvarez-Dardet, C. 2005. Desigualdades socio económicas y planes de salud en las comunidades autónomas del estado español. Gaceta Sanitaria. 19 (4), pp. 277-86.

Boulte, P. 1991. Le diagnostic des Organizations apliqué aux associations. Presses Universitaires de France. Paris

Briones, E. Vives, C. Peiró, R. 2009. Sensibilidad de género de los planes nacionales de salud en el contexto internacional. UNIMAR. CEHEGÍN. Universidad de Murcia.

Bronfenbrenner, U. 1977. Toward an experimental ecology of human development. American Psychologist, 32 pp. 513-531 
Campopiano, G., y De Massis, A. 2014. Corporate social responsability reporting: a content analysis in family and non-family firms. Journal of Business Ethics, pp. $1-24$

Comisión Europea, 2007. Together for Health: A Strategy Approach for the EU 20082013. COM (2007) 630 final. Brussels.

Delai, I., y Takahashi, S. 2013. Corporate sustainability in emerging markets: insights from the practices reported by the Brazilian retailers. Journal of Cleaner Production, 47, pp. 211-221.

Deming, W.E. 1982. Quality, productivity, and competitive position. MA: MIT Press. Cambridge.

Deming, W.E. 1986. Out of the crisis. MA: MIT Press. Cambridge.

Duhl, L.J. 1963. The Urban Condition. Basic Books. New York.

Evans, S. Hills, S. Orme, J. 2012. Doing more for less? Developing sustainable System of social care in the context of climate change and public spending cuts. British Journal of Social Work, Vol 42. Oxford University Press, pp. 744-764.

Fiuza Pérez, M.D. Aguiar Rodríguez, J.F y Monzón Batista, N. 2010. Una década de reflexión sobre los planes de salud en España. Informe SESPAS. Gaceta Sanitaria, 24 (1) pp. 37-41.

Fuertes, C. Pasarín, M. Borrell, C. Artacoz, L. Díez, E. 2012. Feasibility of a community action model oriented to reduce inequalities in health. Health Policy 107, pp. 289-295.

Gagliardi, A. Lemieux-Charles, L. Brown, A.D. Sullivan, T. Goel, V. 2008. Barriers to Patient involvement in health service planning and Evaluation: An exploratory study. Patient Education and Consueling, 70, pp. 234-241.

Gamerschlag, R. Moller, K. Verbeeten, F. 2011. Determinants of voluntary CSR disclosure: empirical evidence from Germany. Rev Manag Sci, 5, pp. 233-262

Gispert, R. Van der Water HPA, Van Herten, LM. 2000. La introducción de objetivos de salud en el marco de la política sanitaria española: una revisión documental del proceso. Gaceta Sanitaria,14 (3) pp. 34-44.

Goss, C, Renzi, C. 2007. Patient and citizen participation in health care decisions in Italy. Z.arzti. Fortbild. Qual. Gesundh.wes. (ZaeFQ). 101, pp. 236-240.

Grimmer, J. Stewart, B. 2013. Text as Data: The Promise and Pitfalls of Automatic Content Analysis Methods for Political Texts. Political Analysis, pp. 1-31. 
Gruen, R.L. Elliot, J.H. Nolan, M.L. Lawton, P.D. Parkhill, A. McLaren, C.J. Lavis, J.N. 2008. Sustainability science: an integrated approach for health-programme planning. Public Health. www.thelancet.com 372.

Hoffman, F.L The Classic. A Plan for a More Effective Federal and State Health Administration. Publicado on line, 28 July 2009.

Disponible en: http://www.ncbi.nlm.nih.gov/pmc/articles/PMC2745440/

[Consultado, 23 febrero 2013]

Israr, S.M e Islam, A. 2006. Good governance and sustainability: A case study from Pakistan. Inetrnational Journal of Health Planning and Management, 21, pp. 313-325.

Kaplan, R.S. Norton, D.P. 1992. The Balanced Scorecard - Measures that Drive Performance. Harvard Business Review Jan-Feb, pp. 71-79.

Kepros, J.P. Opreanu, R.C. 2009. A new model for health care delivery. BMC Health Services Research. BioMed Central.

Krippendorf, K. 1980. Content analysis. An introduction to its methodology. Beverly Hills: Sage

LBAR, 2004. Llei de Barris. Generalitat de Catalunya.

Disponible en: http://www.gencat.cat/diari/4151/04154100.htm

[Consultado, 12 de mayo 2013]

Lee, K. H., Barker, M., y Mouasher, A. 2013. Is it even espoused? An exploratory study of commitment to sustainability as evidenced in vision, mission, and graduate attribute statements in Australian universities. Journal of Cleaner Production, 48, pp. 20-28.

Lemstra, M. Neudorf, C. Opondo, J. 2006. Health Disparity by Neighbourhood Income.

Canadian Journal of Public Health. November -December.

LGS, 1986. Ley General de Sanidad. Título III, Cap II, Art. 54.

Disponible en:

https://www.boe.es/boe/dias/1986/04/29/pdfs/A15207-15224.pdf

[Consultado, 30 enero 2013]

LSPCV. Ley 4/2005 de Salud Pública de la Comunidad Valenciana.

Disponible en: http://www.boe.es/boe/dias/2005/07/14/pdfs/A25066-25085.pdf

[Consultado, 6 febrero 2013]

LSSCL. Ley 1/1993 de 6 de abril, de Ordenación del Sistema Sanitario de Castilla y León. 
Disponible en:

http://www.urjc.es/outs/Leyes_autonomicas/Castilla_y_Leon/Ley1_1993.pdf

[Consultado, 6 febrero 2013]

Marshall, D., Pyron, T., Jimenez, J., Coffman, J., Pearsol, J., y Koester, D. 2014. Improving Public Health Through State Health Improvement Planning: A Framework for Action. Journal of Public Health Management and Practice, 20(1), pp. 23-28.

Matus C. 1993. Política, planejamento e governo. Bra- sília: Instituto de Pesquisa Econômica Aplicada.

Merlo, J. Basile, C. Yang, M. Lynch, J. Rastam, L. 2004. A brief conceptual tutorial on multilevel analysis in social epidemiology: interpreting Neighbourhood differences and the effect of Neighbourhood characteristics on individual health. J Epidemial Community Health, 59, pp. 1022-1029.

Ministerio de Sanidad, Servicios Sociales e Igualdad. 2014. Informe anual del Sistema Nacional de Salud 2012. Informes, Estudios e Investigación 2014.

Disponible en: https://www.msssi.gob.es/estadEstudios/estadisticas/sisInfSanSNS/tablasEstadis ticas/infsns2012.pdf

[Consultado, 10 enero 2015]

Minkler, M. García, A.P. Williams, J. LoPresti, T y Lilly, J. 2010. Sí Se Puede: Using Participatory Research to Promote Environmental Justice in a Latino Community in San Diego, California. Journal of Urban Health: Bolletin of the New York Academy of Medicine, 87, (5), pp. 796-812.

Nancholas, S. 1998. A logical framework. Health Policy and Planning, 13, pp. 189-193.

Nguyen, F. Mounkid, N. Charles, C. Gafni, A. Whelan, T, Carrere, M.O. 2014. Treatment decisión-making in the medical encounter: Comparing the attitudes of French surgeons and their patients in breast cáncer care. Patient Education and Counseling, 94, pp. 230-237.

Olsen, IT. 1998. Sustainability of health care: a framework for analysis. Health Policy Plan 13 (3), pp. 287-295.

PAND, 2003. Plan de salud de la Comunidad Autónoma de Andalucía 2003-2008. Andalucía en salud: construyendo nuestro futuro juntos. Disponible en: http://www.juntadeandalucia.es/[Consultado, 15 de agosto, 2013] 
PCAN, 2004. Plan de Salud de la Comunidad Autónoma de Canarias 2004-2008. Mas salud y mejores servicios.

Disponible en:

http://www2.gobiernodecanarias.org/sanidad/scs/scs/1/plansalud/plansalud2004 _2008/Plan_de_Salud_de_Canarias_2004_2008.pdf

[Consultado, 11 de agosto, 2013]

PCAT, 2012. Plan de Salud de la Comunidad Autónoma de Cataluña 2011-2015. Disponible en:

http://www20.gencat.cat/docs/salut/Home/El\%20Departament/Pla_de_Salut_20

11_2015/documents/arxius/plan\%20de\%20salud\%20Catalunya_es.pdf

[Consultado, 7 de agosto, 2013]

PCLM, 2001. Plan de Salud de la Comunidad Autónoma de Castilla la Mancha 20012010. Disponible en:

http://sescam.jccm.es/web1/ciudadanos/elSescam/Plan_de_Salud_de_Castilla-

$\underline{\text { La_Mancha.pdf }}$

[Consultado, 17 de agosto, 2103]

PCYL, 2008. Plan de Salud de la Comunidad Autónoma de Castilla y León 2008-2012.

Disponible en:

http://www.saludcastillayleon.es/institucion/es/planes-estrategias/iii-plan-saludcastilla-leon

[Consultado, 19 de agosto, 2013]

Pearce, J. Witten, K. Hiscock, R. Blakely, T. 2006. Are socially disadvantaged

neighbourhoods deprived of health-related community resources? International Journal of Epidemiology 2007 (36) pp. 348-355.

Peiró, R. Ramón, N. Moyá, C. Borrell, C. 2004. Sensibilidad de género en la formulación de planes de salud en España: lo que pudo ser y no fue. Gaceta Sanitaria, 18 (2), pp. 36-46.

Peiró, R. Artells, J.J. Meneu, R. 2011. Identificación y priorización de actuaciones de mejora de la eficiencia en el Sistema Nacional de Salud. Gaceta Sanitaria, Vol. 25 (2), pp. 95-105.

PEXT, 2009. IV Plan de Salud de la Comunidad Autónoma de Extremadura 2009-2012.

Disponible en:

http://www.gobex.es/filescms/cons007/uploaded_files/plan09_12.pdf

[Consultado, 21 de agosto, 2013] 
Phillips, M.E. 1994. Industry mindsets: Exploring the cultures of two macroorganizational settings. Organizational Science, 5 (3), pp. 384-402.

Piñuel, J.L. 2002. Epistemología, metodología y técnicas de análisis de contenido. Estudios de sociolingüística 3 (1) pp. 1-42.

Pluye, P. Potvin, L. Denis, J.L. 2004a. Making public health programs last: conceptualizing sustainability. Evaluation and program planning 27, Pp. 121133.

Pluye, P. Potvin, L., Denis, J. L., y Pelletier, J. 2004b. Program sustainability: focus on organizational routines. Health Promotion International, 19 (4), pp. 489-500.

PMUR, 2010. Plan de Salud de la Comunidad Autónoma de Murcia 2010-2015. Disponible en:

http://www.murciasalud.es/recursos/ficheros/185877-Plan_salud_2010-2015.pdf [Consultado, 25 de agosto, 2013]

PNAV, 2006. Plan de Salud de la Comunidad Autónoma de Navarra 2006-2012.

Disponible en:

http://www.navarra.es/NR/rdonlyres/17D59CCB-2854-4284-90C3-

FA44CFE0927F/152915/PlandeSaluddeNavarra20062012.pdf

[Consultado, 22 de agosto, 2013]

Pruss-Ustum, A. Corvalan, C. 2006. Preventing disease through healthy environments.

Towards and estimate of the environmental burden of disease. WHO.

Disponible en:

http://www.who.int/quantifying_ehimpacts/publications/preventingdisease.pdf

[Consultado, 27 de agosto, 2013]

PSPV, 2002. Plan de salud del País Vasco 2002-2010.

Disponible en:

http://www.osasun.ejgv.euskadi.net/r52-

20735/es/contenidos/informacion/plan_salud/es_4043/psalud_c.html

[Consultado, 20 de agosto, 2013]

PSR, 2009. Plan salud de La Rioja 2009-2013

Disponible en:

http://www.riojasalud.es/noticias/1557-presentado-el-ii-plan-de-salud-de-larioja-2009-2013? showall=1

[Consultado, 18 de agosto, 2013] 
Pruss-Ustum, A. Bonjour, S. Corvalan, C. 2008. The impact of the environment on health by country: a meta synthesis. Environ Health; 7:7

PVAL, 2010. Plan de Salud de la Comunidad Autónoma de Valencia 2010-2013. Disponible en: http://www.san.gva.es/documents/153218/167779/III_Plan_de_Salud_10_13.pdf [Consultado, 24 de agosto, 2013]

Reifsnider, E. Gallagher, M. Forgione, B. 2005. Using ecological models in Research on health disparities. Journal of profesional nursing. (21) 4 (July-August) pp. 216-222.

Repullo, J.R. Otero, A. 1999. Planes de salud: sueño, espejismo y némesis. Gaceta Sanitaria, 13, (6). Disponible en:

http://zl.elsevier.es/es/revista/gaceta-sanitaria-138/planes-salud-sueñoespejismo-o-nemesis-13008407-debates-1999

[Consultado, 17 agosto 2103]

Sánchez, F.I. Abellán, J.M. Martínez, J.E. 2008. ¿Cómo se deben establecer y evaluar las prioridades en salud y servicios de salud? Métodos de priorización y disparidades regionales. Cap. 3 Prioridades generales y prestaciones individuales. Informe SESPAS.

Sarriot EG. Winch, PJ. Ryan, LJ. Bowie, J. Kouletio, M. 2004. A methodological approach in NGO-implemented primary health care programs. International Journal Health Planning and Management 19 (1); pp. 23-41.

Saunders, R. 1994. W. Edwards Deming, Quality Analysis, and Total Behavior Management. The Behavior Analyst. Parsons Research Center. University of Kansas. Pp. 115-125.

SBARRIS, 2004. Departament de Salut de la Generalitat de Catalunya.

Disponible en: www.gencat.cat/salut/salutbarris.htm

[Consultado, 11 mayo 2013]

Scheirer, M. A. 2005. Is sustainability possible? A review and commentary on empirical studies of program sustainability. American Journal of Evaluation, 26(3), pp. 320-347.

Scheirer, M.A. 2013. Linking Sustainability Research to Intervention Types. Framing Health Matters. American Journal of Public Health, 103, (4)

Scheirer, M. A., y Dearing, J. W. 2011. An agenda for research on the sustainability of public health programs. American Journal of Public Health, 101(11), pp. 2059. 
Schell, S. F., Luke, D. A., Schooley, M. W., Elliott, M. B., Herbers, S. H., Mueller, N. B., y Bunger, A. C. 2013. Public health program capacity for sustainability: a new framework. Implement Sci, 8 (1), pp. 15-24.

Stahl, T. Wismar, M. Ollila, E. Lahtinen, E y Leppo, K. 2006. Health in all policies. Ministry of Social Affairs and Health, Finland. European observatory on Health System and Policies.

Disponible en: http://ec.europa.eu/health/archive/ph_information/documents/health_in_all_poli cies.pdf

[Consultado, 21 mayo de 2014]

Steckler, A. McLeroy, K. Goodman, R. Bird, S. McCormick, L. 1992. Toward Integrating Qualitative and Quantitative Methods: An Introduction. Health Education Quarterly, 19, (1), pp. 1-8.

Stefanini, A. 1995. Sustainability: the role of NGOs. World health Forum 16, pp 42-46.

Short, J.C, y Palmer, T.B. 2003. Organizational performance referents: An empirical examination of their content and influences. Organizational Behavior and Human Decision Processes, 90 (2), pp. 209-224.

Themba Nixon, M. Minkler, M. Freudemberg, M. 2008. The Role of CBPR in policy advocacy. En: Minkler, M. Wallerstein, N, eds. Community-based particpatory Research for health: from process to outcomes. 2end ed. pp 307-320 JosseyBass. San Francisco.

Tranquada, R. 1973. Participation of the poverty community in health care planning. Soc. Sci \& Med. Vol 7. Pergamon Press, pp. 719-728.

Tresserras, R. 2008. Planificación según prioridades de salud. Criterios de planificación relacionados con los Planes Directores. Med. Clin (Barc). 131 (4) pp. 42-46.

Unerman, J. 2000. Methodological Issues. Reflections on quantification in Corporate social reporting content analysis, Accounting Auditing \& Accountability Journal, 13 (5), pp. 667-680.

Uribe, J. 2011. Argumentación construcción de validez en la Planficación EstratégicaSituacional de Matus. Cad. Saúde Pública, Rio de Janeiro, 27(9) pp.1847-1857.

Valanis, B. 1992. Epidemiology in nursing and health care (2nd ed.) Appleton-CenturyCrofts. Norwalk.

Weber, M. 1995. Économie et societé. Les catégories de la sociologie. Paris: Plon.

Weber, R.P. 1985. Basic content analysis. Beverly Hills, CA: Sage. 
White, M. A. 2013. Sustainability: I know it when I see it. Ecological Economics, 86, pp. 213-217.

WISCO. 2002. Universidad of Wisconsin. Community group member survey. Wisconsin. Program Development and Evaluation of University of Wisconsin. Cooperative Extension.

Disponible en: http://www.uwex.edu/ces/pdande/evaluation/pdf/MEMBSU.pdf [Consultado, 15 mayo 2013]

WPSALUD. 2013. Web del grupo Planes de Salud.

Disponible en:

http://www.planificacionsanitaria.com/estrategias_autonomicas.php

[Consultado, 10 febrero 2013] 
Capítulo 3: Aspectos relevantes para el diseño de planes de salud sostenibles orientados a los grupos de interés. Una propuesta basada en la guía ISO 26000:2010. 


\section{Índice}

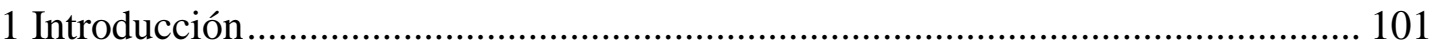

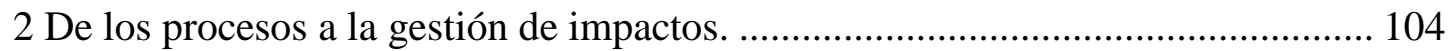

2.1 ISO 26000:2010: materias y asuntos en relación con sanidad. ...................... 106

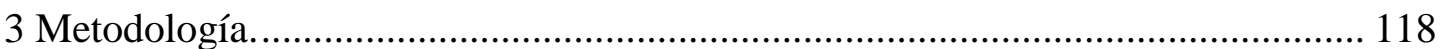

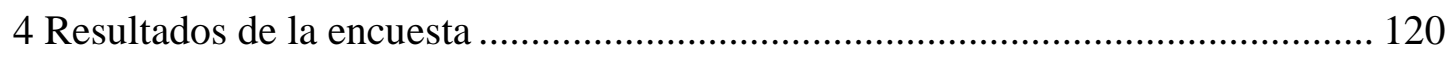

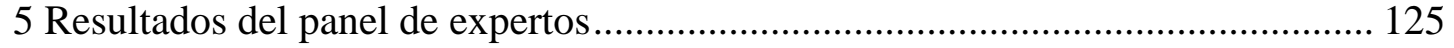

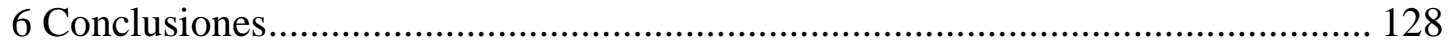

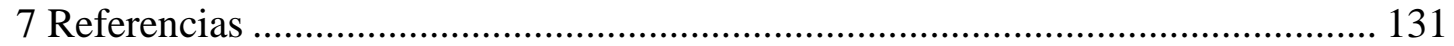




\section{1.- Introducción}

La elaboración de un plan de salud como instrumento de definición y comunicación en el marco de las políticas públicas requiere de un esfuerzo relevante de coordinación de múltiples partes interesadas, de recursos y como señalan Grau et al., (2008) de todos los actantes entendidos estos como el conjunto de elementos que participan en el proceso de construcción del hecho social. Cualquier elemento, no solo persona, que modifique un contexto o intervenga en un proceso, por ejemplo en la elaboración de un documento de planificación sanitaria, es un actante (Latour, 2005). Al conjunto de actantes reunidos con el propósito de intervenir en la acción se les conoce como colectivo (Blanco y Gomá, 2002) según refieren Grau et al., (2008) en su artículo. Los procesos de producción de políticas públicas, como son a nuestro entender la elaboración de estrategias sanitarias, no suponen acciones jerarquizadas de toma de decisiones sino el conjunto de un variado entramado de acciones y actores. Según Kickert et al., (1998), las políticas públicas pueden ser entendidas como el resultado de la labor y las relaciones entre diferentes actores que dependen unos de otros en el proceso de su construcción, a través de un conjunto de preferencias elaboradas en red y que a priori son imprevisibles, complejas, y forman una densa trama (Graña, 2005).

El enfoque de este trabajo se centra en situar las políticas públicas, concretamente las relativas a sanidad, en un contexto teórico de participación activa de la comunidad y el diálogo social. Materias y asuntos que son relevantes en el marco de una adecuada relación con los grupos de interés como se recoge en el estándar internacional ISO 26000 (2010). La guía ISO 26000 publicada en el año 2010 tiene un enfoque holístico y no ha sido diseñada con propósitos de certificación. Basada en un proceso multistakeholder innovador permite a las organizaciones públicas y privadas establecer aspectos y acciones de responsabilidad social acordes a sus particularidades (Maas y Reniers, 2014). Pretendemos de este modo situarnos en la propuesta de un documento, el plan de salud, elaborado con criterios de transversalidad no solo institucional, sino quizá lo que puede resultar un reto mayor, desde una permeabilidad real al conjunto de partes interesadas que el gestor sanitario debería tener en su radar, al margen de la consideración o relevancia que les otorgue a priori, ya sea por interés político, o como consecuencia de las circunstancias coyunturales. 
Tras la introducción presentamos una revisión bibliográfica relacionada con los sistemas y procesos de gestión en sanidad, así como con las materias y asuntos contenidos en la guía de responsabilidad social. Posteriormente se muestran los resultados de la encuesta y los obtenidos del panel de expertos, para fundamentar el análisis de materialidad y la determinación de asuntos relevantes. Finaliza el trabajo con las conclusiones y la construcción de la tabla de indicadores según el Global Reporting Initiative para cada asunto (GRI, 2013).

La Comisión Europea en el año 2001 ya indicaba que las políticas públicas tienen un papel clave a la hora de apoyar las prácticas de responsabilidad social y establecer marcos en los que las cuestiones sociales y medioambientales sean tomadas en consideración en las estrategias de las organizaciones (EC, 2001). La idea de elaborar dichas políticas en el marco de trabajo de un estándar basado en criterios de desarrollo sostenible que a la vez sea reconocible e internacionalmente aceptado es una línea de actuación que puede resultar particularmente apropiada. Encontramos antecedentes en los procesos o sistemas de calidad que han aportado valor a la hora de establecer dichas estrategias. No obstante desde una perspectiva sociológica hay diferencias entre la elaboración formal y la social de un sistema o proceso de calidad. Una aplicación integral de los dos aspectos sería válida a nuestro entender para la construcción de un sistema aplicado a organizaciones sanitarias (Harteloh, 2003).

El objetivo que nos marcamos es la identificación de aspectos relevantes para el diseño de un plan de salud realizado con criterios de desarrollo sostenible tomando como base el estándar internacional ISO 26000. Esta guía contiene materias fundamentales en el ámbito de la sanidad relativas a aspectos económicos, sociales y medioambientales y una extensa serie de asuntos relacionados con la salud de la población. Por otro lado, proponemos un panel de indicadores de seguimiento referenciados a un estándar internacionalmente reconocido como Global Reporting Initiative (GRI, 2013) que puede contribuir a un resultado fácil de comparar y de seguir en el tiempo.

Un plan diseñado para la mejora de los resultados requiere de un determinado control racional y de liderazgo. En el caso del sector sanitario, los procesos enfocados en asegurar la calidad deben estar referidos a determinadas guías, estándares y protocolos, ya que en general solo los procesos con adecuados niveles de control serán capaces de satisfacer las demandas de los pacientes (Harteloh, 2003). Además la comparabilidad es una característica deseable en los planes que se llevan a cabo en el sistema sanitario y para ello los indicadores, referidos a estándares reconocibles, serían un factor 
determinante. Hay evidencia demostrada en estudios del sector referidos a la toma de decisiones como un proceso social caracterizado por la construcción de indicadores y el uso de datos procedentes de las interacciones entre profesionales del sistema sanitario, pacientes, un criterio médico flexible y una decisión basada en esas relaciones (Berg, 1997 ; Bloor, 1976; Young, 1981; Fisher y Todd, 1983; Strauss et al., 1985; Clrak et al., 1991; Berg, 1992; Anspach, 1993; Atkinson, 1995; Casper y Berg, 1995). Es necesario destacar, como hacen Counte y Meurer (2001), que los consumidores y pacientes cada vez son más activos en su papel de stakeholders y en la demanda de información que reclaman relativa al valor que aportan las innovaciones sanitarias, por citar un ejemplo recurrente.

Las primeras propuestas de estructuras de sistemas de salud basadas en marcos de trabajo con procesos y resultados (Donabedian, 1966, 1988), ya distinguían la diferencia entre los procesos de provisión de salud, care given, y aquellos de cuyas consecuencias de la interacción entre el individuo y el sistema se obtenían los resultados, los outcomes. Si bien el objeto del presente trabajo es la construcción de un plan de salud con criterios amplios de desarrollo sostenible, son la vertiente social y la medioambiental- por su importancia entre los actores y el impacto que tienen sobre la salud- las que concentran buena parte de nuestra atención.

La literatura identifica dos procesos claves en salud. Las intervenciones técnicas por un lado y las interacciones personales de los pacientes con los miembros del sistema sanitario por otro, como señalan Campbell et al., (2000) con base en las publicaciones de Blumenthal (1996), Donabedian (1988, 1992); Irvine (1990) y Tarlov et al.,(1989) o Steffen (1988). Una perspectiva social requiere información relativa a todos los usuarios potenciales del sistema de salud (Birch y Gafni, 1992). La inclusión de asociaciones o representantes de pacientes es cada vez más común en el proceso de elaboración de planes de salud e interesa poner el foco en la construcción de indicadores asociados a esas colaboraciones para determinar el nivel de impacto que tienen en el resultado final. Los indicadores sociales aparecen integrados y armonizados en diferentes modelos de gestión de los gobiernos y de hecho, al estar incluidos en los objetivos del milenio como señalan Pega et al., (2014), gozan de mayor relevancia. Esta circunstancia se ha visto reforzada en el reporte de la Comisión sobre Seguimiento de Resultados Económicos y Sociales (Stiglitz et al., 2009). Otros ejemplos documentados por la OMS, como el programa UNAIDS, señalan a los miembros de la sociedad civil como actores en los procesos de reporting de la información cualitativa y cuantitativa para los gobiernos 
relacionada con derechos humanos o legislación medioambiental, ambas materias recogidas en la guía ISO 26000. Estos sistemas de reporte añaden además auditorías externas o internas por parte de expertos independientes que garantizan la calidad de la información (Taylor et al., 2014).

Los determinantes sociales representan aspectos fundamentales en el abordaje de la salud y parece crucial su análisis y seguimiento. El concepto de "social monitoring" hace referencia a la producción y provisión de información relevante, incluyendo la presentación de la misma, como señalan Pega et al., (2014) citando a (Habbich y Noll, 1994). Esta información refiere aspectos económicos, políticos, culturales y sociopsicológicos tanto de los actores como del propio sistema (Lass y Reusswig, 2002). Lo social se enmarca en las interacciones que efectúan entre sí todos los actantes y es el resultado del proceso de asociaciones, de ahí nuestra propuesta de trabajo de construir modelos de elaboración de políticas públicas de la forma más inclusiva posible.

\section{2.- De los procesos a la gestión de impactos.}

Como señala Jonker (2000), concluida en gran medida la transición desde el concepto de calidad de producto hacia el de calidad total se viene produciendo una demanda creciente respecto de la inclusión de los impactos sociales y medioambientales en los marcos, procesos y estándares de trabajo (Maas y Reniers, 2014). Los sistemas de calidad modernos, incluyen aspectos que conciernen a la responsabilidad social. Con la publicación de ISO 26000 cada organización tiene la posibilidad de ajustar su política en esta materia. Dicha guía provee de una serie de asuntos esenciales a considerar por toda entidad que se oriente a la medición de los impactos sociales y medioambientales además de los económicos (Maas y Reniers, 2014).

En sanidad existe un amplio conocimiento y numerosas publicaciones sobre el impacto de los hábitos de vida poco saludables y su incidencia en la salud de la población, así como acerca de los determinantes sociales y de los factores ambientales. El reto mayor que comenzamos a ver en los planes de salud es el intento y los avances en algunos casos, de coordinar estrategias integradoras de aquellas dimensiones que afectan a la salud de la población. En particular los condicionantes sociales y ambientales, menos precisos o tradicionales en medicina como los genéticos o derivados de pandemias infecciosas pero no menos importantes en términos de resultados sobre la salud y su proyección en el gasto sanitario y la sostenibilidad del sistema. Una de las tareas más 
relevantes de los líderes de las organizaciones para afrontar este tipo de retos es seleccionar adecuadamente los asuntos más relevantes que deben ser abordados. Esto puede realizarse a través de un análisis de materialidad basado en investigación social cualitativa, acorde al sector salud (Maas y Reniers, 2014). Para ello, estos autores utilizaron ISO 26000 como marco de referencia y los indicadores del GRI para relacionarlos. Hay que añadir que conocer las preocupaciones e identificar las expectativas de la población contribuiría a dotar al planificador de una inestimable información para su estrategia de planificación.

La estructura de la guía ISO 26000 y su diseño están basados en el documento publicado por Brundtland sobre el concepto de desarrollo sostenible (Kurman et al., 2012), situando el foco de atención en la responsabilidad social de las organizaciones y sus impactos sociales y medioambientales. La guía puede ser usada para recoger las expectativas y necesidades de la sociedad y ajustar las líneas de actuación a nivel táctico. Paralelamente, el Global Reporting Initiative (GRI, 2013) editó de forma conjunta con ISO una tabla de concordancia de indicadores relacionados con los asuntos incluidos en la guía de responsabilidad social. Los investigadores continúan esforzándose por encontrar herramientas que permitan medir cada vez con mayor precisión los objetivos de sostenibilidad (Hahn, 2012).

En el libro verde de la Comisión Europea (CELV, 2001) se recoge textualmente que "las políticas públicas tienen un papel clave en impulsar un sentido mayor de la responsabilidad social y establecer marcos de trabajo para asegurar que se integran en los modelos de negocio las cuestiones sociales y medioambientales”. En relación con estos aspectos claves del desarrollo sostenible se ha sugerido además que la construcción de estándares y modelos de relación con los grupos de interés contribuye a la creación de acuerdos y colaboraciones, a compartir conocimiento y ganar legitimidad (Balzarova y Castka, 2012). En esta línea añaden, es posible mejorar y fijar las cuestiones relevantes en el entorno social y medioambiental (Fransen y Kolk, 2007; Dejean et al., 2004). Una de las grandes diferencias en este tipo de estándares estaría precisamente en el hecho de incluir la participación activa de las partes interesadas. No se trata por lo tanto de un marco de actuaciones elaborado por la parte impulsora del plan o el sistema sanitario sino un camino de construcción común y un lugar de encuentro con todos los actores concernidos y, sin duda, con el paciente y ciudadano que es el destinatario final de las políticas públicas de salud. Si bien la participación de asociaciones de pacientes y otros grupos de interés en los planes de salud más recientes 
es apreciable, incluso en su implementación a nivel local, un modelo específico de construcción de la relación con los stakeholders ayudaría a tener en consideración los pilares que consideramos deben ser integrados en las estrategias de políticas públicas (Brodhag y Taliere, 2006) esto es; la parte económica, social y medioambiental. Añaden los autores que una estrategia nacional orientada a criterios de desarrollo sostenible debería basarse en un sistema de indicadores bien estructurado y que posibilite el seguimiento de los objetivos.

\section{1.- ISO 26000:2010: materias y asuntos en relación con sanidad.}

La guía ISO 26000 contiene siete materias fundamentales (Tabla 1), cuyos asuntos pueden ser identificados en la bibliografía sobre sanidad, en el discurso político de los planificadores sanitarios y en los documentos editados por los diferentes gobiernos autonómicos en sus planes de salud, como repasaremos a continuación materia por materia.

Tabla 1: materias fundamentales de la guía ISO 26000:2010

Gobernanza

Derechos Humanos

Prácticas Laborales

Medio Ambiente

Prácticas Justas de Operación

Asuntos de Consumidores

Participación Activa y Desarrollo de la Comunidad

Fuente: elaboración propia a partir de la guía ISO 26000:2010

Cada una de las materias de la guía incluye un número variable de asuntos junto con sugerencias a seguir en forma de posibles planes de acción. Al no ser objeto de certificación, ISO 26000 no contiene requisitos en el sentido que aparecen en los sistemas de gestión como las normas de calidad. 


\subsubsection{Gobernanza}

Gobernar hace referencia al proceso de elección de valores y criterios, objetivos y medios, las rutas estratégicas de acción, los actores y los instrumentos para conseguir determinados fines (Aguilar, 1996). Por su parte, como señalan Barbazza y Tello (2014) en referencia a van Olmen et al., (2012) y Mikkelsen-Lopez et al., (2011), el nuevo término gobernanza, introducido en la literatura anglosajona de forma más visible a partir de los años noventa, ha sido repetidamente utilizado en referencia a una de las funciones clave en las teorías y modelos de trabajo del sistema sanitario. Barbazza y Tello (2014) apuntan algunas de las dimensiones más comunes utilizadas para definir el concepto y función de gobernanza. Entre ellas mencionan las siguientes: responsabilidad sobre las decisiones y objetivos, regulación y formulación de políticas e incluyen la definición de la dirección estratégica. Llama la atención que aspectos como la resolución de conflictos o la corrupción que son universalmente reconocidos como esenciales en un adecuado sistema de gobernanza no aparezcan de forma explícita en los modelos analizados por los autores, sin que por ello dejen de estar en el centro de atención de la opinión pública. En un segundo nivel encontramos en la clasificación de Barbazza y Tello aspectos relativos al control, la coordinación, la colaboración y la comunicación. Otros autores definen la gobernanza en función de tres tipos fundamentales (Smith et al., 2012): i) basado en la jerarquía ii) el mercado y iii) las relaciones. La jerarquía desde la perspectiva de la elaboración de reglas y asignación de recursos de arriba hacia abajo, o modelo top down de control directo. El mercado con énfasis especial en compras, regulaciones del sector y creación de incentivos y, por último, las relaciones con el foco en el conocimiento y los valores compartidos. Este modelo combinado podría aportar una interesante versión de la gobernanza combinada con el liderazgo necesario en organizaciones complejas como un sistema público de salud.

Como ponen de manifiesto Marks et al., (2010), los modelos de gobernanza pueden influir en los resultados de salud de la población dado que al estar asociados con patrones de incentivos respecto de objetivos, regulaciones y estilos de dirección y liderazgo de las organizaciones el resultado final aparece como una de las variables del propio modelo. En el estudio de estos autores se realizaron diferentes sesiones de focus group a directivos de nivel sénior en el Reino Unido con objeto de observar la opinión de los stakeholder sobre la gobernanza en el sistema de salud. Como resultado, en 
primer lugar manifestaron una visión extensa de lo que debería ser el punto de mira del gestor. Producir salud y bienestar incluyendo la protección sanitaria, el cuidado social y la regeneración económica, una evidente extensión de la mera provisión de servicios hacia una visión más holística y centrada en la persona y su contexto. Otros aspectos relacionados con los sistemas de incentivos y objetivos de los gestores fueron tratados destacando la necesidad de fortalecer la responsabilidad de las acciones y las actuaciones a nivel local en las implementaciones de las políticas sanitarias.

La gobernanza es un asunto global del que la OMS también se ocupa y de manera especial a partir de la situación de crisis desencadenada en 2008, impulsando un panel para dar mayor relevancia a la gobernanza en la salud a nivel global (Mackey y Liang, 2013). Señalan los autores que la creciente duplicación de esfuerzos por falta de coordinación añadida a los problemas financieros hacen muy necesarias estas actuaciones (Leach-Kemon et al., 2012; Sridhar y Batniji, 2008).

La coordinación es importante pero hay múltiples fuerzas e intereses adyacentes a los sistemas de gobernanza que deben ser gestionados. La salud es, además de un derecho universal, quizá el bien más preciado por la población, y la provisión de cuidados y recursos para mantenerla genera un considerable negocio a corporaciones y grupos de interés que presionan para conseguir los mejores resultados en términos económicos. Como apuntan Hernández y Lumbreras (2014) parece existir un intento de captura cultural como fin último del sistema de influencias de las corporaciones. El ideal pretendido sería aquel en el que los intereses de las empresas hubieran sido asimilados por el sistema y dejaran de ser necesarias la influencias directas. Un efecto que señalan es la posible deriva de las inversiones hacia el aumento de la financiación privada de la ciencia, enfocada en las soluciones clínicas menos coste-efectivas en vez de en soluciones orientadas al entorno en el que las personas viven, enferman y finalmente desaparecen.

Las decisiones, por lo tanto, son críticas desde la perspectiva de las consecuencias derivadas de las mismas sobre la salud de la población. El asunto contenido en gobernanza en la guía ISO 26000 hace referencia a los procesos y estructuras en la toma de decisiones en la organización. Además cuestiones relativas a la debida diligencia y la responsabilidad sobre los efectos de las decisiones deberían ser monitorizados adecuadamente en sanidad. 


\subsubsection{Derechos Humanos}

Son derechos básicos que todos tenemos por haber nacido en este mundo. La guía ISO 26000 hace especial hincapié en ellos y señala dos tipos de categorías recogidas en la carta universal de los derechos humanos: por un lado los civiles y políticos, y por otro los sociales, culturales y económicos entre los que se incluye el derecho al máximo nivel alcanzable de salud. En 1951 la Secretaría de Naciones Unidas recogía el derecho a la salud en el compromiso de los estados haciendo énfasis en cuatro puntos i) definición de la promoción de la salud, ii) la importancia de la medición del impacto de los determinantes sociales en la salud, iii) la responsabilidad de los gobiernos en la provisión de la salud y iv) el rol de los ministerios en la creación de sistemas de salud pública (Meier y Onzivu, 2014). Por su parte el artículo doce del Pacto Internacional de Derechos Económicos, Sociales y Culturales (PIDESC), señala las medidas que deberían adoptar los estados con la finalidad de asegurar la plena efectividad de este derecho y que deben incluir aquellas necesarias para i) La reducción de la mortinatalidad y de la mortalidad infantil y el sano desarrollo de los niños, ii) la mejora en todos sus aspectos de la higiene del trabajo y del medio ambiente iii) la prevención, el tratamiento y el control de las enfermedades epidémicas, endémicas, ocupacionales y de otra índole y iv) la creación de condiciones que aseguren a todas las personas servicios médicos y atención médica en caso de enfermedad (OMS, 2008).

El reflejo es claro respecto de las obligaciones que las naciones asumen en relación con la salud de las personas, no solo en el ámbito de la curación, sino que indica como esenciales la provisión de medidas que mejoren los indicadores de los grupos más vulnerables. El asunto número cinco de la materia relacionada con los derechos humanos en la guía de responsabilidad social sugiere la posibilidad de facilitar a los miembros de dichos colectivos la toma de conciencia sobre sus derechos (ISO 26000, 2010). La década de los noventa y la aparición del sida marcó un punto de inflexión en materia de derechos humanos y salud. Jonathan Mann fundo el movimiento "Health and Human Rigths" y llevó a cabo numerosos programas y políticas de salud con grupos de interés afectados y tradicionalmente excluidos socialmente: prostitutas, homosexuales, drogodependientes etcétera. El objetivo fue activar la lucha contra la pandemia cuyos efectos eran devastadores y mortales, no solo físicamente sino también socialmente, lo que de facto significaba una muerte anticipada por el ostracismo previo al deceso y el 
final de la vida biológica de los afectados. El propio Mann reconoce que el derecho a la salud engloba sobre todo las condiciones en las que las personas viven y que los factores sociales constituyen el mayor determinante de la salud (Mann, 1997).

Podría ser, al menos en parte, en el ámbito de las políticas públicas donde comienzan y se condicionan los determinantes de la salud y la arena en la que se puede obtener un efecto positivo cuando aquellas se basan en los derechos humanos (Franco-Giraldo y Álvarez-Dardet, 2008). No en vano el derecho a la salud no es por sí solo algo tangible o la expresión de un deseo en el que el sujeto actúa de forma pasiva, sino que se debe completar con otros derechos como los relativos a la libertad de expresión, de elección, identidad y sobre todo de participación en el desarrollo de políticas públicas. Cabe la posibilidad de que los conceptos relacionados con derechos humanos y derechos a la salud queden en una situación un punto abstracta (Marks, 2008) y por ello, conviene aclarar la diferencia. Los objetivos de salud se sitúan en los requerimientos para alcanzar el bienestar físico, mental y social de la existencia humana y la clave en el desarrollo de las condiciones materiales que hacen que los individuos se beneficien de los procesos económicos para mejorar sus condiciones de vida. Los derechos humanos por su parte se centran en acordar con los poderes públicos las regulaciones y leyes necesarias para preservar la dignidad humana y ambos derechos tienen en común la búsqueda del bienestar y la salud de las personas.

\subsection{3.- Prácticas laborales}

Un documento de política pública como un plan de salud no puede, ni tiene como objetivo, abarcar todos los asuntos relacionados con materias de responsabilidad social. Sin embargo, como en cualquier organización entendemos que sería recomendable atender los aspectos de su actividad principal que pudieran tener reflejo en ella. En esta materia el asunto principal pudiera estar relacionado con la salud y seguridad ocupacional, así como con el desarrollo humano y la formación en el lugar de trabajo (ISO 26000, 2010). Es necesario recordar en este punto que la responsabilidad social tiene dos dimensiones, interna y externa, o directa e indirecta (Elkington, 1999 y Niskala et al., 2009). La dimensión o perspectiva interna se centra fundamentalmente en los empleados, incluyendo los subcontratados y en el caso particular de la sanidad, dado el nivel de riesgo y la alta responsabilidad de sus actuaciones nos parece pertinente un elevado grado de atención en los planes de salud. Como cita Koskela (2014) tomado del 
texto de BSI (2007) es importante atender la salud y la seguridad de los empleados incluyendo los trabajadores temporales y las visitas a los centros de trabajo de cualquier persona ajena a la organización. De acuerdo con ISO 26000 integrar la prevención de la salud y la seguridad de los trabajadores incluye la prevención de los riesgos y la adaptación del lugar de trabajo y formación de los empleados para evitarlos. Todas las acciones mencionadas o sugeridas en la guía ISO 26000 en relación a prácticas laborales se encuentran en sistemas de gestión de seguridad laboral como OSHAS 18001, a excepción de los riesgos psicosociales (Ranangen y Zobel, 2014). La salud y seguridad laboral es una disciplina amplia que abarca, según autores como Erickson (1996), Reese (2003) y Montero et al., (2009) los siguientes aspectos i) la promoción y mantenimiento de los estándares más altos de salud física, mental y bienestar de los trabajadores ii) la prevención de pérdida de salud debido a las condiciones de trabajo iii) la protección de los trabajadores de los riesgos para la salud y iv) la adaptación del puesto de trabajo a las condiciones fisiológicas y psicológicas de los empleados. Se puede constatar que algunos de los puntos señalados tienen además vinculación directa con aspectos relativos a derechos humanos.

En el año 2014 la sanidad española se enfrentó al reto de combatir riesgos epidémicos derivados de casos de Ébola en sus instalaciones y se puso de manifiesto la necesidad de planes adecuados para los trabajadores que se enfrentan a estas situaciones en el lugar de trabajo. Al margen del efecto mediático del riesgo de pandemia procedente de una enfermedad tan exótica como letal, pueden existir en el día a día situaciones similares de menor visibilidad para los medios de comunicación pero de iguales efectos para los empleados del sector sanitario. La relevancia de la seguridad y salud laboral es patente en los marcos internacionales que la relacionan con la responsabilidad social y los sistemas de elaboración de informes (Montero et al,. 2004). En el artículo de estos autores se reflejan tanto ISO 26000 entre los esquemas en los que figura esta materia como Global reporting Initiative entre los modelos de reporte.

\subsection{4.- Medio Ambiente}

La literatura y bibliografía asociada a la salud y el medio ambiente es profusa y recoge sin lugar a interpretaciones en otro sentido la relación directa entre las dos variables. El número de artículos y publicaciones sobre emisiones contaminantes y efectos sobre la salud es muy extenso y su estudio o consideración trasciende en mucho el objetivo de 
este trabajo. Al hablar de medio ambiente debemos pensar en cambio climático y sus efectos, quizá lentos pero cada vez más trascedentes. Aspectos como la gestión de residuos y el contexto social entre otros pueden afectar a la salud de las personas en el ámbito en el que se desenvuelven. Algunos modelos y estudios han considerado una pobre condición medioambiental como peor que unas pobres condiciones sanitarias (Canavese, 2013). Determinadas exposiciones pueden resultar igualmente lesivas aun siendo menos evidentes como la calidad del aire tanto exterior como interior (WHO, 2010). La prevención de la contaminación y el uso eficiente de los recursos aparecen en el modelo ISO 26000 como asuntos que consideramos relacionados con la sanidad y su entorno, sin desestimar otros que igualmente pudieran tener una alta incidencia. En la consideración de estos aspectos en la elaboración de un plan de salud parece importante, siguiendo la tendencia de trasladar la salud a todas las políticas, combinar los esfuerzos de forma transversal con otras agencias del gobierno dedicadas a medio ambiente y eficiencia energética, al control de las emisiones, la regulación, elaboración y seguimiento de indicadores.

En la primera década del siglo veintiuno más de la mitad de la población habita en las ciudades, y en muchos casos en lugares donde no se salvaguarda la calidad de vida de sus habitantes (Cañizares, 2005), dado que existen graves problemas en el ecosistema en relación con la calidad del agua, saneamiento, contaminación y eliminación de residuos. Los llamados "problemas marrones" (VV.AA, 1998) han hecho de la problemática ambiental una cuestión política a todos los niveles. El incremento de las enfermedades crónicas con el aumento de la edad expone a las personas a impactos negativos adicionales que conviene gestionar procedentes de la mala calidad del agua, el aire y las emisiones contaminantes (Stroetmann, 2013). La cuestión ambiental tiene por otro lado innumerables estudios de impacto en el marco nacional e internacional. En el caso de España según recoge (Ballester et al., 2006), el estudio EMECAS realizado en trece ciudades españolas indica que un incremento de tres microgramos por metro cúbico en los niveles de partículas se asocia a un incremento del cero con ocho de la mortalidad diaria. Las emisiones y el calentamiento son por lo tanto cuestiones que de forma directa afectan a la salud de las personas y las políticas públicas están llamadas a potenciar al fortalecimiento de acciones que mitiguen estos impactos (Tirado, 2010), además de promover la concienciación en la población. 


\subsection{5.- Asuntos de consumidores}

En el sector sanitario el consumidor de los servicios dispensados es el paciente y por lo tanto el conjunto de todos los ciudadanos que tarde o temprano nos vemos en la necesidad de ser asistidos por el sistema. El paciente es a menudo el beneficiario directo de las actuaciones, pero no hay que olvidar que otros actores se ven concernidos de forma coyuntural. La persona enferma precisa también, y a menudo cuenta con ello, de la solidaridad y el apoyo de la familia, amigos o allegados. Estos usuarios indirectos del sistema se relacionan con el mismo al tiempo que el paciente es atendido de su situación de salud y reciben un servicio secundario que hay que considerar al nivel que corresponde. El clima laboral que respiran los trabajadores de la organización sanitaria es esencial para que los pacientes y sus familias, considerados como consumidores, reciban un servicio adecuado. Cuando los profesionales de la salud viven con procedimientos y medios que proporcionan resultados positivos en la salud de los pacientes reciben un feedback positivo. Aumenta el nivel interno de satisfacción en el trabajo y se convierten en entusiastas del servicio (Schneider, 1980). Para ello, la relación profesional de la salud - gestor sanitario debería ser fluida y estar alineada con objetivos comunes orientados al paciente. Una situación como la descrita se basa en los objetivos de responsabilidad social del trabajo ético y bien realizado en el sector sanitario (Russo, 2014). Este autor hace mención de la necesidad de señalar también la responsabilidad del paciente, el uso adecuado de los medios y directrices que recibe y el estímulo y la motivación necesarias para un correcto auto-cuidado (Callahan,1998) y Civaner y Arda, (2008). De acuerdo con las contribuciones del trabajo realizado por Russo (2014) es posible concluir que la gobernanza compartida y la responsabilidad personal y profesional, así como una acercamiento holístico a las cuestiones de salud y la cooperación entre todos los actores, son ingredientes esenciales para desarrollar un modelo de responsabilidad social en salud que satisfaga las necesidades del usuario paciente.

\subsection{6.- Practicas justas de operaciones}

Las relaciones del sistema sanitario con la cadena de valor y en concreto con los proveedores y contratistas es por lo general controvertida. Las administraciones públicas son un cliente de gran tamaño. De hecho para muchas empresas es el único cliente ya que no operan en el sector privado. Entre las materias recogidas en ISO 
26000 figuran los asuntos relacionados con la corrupción, entendida como el abuso de poder, sobornos y el tráfico de influencias en el que pudieran estar implicados funcionarios públicos dado que puede distorsionar la competencia por la distribución de la riqueza y el crecimiento económico (ISO 26000, 2010). Como señalan Meneu y Ortún (2011) entre los indicadores de buen gobierno está el control de la corrupción para monitorizar la desviación de lo público hacia la ganancia privada. Para establecer mayores criterios de transparencia se debería articular según el estándar propuesto una participación política responsable.

Pero no es solo en el campo de la provisión de productos farmacéuticos o sanitarios donde las operaciones comerciales del sector merecen atención. Los modelos de concesión administrativa en el caso español, de financiación pública y gestión privada para la provisión de servicios sanitarios, han creado un nuevo impulso de negocio en diferentes comunidades autónomas y es donde mayor disparidad de criterios existe alrededor de su conveniencia y adjudicación. Las concesiones de treinta años al sector privado pueden ser vistas como inapropiadas en diferentes sectores de la sociedad y obviamente, suponen un giro en la estrategia para la administración. Además de la transparencia el consenso parece obligado en estas transacciones comerciales de trascendencia para la sanidad y la sociedad durante un número significativo de años que puede prolongarse durante décadas.

\subsection{7.- Participación activa y desarrollo de la comunidad}

La construcción de capacidades, habilidades y conocimientos para hacer posible la autogestión comunitaria es en realidad un proceso de aprendizaje continuo y permanente. El proceso podría ser definido como de acción-reflexión-acción (Hernández et al., 2014). Parece necesario que se realicen acciones proactivas desde la administración sanitaria para motivar al menos un proceso de toma de conciencia en la comunidad, previa a las acciones encaminadas a los resultados en salud. El impulso desde la administración sanitaria en el sentido de empoderar el conocimiento y las habilidades propiciaría una reflexión de la comunidad y de ella cabría esperar una acción positiva en consecuencia. Hay experiencias en materia de educación en hábitos de consumo, desde luego en adicciones perjudiciales para la salud, pero también en el campo de lo cotidiano como la alimentación. Una participación activa del grupo de interés correspondiente, en este caso pacientes, o incluso la población general por 
extensión, parece necesaria. Desarrollar una visión amplia del problema puede permitir seleccionar las estrategias y acciones relevantes y evitar las barreras o malos entendidos en la forma de avanzar e invertir en salud desde las administraciones (Beaudry, 2009; Acuña et al., 2014).

Los colectivos con riesgos especiales y de exclusión social y las comunidades más vulnerables precisan una atención especial. Un esfuerzo mayor por parte de la administración sanitaria, no solo para resolver los problemas de salud sino para la educación sanitaria. Estas estrategias de prevención y promoción de la salud que encontramos en diferentes planes publicados por las comunidades autónomas son una buena iniciativa. Las estrategias de base comunitaria pueden propender a mejorar la calidad de vida de estos grupos poblacionales a través de la formación (Mantilla et al., 2013) mediante un modelo secuencial de investigación - acción - participación, propuesto por Lessard-Herbert, Susman y Evered según citan los autores y menciona Bosco (1987) llevado a cabo en Colombia. El estudio realizado en la región de Chocó se definió en base a una secuencia inicial de diagnóstico - exploración. Se realizó para determinar el grado de conocimiento y las prácticas alimentarias y nutricionales de la población a través de encuentros y grupos de trabajo. En una segunda fase se definieron las estrategias a realizar que fueron implementadas en la tercera fase a través de un panel de veintiuna acciones educativas. Los autores concluyen que incluir a las comunidades durante el proceso, dio lugar a que tanto las estrategias educativas utilizadas como los materiales, tuvieran una mayor aceptación y contribuyó a generar estrategias de sostenibilidad (Mantilla et al., 2013).

La participación activa de la comunidad debería propender a una mayor toma de conciencia sobre los problemas de salud. La educación de forma conjunta con el empoderamiento de los miembros del grupo sería susceptible de mover a la acción positiva, el establecimiento de prácticas más saludables de vida y una menor aceptación de aquellas situaciones que puedan comprometer la salud de la comunidad. La administración sanitaria tiene elementos de enlace con las comunidades de pacientes a través de las asociaciones. Adicionalmente, las autoridades locales de las comunidades, ayuntamientos y otros estamentos públicos educativos tienen la oportunidad de reforzar la conducta saludable y sus resultados a medio plazo podrían ser mejores de forma directamente proporcional al nivel de implicación y participación de las personas. 


\subsection{8.- Materias y asuntos destacados}

En este trabajo se ha tomado una muestra de la revisión bibliográfica que evidencia una serie de materias y asuntos de responsabilidad social tratados en la literatura y que conciernen al sector sanitario. Cada uno de los asuntos recogidos en la (Tabla 2) es susceptible a su vez de un estudio individualizado, tal es la producción de artículos y publicaciones que en materia de sanidad existen en relación a la mayoría de ellos. Nos hemos inclinado por incluir aquellos que, ya sea a través de la revisión bibliográfica o del conocimiento experto previo incorporado, tenemos evidencias de que se trata de una preocupación en el sector, o cuando menos, un asunto tratado con frecuencia. Constituyen los temas base sobre los cuales llevar a cabo un proceso de consulta que permita proponer un plan de salud con criterios de desarrollo sostenible. 
Tabla 2: Materias y asuntos relacionados con sanidad en ISO 26000:2010 sometidos a estudio

\begin{tabular}{|c|c|c|}
\hline Materia & Asunto & Observaciones \\
\hline Gobernanza & Rendición de cuentas & Revisar y evaluar resultados \\
\hline Derechos Humanos & Debida diligencia & Relación usuario/sistema salud \\
\hline Derechos Humanos & Situaciones de riesgo & Evaluaciones independientes \\
\hline Derechos Humanos & Evitar complicidad & Formar y trasladar proveedores \\
\hline Derechos Humanos & Resolver reclamaciones & Eficacia y disponibilidad \\
\hline Derechos Humanos & Discriminación & Atención grupos vulnerables \\
\hline Derechos Humanos & Sociales y culturales & Garantizar cumplimiento \\
\hline Derechos Humanos & Derechos en el trabajo & Asociación y oportunidades \\
\hline Prácticas Laborales & Relaciones laborales & Seguridad y no discriminación \\
\hline Prácticas Laborales & Condiciones de trabajo & Convenios, horas extras \\
\hline Prácticas Laborales & Diálogo social & Impactos en el empleo \\
\hline Prácticas Laborales & Salud y Seguridad & Gestión riesgos actividad \\
\hline Prácticas Laborales & Formación y desarrollo & Desarrollo carrera y soporte \\
\hline Medio Ambiente & Prevenir contaminación & Contaminación y consumos \\
\hline Medio Ambiente & Uso sostenible recursos & Renovables y reciclados \\
\hline Medio Ambiente & Mitigar cambio climático & Emisiones GEI \\
\hline Medio Ambiente & M. Ambiente biodiversidad & Tecnologías y procesos \\
\hline Asuntos Consumidores & Información objetiva & Productos y servicios \\
\hline Asuntos Consumidores & Protección de la salud & Instalaciones y servicios \\
\hline Asuntos Consumidores & Reclamaciones & Tratamiento adecuado \\
\hline Asuntos Consumidores & Acceso a servicios & Regulaciones \\
\hline Asuntos Consumidores & Educación y conciencia & Leyes, tratamientos \\
\hline Prácticas Operación & Corrupción & Dar ejemplo y evitar \\
\hline Prácticas Operación & Participación política & Lobby transparencia \\
\hline Prácticas Operación & Competencia justa & Favorecer monopolios \\
\hline Prácticas Operación & RSE en cadena de valor & Compra pública responsable \\
\hline P.A.D. Comunidad & Participación activa & Involucrar pacientes \\
\hline P.A.D. Comunidad & Educación y cultura & Áreas investigación \\
\hline P.A.D. Comunidad & Creación de empleo & Maximizar empleo \\
\hline P.A.D. Comunidad & Desarrollo y acceso & Tecnologías sin impactos \\
\hline P.A.D. Comunidad & Favorecer localidad & Entorno emprendedor \\
\hline P.A.D. Comunidad & Salud y comunidad & Eliminar impactos \\
\hline P.A.D. Comunidad & Inversión social & Alianzas ONGs \\
\hline
\end{tabular}

Fuente: elaboración propia a partir de la revisión bibliográfica 


\section{3.- Metodología.}

Para la realización de una propuesta de plan de salud con base en criterios de desarrollo sostenible en el marco de la guía ISO 26000, es fundamental delimitar qué aspectos ligados a la sostenibilidad son considerados materiales para ser incluidos. Para ello, siguiendo a Muñoz Torres et al., (2012), el estudio se ha realizado en tres fases: i) revisión bibliográfica, ii) encuesta y iii) grupo de consenso.

Así, en primer lugar, se realizó una revisión de la literatura de las materias fundamentales contenidas en dicha guía en el contexto de la salud y la planificación sanitaria, tanto a nivel nacional como internacional para determinar los contenidos que tienen a priori una relación apreciable con las políticas de salud y sus instrumentos públicos de planificación. El objetivo es obtener un cuadro de materias y asuntos relevantes derivados del contexto y la revisión bibliográfica para el modelo que proponemos y que quedará abierto a otros asuntos que pudieran ser considerados en el transcurso de la investigación. A continuación, se llevó a cabo una encuesta a una muestra no probabilística, intencional, de setenta cargos o representantes de los diferentes grupos de interés extraídos del análisis de contexto. Con las puntuaciones obtenidas de la encuesta construimos una gráfica de puntuaciones medias y dispersión con base en la desviación típica de dichos datos para evidenciar el nivel de disenso en determinados asuntos sobre los que se ha preguntado. Finalmente, tras la selección de un panel de expertos, se realizó un grupo de consenso sobre las diferencias observadas y se compararon los resultados obtenidos en la encuesta y los procedentes del análisis y la revisión bibliográfica. El grupo de expertos puntuó de nuevo sobre la relevancia de aquellos asuntos que han presentado mayor disenso o dispersión en los resultados de la encuesta, y con este proceso determinamos aquellos aspectos a ser incluidos o excluidos en un plan de salud en nuestro modelo.

La revisión de criterios en la bibliografía y la construcción de indicadores basados en estándares en el terreno sanitario tiene ventajas y limitaciones, dado que requiere una correcta situación del contexto y las circunstancias de los pacientes (Campbell et al., 2000). En cualquier caso es recomendable combinar las evidencias con la opiniones expertas, de acuerdo con la metodología RAND, ampliamente conocida en estudios y 
análisis del sector salud. En los últimos años RAND ha sido utilizada en la elaboración de indicadores de calidad y evaluación de procesos de cuidados de la salud. El método se realiza en varias fases. Tras la revisión bibliográfica se crean marcos o modelos excluyentes basados en las variables halladas, se selecciona un panel de expertos y se puntúan las diferentes posibilidades primero de forma individual y en segunda ronda de forma grupal, una modificación de la propuesta de (González et al., 2009). La revisión de la literatura para elaborar un marco inicial de conceptos en el sector salud ha sido utilizada por Schell et al., (2013) y tomada por los autores en referencia a (Trochim, 2007) para elaborar una propuesta de diseño sostenible de programas de salud a través de la elaboración de un mapa conceptual.

La literatura revela el uso cada vez más frecuente de paneles de expertos para asegurar la calidad en la construcción de modelos de diagnóstico de congruencia en las organizaciones (Vveinhardt y Gulbovaité, 2015). Las manifestaciones de los responsables y gestores sanitarios acerca de la necesidad de implementar acciones de responsabilidad social en las instituciones de salud hace pensar que aquellas tuvieran un reflejo en los instrumentos de política sanitaria como los planes de salud. Lynn (1986) define dos fases esenciales en la metodología i) una revisión comprensiva de la literatura y la generación de instrumentos como cuestionarios con mecanismos de medición cuantitativa y una revisión de expertos para evaluar la relevancia de los asuntos tratados. Especial atención merece la selección de las personas que van a formar parte del panel de expertos, los cuales deben tener un avalado conocimiento y experiencia en la materia, un estatus profesional relacionado y la cualificación académica acorde a la disciplina estudiada. También se recomienda que posean avales de investigación tales como publicaciones académicas y participaciones en congresos y eventos del sector. De acuerdo con Lynn (1986) el número de expertos ideal es de entre seis y ocho y no debería ser inferior a cinco. Para la presente investigación se ha elaborado una presentación con los resultados de la encuesta, datos sobre la metodología y los resultados obtenidos en tres tablas i) materias claramente relevantes ii) materias relevantes pero con un cierto nivel de disenso y iii) materias con elevado disenso sobre las que se pide una puntuación final de uno o cero en función de si las consideran relevantes o irrelevantes.

De la revisión de contexto y bibliografía se han tomado los criterios de selección de los grupos de interés sobre los que construir la muestra poblacional (Gráfico 1) y una muestra de expertos y profesionales de los mismos: gestores que han participado en la 
elaboración de planes de salud, académicos, asociaciones de pacientes, clínicos y personal interno del sistema sanitario de las comunidades autónomas. El tamaño de la muestra es de setenta encuestados, obtenidos a través de invitaciones directas de los investigadores e incluidos tras la aceptación en la participación por parte de cada miembro invitado.

Gráfico 1: Distribución gráfica de los grupos de interés incluidos en la muestra.

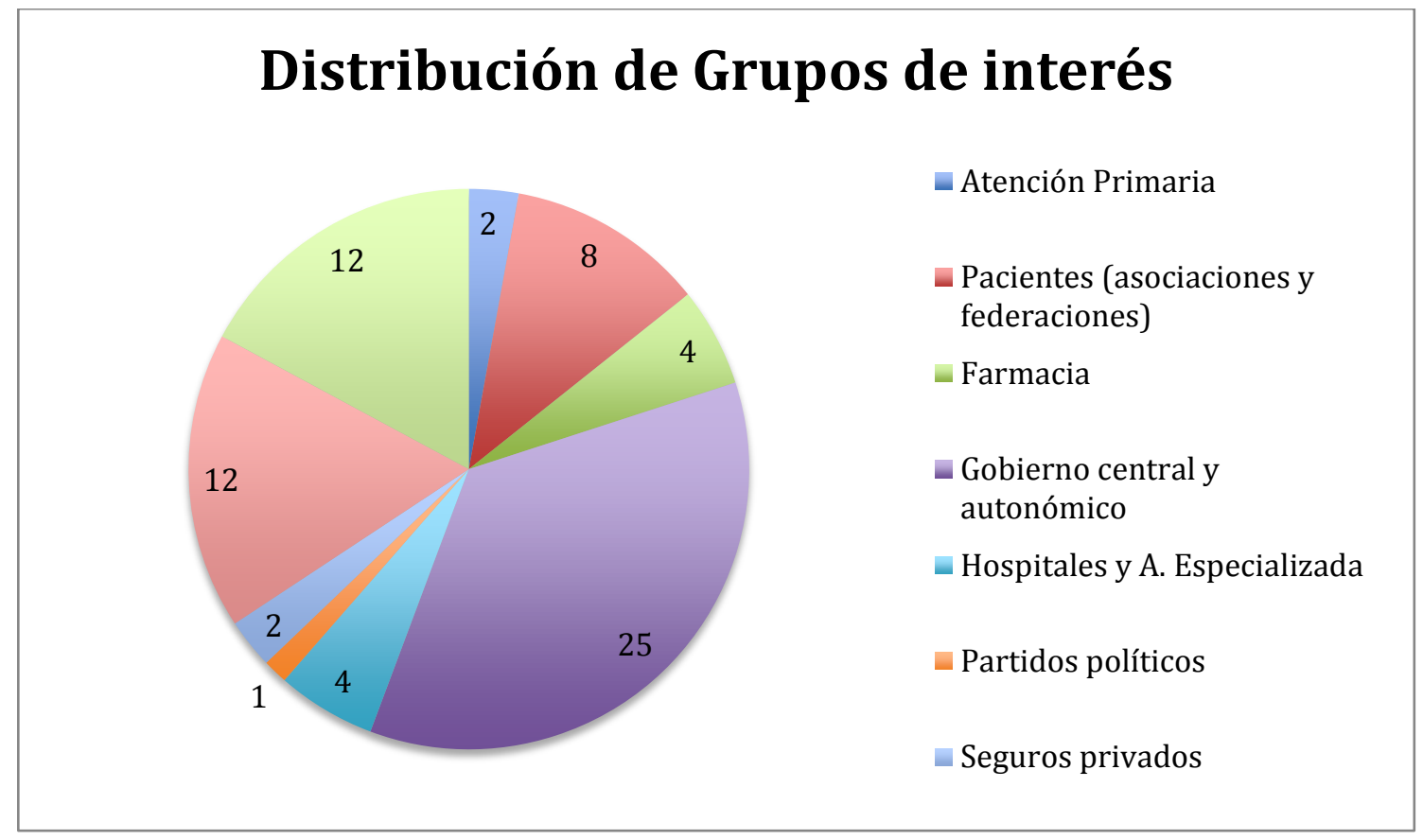

Fuente: elaboración propia a partir de la revisión bibliográfica y de contexto.

Posteriormente se desarrolló una sesión de grupo de consenso, a partir de una selección de expertos obtenida de la muestra previa de encuestados. Se les entregó una tabla con los asuntos de mayor disenso y se les pidió que puntuaran con uno o cero para determinar si serían considerados como relevantes o excluidos de la propuesta de plan de salud.

\section{4.- Resultados de la encuesta}

La encuesta se realizó a través de plataforma online y se solicitó a los participantes que puntuaran en una escala de uno a cinco, modelo de escala introducida por Likert en 1932 según recoge el artículo de Bozal (2006). La escala sumativa de Likert es un instrumento en el que se presenta una pregunta al encuestado y se le asigna un valor a la 
respuesta de menor a mayor nivel de relevancia. En este trabajo se realizaron preguntas sobre los treinta y tres asuntos relacionados en la (Tabla 2). Se obtuvieron datos de un total de treinta y tres de los setenta cuestionarios lo que representa un índice de respuesta superior al $47 \%$ por ciento. El formulario estuvo disponible durante las dos semanas finales del mes de enero de 2015.

Los resultados se presentan de forma gráfica junto con la desviación media obtenida en cada uno de los asuntos de la investigación (Gráfico 2). En la zona A del gráfico se sitúan los asuntos que presentan un bajo grado de disenso y que por lo tanto resultan claramente relevantes para los encuestados (Tabla 3). Las puntuaciones medias de estas materias y asuntos son superiores a cuatro con tres y obtienen una desviación típica inferior a cero con siete. Cuatro de las siete materias fundamentales de ISO 26000 tienen asuntos incluidos como relevantes. En derechos humanos la debida diligencia y la no discriminación destacan sobre otros aspectos incluidos en la encuesta. Prevenir la contaminación y cuestiones relacionadas con pacientes y consumidores así como la prevención aparecen como cuestiones relevantes para los grupos de interés.

Tabla 3: asuntos con bajo nivel de dispersión y claramente relevantes

\begin{tabular}{lc}
\hline Materia y asunto & Zona A \\
\hline Derechos Humanos / Debida Diligencia & 2 \\
Derechos Humanos / Discriminación & 6 \\
Medio Ambiente / Prevenir contaminación & 14 \\
Asuntos Consumidores / Acceso a servicios & 21 \\
Asuntos Consumidores / Educación y conciencia & 22 \\
P.A.D Comunidad / Participación activa & 27 \\
P.A.D Comunidad / Educación y cultura & 28
\end{tabular}

Fuente: elaboración propia a partir de resultados de la encuesta

La zona B del (Gráfico 2) engloba los asuntos con tres con nueve de puntuación media o superior y una desviación de hasta cero con ocho (Tabla 4). Estas materias y asuntos entendemos son susceptibles de revisión o estudios posteriores, quizá vinculados a la procedencia de la puntuación según los grupos de interés seleccionados antes de encuadrarlos como claramente relevantes. Una opción que en cualquier caso trasciende el objetivo del presente trabajo cuya finalidad es establecer una primera aproximación a las materias y asuntos que tendrían cabida en instrumentos de planificación sanitaria. La 
gobernanza aparece en esta zona $\mathrm{B}$, una materia que preocupa en la literatura pero que al ser pensada como asunto a incluir en los planes de salud presenta un cierto nivel de discrepancia y que entendemos puede venir motivada precisamente por intereses contrapuestos en los diferentes stakeholders. Aparecen las prácticas laborales referidas a la salud y la seguridad laboral como asuntos relevantes con cierto nivel de desacuerdo, así como la prevención de la iatrogenia y los efectos no deseados del uso del sistema sanitario y el fomento de la inversión social.

Tabla 4: asuntos relevantes con nivel medio de dispersión

\begin{tabular}{lc}
\hline Materia y asunto & Zona B \\
\hline Gobernanza / Rendición de cuentas & 1 \\
Derechos Humanos / Situaciones de riesgo & 3 \\
Derechos Humanos / Sociales y culturales & 7 \\
Derechos Humanos / Derechos en el trabajo & 8 \\
Prácticas laborales / Salud y seguridad & 12 \\
P.A.D Comunidad / Desarrollo y acceso & 30 \\
P.A.D Comunidad / Salud y comunidad & 32 \\
P.A.D Comunidad / Inversión social & 33 \\
\hline
\end{tabular}

Fuente: elaboración propia a partir de resultados de la encuesta

En la (tabla 5) se muestran los asuntos definidos como relevantes en la zona $\mathrm{C}$ del (Gráfico 2), la cual muestra un elevado nivel de disenso medido por la desviación típica. En todos los casos mayor de cero con ocho y con puntuaciones medias en algunos asuntos en el entorno de tres con cinco, relativamente baja si la comparamos con el resto de puntuaciones medias. Sobre estos asuntos se ha realizado una ronda de análisis con el panel de expertos para determinar finalmente cuáles de ellos no eran realmente relevantes para ser incluidos en un plan de salud. Para ello se preparó una breve presentación explicativa de la metodología y los resultados obtenidos de la encuesta y se les hizo llegar una tabla en la que puntuar con cero o uno en función de si debían desestimarse o considerarse los asuntos como relevantes. 
Tabla 5: asuntos relevantes con nivel alto de disenso o dispersión

\begin{tabular}{ll}
\hline Materia y asunto & Zona C \\
\hline Derechos Humanos / Evitar complicidad & 4 \\
Derechos Humanos / Resolver reclamaciones & 5 \\
Prácticas laborales / Relaciones laborales & 9 \\
Prácticas laborales / Condiciones de trabajo & 10 \\
Prácticas laborales / Diálogo social & 11 \\
Prácticas laborales / Formación y desarrollo & 13 \\
M. Ambiente / Uso sostenible recursos & 15 \\
M. Ambiente / Mitigar cambio climático & 16 \\
M. Ambiente / M.A. Biodiversidad & 17 \\
Asuntos consumidores / Protección de la salud & 19 \\
Asuntos de consumidores / Reclamaciones & 20 \\
Prácticas Justas / Corrupción & 23 \\
Prácticas Justas / Participación política & 24 \\
Prácticas Justas / RSE en cadena de valor & 26 \\
P.A.D Comunidad / Creación empleo & 29 \\
Asuntos consumidores / Información objetiva & 18 \\
Asuntos consumidores / Competencia justa & 25 \\
P.A.D Comunidad / Favorecer localidad & 31
\end{tabular}

Fuente: elaboración propia a partir de resultados de la encuesta

Los asuntos con menor nivel de consenso se reparten de un modo u otro en las siete materias fundamentales de la guía ISO 26000. Destacamos el hecho de que tres de los asuntos estén encuadrados en prácticas laborales, debido quizá a una falta de comprensión del papel que estos aspectos pudieran desempeñar en un plan de salud. Parece menos llamativa la baja puntuación obtenida por los asuntos relacionados con el cambio climático o la biodiversidad, dado que el sistema sanitario suele ser entendido en el terreno de la inmediatez que supone el acto de curar y quizá un poco menos en su rol estratégico en materia de desarrollo sostenible. La corrupción, el lobby y la participación política también pierden peso en cuanto a la importancia que se les otorga, algo que contrasta con el elevado grado de exposición pública que tienen las decisiones sobre el sistema sanitario y la implicación política e ideológica en las mismas. El hecho de que no se perciba como relevante el evitar monopolios, coincide con las políticas de 
compras actuales del sistema sanitario en cuya expresión extrema encontramos las subastas de medicamentos adjudicadas a un solo proveedor.

Gráfico 2: Puntuaciones medias y desviaciones típicas por asunto obtenidas en la encuesta*

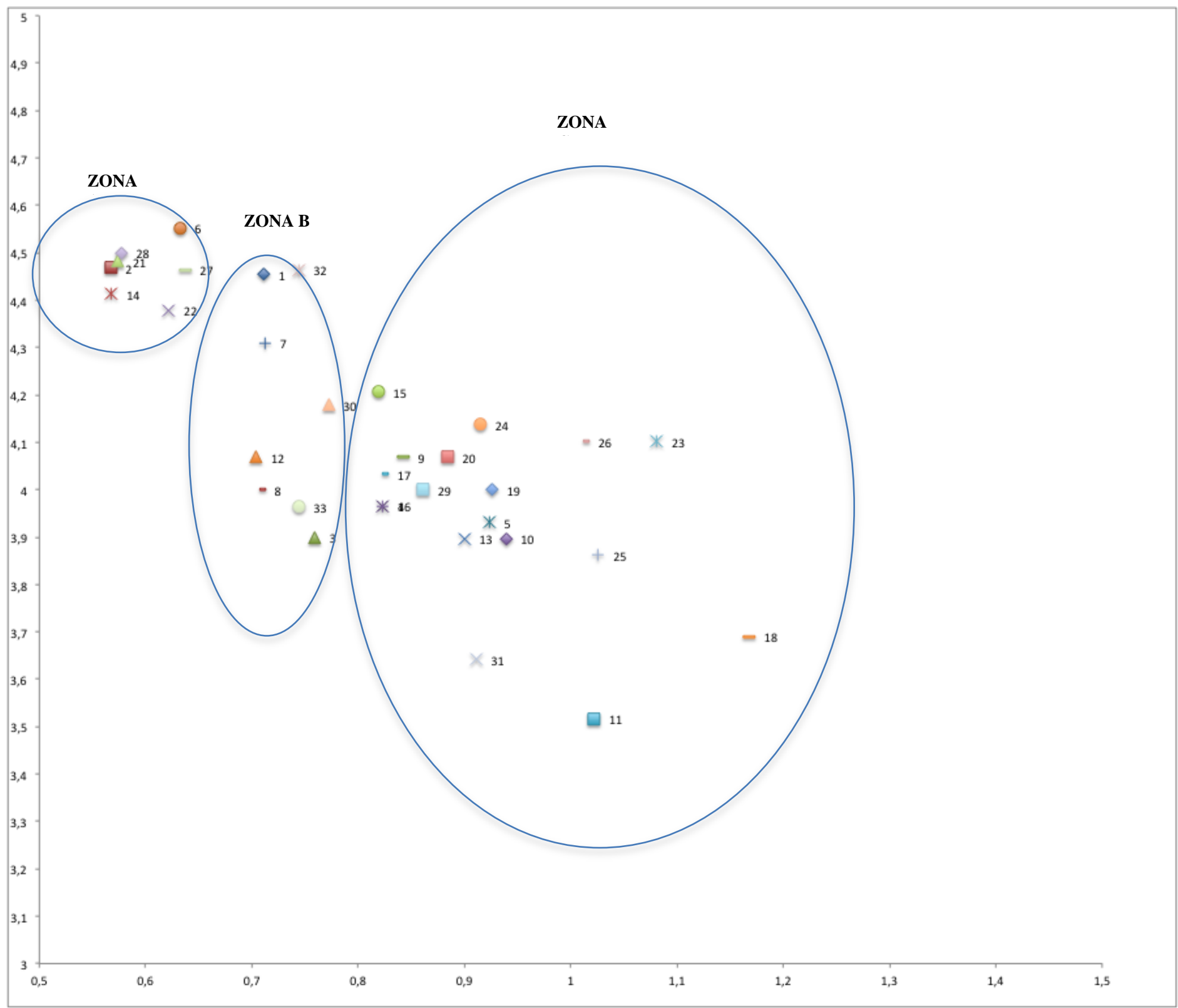

Fuente: elaboración propia a partir de los datos de la encuesta.

- ordenadas: puntuación 1-5 en orden de menor a mayor relevancia otorgada por los encuestados.

- abscisas: desviaciones típicas sobre la media por asunto. 


\section{5.- Resultados del panel de expertos}

Las respuestas positivas recibidas en la encuesta en referencia a una posible participación en un panel de expertos fueron veinte. A todos ellos se les contactó con la intención de realizar una sesión de discusión. El panel de expertos quedó fijado en seis participantes con la necesaria experiencia profesional y perfil académico (Tabla 6).

Tabla 6: participantes en el panel de expertos

\begin{tabular}{lll}
\hline Organización & Departamento & Grupo de interés \\
\hline EOI. Organización Industrial & Gestión Hospitales & Univ. C. Investigación \\
Centro Reg. Transfusiones & Dirección & Atención especializada \\
Profesionales enfermería & Programa de pacientes & Servicios de Salud \\
Instituto Oncología & Dirección & Gobierno central y autonómico \\
Consejo General Farmacia & Comunicación & Asociaciones y Federaciones \\
EASP & Dirección Salud Global & Univ. C. Investigación \\
\hline
\end{tabular}

Fuente: elaboración propia a partir de la muestra de la encuesta.

Dadas las habituales dificultades para la coordinación de un panel de expertos debido a las agendas de las posiciones directivas elegidas, se preparó una documentación adicional explicativa. En primer lugar les fue enviada una presentación con descripción de la metodología utilizada, los resultados obtenidos de la encuesta y el propósito de la nueva puntuación en base a incluir o descartar aquellos asuntos que presentaban mayor disenso. Se recibieron las seis respuestas con las puntuaciones que se presentan en la (Tabla 7).

Con asteriscos aparecen los cuatro asuntos que por mayoría resultan no ser relevantes para incluir en un plan de salud i) medio ambiente y en particular su relación con la biodiversidad ii) prácticas justas de operaciones, cuestiones relacionadas con lobbies y participación política iii) asuntos de consumidores, relacionados con evitar la tendencia a favorecer monopolios de oferta y iv) participación y en concreto el fomento de la actividad local. Estas materias y asuntos quedaron descartados como relevantes en el presente trabajo para ser incluidas en un plan de salud con los criterios de orientación a desarrollo sostenible y responsabilidad social basados en ISO 26000. 
Tabla 7: puntuaciones del panel de expertos sobre los asuntos con elevado disenso.

\begin{tabular}{|c|c|c|c|c|c|c|c|c|c|c|c|c|c|}
\hline Materia y asunto & asunto & $\mathbf{1}$ & $\mathbf{0}$ & 1 & $\mathbf{0}$ & $\mathbf{1}$ & $\mathbf{0}$ & $\mathbf{1}$ & $\mathbf{0}$ & $\mathbf{1}$ & $\mathbf{0}$ & 1 & $\mathbf{0}$ \\
\hline Derechos Humanos / & 4 & 1 & & 1 & & & 0 & & & 1 & & & 0 \\
\hline \multicolumn{14}{|l|}{ Evitar complicidad } \\
\hline Derechos Humanos / & 5 & 1 & & 1 & & 1 & & & 0 & 1 & & 1 & \\
\hline \multicolumn{14}{|l|}{ Resolver reclamaciones } \\
\hline Prácticas laborales / & 9 & 1 & & 1 & & 1 & & 1 & & 1 & & 1 & \\
\hline \multicolumn{14}{|l|}{ Relaciones laborales } \\
\hline Prácticas laborales / & 10 & & 0 & 1 & & 1 & & 1 & & 1 & & 1 & \\
\hline \multicolumn{14}{|l|}{ Condiciones de trabajo } \\
\hline Prácticas laborales / & 11 & 1 & & 1 & & 1 & & 1 & & & 0 & & 0 \\
\hline \multicolumn{14}{|l|}{ Diálogo social } \\
\hline Prácticas laborales / & 13 & 1 & & 1 & & 1 & & 1 & & & 0 & 1 & \\
\hline \multicolumn{14}{|l|}{ Formación y desarrollo } \\
\hline M. Ambiente / Uso & 15 & 1 & & 1 & & 1 & & & 0 & 1 & & & 0 \\
\hline \multicolumn{14}{|l|}{ sostenible recursos } \\
\hline \multicolumn{13}{|l|}{ cambio climático } & 0 \\
\hline M. Ambiente / & 17 & & 0* & 1 & & & $\mathbf{0}^{*}$ & & 0* & 1 & & & 0* \\
\hline \multicolumn{14}{|l|}{ Biodiversidad } \\
\hline Asuntos consumidores / & 18 & 1 & & 1 & & 1 & & & 0 & & 0 & 1 & \\
\hline \multicolumn{14}{|l|}{ Información objetiva } \\
\hline Asuntos consumidores / & 19 & 1 & & 1 & & 1 & & 1 & & 1 & & & 0 \\
\hline \multicolumn{14}{|l|}{ Protección de la salud } \\
\hline Asuntos de pacientes / & 20 & 1 & & 1 & & 1 & & & 0 & 1 & & 1 & \\
\hline \multicolumn{14}{|l|}{ Reclamaciones } \\
\hline Prácticas Justas / & 23 & 1 & & 1 & & 1 & & & 0 & & 0 & 1 & \\
\hline \multicolumn{14}{|l|}{ Corrupción } \\
\hline Prácticas Justas / & 24 & 1 & & & $\mathbf{0}^{*}$ & & 0* & & $0 *$ & 1 & & & $0 *$ \\
\hline \multicolumn{14}{|l|}{ Participación política } \\
\hline Asuntos consumidores / & 25 & 1 & & & $\mathbf{0}^{*}$ & 1 & & & $0 *$ & & $\mathbf{0}^{*}$ & & $0 *$ \\
\hline \multicolumn{14}{|l|}{ Competencia justa } \\
\hline $\begin{array}{l}\text { Prácticas Justas / RSE en } \\
\text { cadena de valor }\end{array}$ & 26 & 1 & & 1 & & 1 & & 1 & & 1 & & & 0 \\
\hline P.A.D Comunidad / & 29 & & 0 & 1 & & 1 & & 1 & & 1 & & & 0 \\
\hline \multicolumn{14}{|l|}{ Creación de empleo } \\
\hline P.A.D Comunidad / & 31 & & 0* & 1 & & & 0* & & 1 & & $\mathbf{0}^{*}$ & & $0 *$ \\
\hline \multicolumn{14}{|l|}{ Favorecer localidad } \\
\hline P.A.D Comunidad / & 33 & 1 & & 1 & & 1 & & 1 & & & 0 & 1 & \\
\hline Inversión social & & & & & & & & & & & & & \\
\hline
\end{tabular}


Se elabora y presenta la tabla siete a partir de los trabajos realizados. Los asuntos finalmente identificados como relevantes son susceptibles de tener indicadores asociados en el sistema de informes publicado por el Global Reporting Initiative en su versión G4 (Tabla 8).

Tabla 8: vinculación de materias y asuntos ISO 26000:2010 con indicadores GRI G4.

\begin{tabular}{|c|c|c|}
\hline Materia & Asunto & Indicador GRI G4 \\
\hline Gobernanza & Rendición de cuentas & G4-LA12 \\
\hline Derechos Humanos & Debida diligencia & G4-HR10 / G4-HR11 \\
\hline Derechos Humanos & Situaciones de riesgo & G4-HR7 \\
\hline Derechos Humanos & Evitar complicidad & $\begin{array}{l}\text { G4-EN32 / G4-EN33 / G4-HR2 / G4- } \\
\text { SO9 / G4-SO10 }\end{array}$ \\
\hline Derechos Humanos & Resolver reclamaciones & $\begin{array}{l}\text { G4-EN34 / G4-LA16 / G4-HR12 / G4- } \\
\text { SO11 }\end{array}$ \\
\hline Derechos Humanos & Discriminación & G4-HR3 \\
\hline Derechos Humanos & Sociales y culturales & G4-EC7 / G4-EC8 / G4-SO01 / G4SO2 \\
\hline Derechos Humanos & Derechos en el trabajo & G4-HR5 \\
\hline Prácticas Laborales & Relaciones laborales & G4-LA4 / G4-LA14 \\
\hline Prácticas Laborales & Condiciones de trabajo & G4-LA2 / G4-LA3 \\
\hline Prácticas Laborales & Diálogo social & G4-HR4 \\
\hline Prácticas Laborales & Salud y seguridad & G4-LA5 / G4-LA6 / G4-LA7 /G4-LA8 \\
\hline Prácticas Laborales & Formación y desarrollo & G4-LA9 \\
\hline Medio Ambiente & Prevenir contaminación & $\begin{array}{l}\text { G4-EN20 / G4-EN21 /G4-EN22 / G4- } \\
\text { EN23 / G4-EN25 / G4-SO2 }\end{array}$ \\
\hline Medio Ambiente & Uso sostenible recursos & $\begin{array}{l}\text { G4-EN2 / G4-EN3 / G4-EN4 / G4-EN5 / } \\
\text { G4-EN6 / G4-EN7 / G4-EN8 / G4-EN10 }\end{array}$ \\
\hline Medio Ambiente & Mitigar cambio climático & $\begin{array}{l}\text { G4-EN15 / G4-EN16 / G4-EN18 / G4- } \\
\text { EN19 / G4-EN20 }\end{array}$ \\
\hline Asuntos Consumidores & Información objetiva & G4-SO7 \\
\hline Asuntos Consumidores & Protección de la salud & G4-PR1 / GR-PR2 / G4-PR8 / G4-PR9 \\
\hline Asuntos Consumidores & Reclamaciones & G4-SO11 \\
\hline Asuntos Consumidores & Acceso a servicios & \\
\hline Asuntos Consumidores & Educación y conciencia & \\
\hline Prácticas Operación & Corrupción & G4-SO4 / G4-SO5 \\
\hline Prácticas Operación & RSE en cadena de valor & G4-EN30 / G4-EN32 / G4-EN33 \\
\hline P.A.D Comunidad & Participación activa & G4-PR3 / G4-PR4 \\
\hline P.A.D Comunidad & Educación y cultura & \\
\hline P.A.D Comunidad & Creación de empleo & G4-LA10 \\
\hline P.A.D Comunidad & Desarrollo y acceso & G4-SO9 \\
\hline P.A.D Comunidad & Salud y comunidad & G4-LA6 / G4-LA7 \\
\hline P.A.D Comunidad & Inversión social & G4-EC7 \\
\hline
\end{tabular}

Fuente: elaboración propia basada en el análisis de materialidad. Propuesta de indicadores GRI - G4. 


\section{6.- Conclusiones}

El trabajo trata de aportar un método, fundamentado en la experiencia en diferentes sectores y la literatura académica, acerca de la determinación de asuntos relevantes para los grupos de interés en el sector sanitario con el foco situado en la elaboración de un plan de salud. Para ello ISO 26000 ofrece una guía basada en materias y asuntos relacionados con la responsabilidad social en las organizaciones, y Global Reporting Initiative incluye indicadores específicos. La propuesta final del trabajo consiste en ofrecer tras el preceptivo análisis de materialidad, un panel de cuestiones clave que resultan relevantes y pertinentes para los grupos de interés consultados, y localizarlos en sus indicadores GRI con objeto de que puedan ser tomados como referencia para futuros planes de salud en España.

Veintinueve asuntos de los treinta y tres incluidos en el trabajo, repartidos en las siete materias contenidas en la guía de responsabilidad social ISO 26000:2010, resultan relevantes para los grupos de interés en relación con su posible inclusión en los planes de salud. El número es significativo dado que la guía completa presenta treinta y siete asuntos en total encuadrados en siete materias. Tan solo han sido descartados en la investigación cuatro de los asuntos presentados en la encuesta y el panel de expertos, por no existir un consenso razonable respecto de su relevancia. Otros cuatro asuntos fueron excluidos previamente durante la revisión bibliográfica al no ser considerados relevantes.

Los resultados muestran que las siete materias y alrededor del setenta y ocho por ciento de los asuntos relacionados con responsabilidad social, y en particular los incluidos en la guía ISO 26000:2010 son susceptibles de formar parte de los planes de salud con criterios de responsabilidad social. Así se ha puesto de manifiesto a través del análisis de materialidad llevado a cabo. Concluimos por lo tanto en la recomendación de que sean considerados en dichos planes de salud de las comunidades autónomas de forma genérica. La recomendación se basa en unas evidencias que han sido localizadas tanto a nivel teórico en las revisiones de la literatura como en la investigación social cualitativa posterior.

En la consideración práctica acerca de qué asuntos deberían ser incluidos en un plan de salud concreto sería recomendable atender a las características y circunstancias de cada comunidad autónoma. Cabe esperar que asuntos relativos a promoción e intervención en 
la comunidad local estén más desarrollados en unos planes que en otros, ya sea tanto por tradición o elección de los gestores, como por los posicionamientos ideológicos. Observamos que algunos de los asuntos señalados cuentan actualmente con un sistema de seguimiento e indicadores. Las cuestiones medioambientales tradicionalmente han merecido diferentes grados de atención comparada en las comunidades autónomas. En algunas de ellas encontramos capítulos específicos en la materia y en otras una ausencia completa al respecto.

Una implementación estratégica de políticas de responsabilidad social basada en ISO 26000 en las administraciones sanitarias podría contribuir de forma significativa en el proceso de desarrollo de materias y asuntos en sanidad. El primer paso recomendable pasaría por una autoevaluación del sistema, es decir, identificar aquellas buenas prácticas que se están llevando a cabo y que pueden ser encuadradas en un marco de actuaciones basadas en la guía de responsabilidad social. Sería útil establecer planes de acción según las recomendaciones de la guía para enlazarlos con las actuaciones propias del sistema sanitario y en particular, en aquellas que se relacionan con los grupos de interés. La inclusividad en el proceso de diseño de planes y la participación de los pacientes y sus familias.

A pesar de lo heterogéneo de un sistema con diecisiete comunidades autónomas y dos ciudades como Ceuta y Melilla, todas ellas con las competencias sanitarias transferidas, lo cierto es que la responsabilidad social supone un lugar común para todas. Los asuntos que se han relacionado y han sido sometidos a valoración de los encuestados y expertos no parecen depender de la localización, el idioma, los hábitos sociales o la ideología política del momento en cada comunidad autónoma, antes bien, suponen un nexo a través del cuál convergen los intereses legítimos en materia de sanidad de los ciudadanos del estado español.

Un sistema de indicadores comparables y reconocibles contribuye a dotar de comparabilidad las actuaciones y los resultados alcanzados en materia de sanidad y salud de la población. Las comunidades autónomas tienen una oportunidad excelente de impulsar su relación con los grupos de interés en sanidad y en hacer partícipe a la población del reto que supone en las sociedades modernas la provisión de estos servicios básicos y esenciales para el bienestar. Hacerlo con criterios de responsabilidad social contribuye a los objetivos establecidos en Naciones Unidas por la OMS y pone en valor la salud y el sistema sanitario como parte esencial del desarrollo sostenible. 
Los planes de salud tienen ya una larga tradición en nuestro país y la estandarización, la construcción de indicadores relacionados con el desarrollo sostenible y la publicación de informes de seguimiento no ha sido la norma. En este sentido una de las limitaciones en la aplicación de los resultados del estudio pasa por la falta de implementación de procesos estandarizados en la construcción de planes de salud. La descentralización y la visión diferenciada de las prioridades sanitarias por comunidades autónomas, nos lleva además a modelos de planes de salud heterogéneos y su encaje con un modelo basado en estándares e indicadores precisaría de una visión consensuada.

La aportación fundamental del trabajo realizado es mostrar el uso de una metodología descrita ampliamente en la literatura acerca del diálogo social con los grupos de interés, la identificación de asuntos relevantes y la construcción de una matriz de materialidad sobre la que basar el criterio de elección de planes de acción en la elaboración del plan de salud. La voluntad de establecer políticas públicas con miras hacia criterios de desarrollo sostenible y la propia sostenibilidad del sistema sanitario en sentido amplio, será condición previa para que se produzca un futuro uso del modelo propuesto. 


\section{Referencias}

Acuña, M. Guevara, H. Flores, M. 2014. El empoderamiento como estrategia de salud para las comunidades. Revista Cubana de Salud Pública. 40 (3) pp. 353-361.

Aguilar, I. 1996. La hechura de las políticas. Miguel Ángel Porrúa. México.

Anspach, R.R. 1993. Deciding Who Lives. Faitful Choices in the Intensive Care Nursery. University of California Press. Berkeley.

Atkinson, P. 1995. Medical Talk and Medical Work. Sage. London.

Ballester, F. Díaz, J. Moreno, JM. 2006. Cambio climático y salud pública: escenarios después de la entrada en vigor del protocolo de Kyoto. Gaceta Sanitaria 20, pp. $51-57$.

Balzarova, M.A y Castka. 2012. Stakeholder Influence and Contribution to Social Standards Development: The Case of Multiple Stakeholder Approach to ISO 26000 Development. Journal Business Ethics. 111, pp. 265-279.

Barbazza, E y Tello, J. 2014. A review of health governance: Definitions, dimensions and tools to govern. Health Policy. 116, pp. 1-11.

Beaudry, M. 2009. La nutrición Comunitaria desde la perspectiva de la Nutrición Pública. Bol Nutr Infantil Can.

Disponible en: http://www.cania.org.ve/PDF/Boletin5.pdf [Consultado 10 febrero, 2015

Berg, M. 1992. The construction of medical disposal. Medical Sociology and medical problem solving in clinical practice. Sociology of health and illness, 14. pp. 151180.

Berg, M. 1997. Problems and promises of the protocol. Soc. Sci. Med, 44, (8). Elsevier Science Ltd. pp. 1081-1088.

Birch, S. Gafni, A. 1992. Cost-effectiveness/utility analyses. Do current decisión rules lead us to where we want to be. J. Hith Econ.., 11. pp. 279-296. 
Blanco, I. Gomà, R. 2002. Proximidad y participación: marco conceptual y presentación de experiencias. Publicado en: I. Blanco y R. Gomà. Gobiernos locales i redes participativas. Ed. Ariel. Barcelona. pp. 21-42.

Bloor, M. 1976. Bishop Berkeley and the adeno-tonsillectomy enigma. Sociology, 10, pp. 43-61.

Blumenthal, D. 1996. Quality of care - What is it ? New England Journal of Medicine, 335, pp. 891-894.

Bosco, J. 1987. Investigación - Acción- Facultad de Desarrollo Familiar. Universidad de Caldas. Manizales.

Bozal, M. 2006. Escala mixta Likert - Thurstone. Anduli. Revista Andaluza de Ciencias Sociales, 5 .

Brodhag, C y Talière Sophie. 2006. Sustainable Development strategies: Tools for Policy coherence.

BSI. 2007. Occupational Health and Safety Management Systems. Specifications (BS OHSAS 18001-2007). British Standard Institution.

Callahan, D. 1998. La medicina imposible. Baldini \& Castoldi.

Campbell, S.M. Roland, M.O y Buetow, S.A. 2000. Defining quality of care. Social Science and Medicine, 51. pp. 1611-1625.

Canavese, D. Siqueira, N. 2013. A proposal of a fuzzy rule-based system for the analysis of health and health environments in Brazil. Ecological Indicators, 34, pp. 7-14.

Cañizares, MC. 2005. Los asentamientos humanos y la filosofía de la sostenibilidad. Revista de Salud Ambiental. 5 (2), pp. 126-130.

Casper, M. Berg, M. 1995. Constructivist perspectives on medical Work: medical practices and Science and technology studies. Science., Technology and Human Values, 20, pp. 395-407.

Civaner, M. Arda, B. 2008. Do patients have responsabilities in a free-market system? A personal perspective. Nursing Ethics, 15 (2) pp. 263-273.

Clark, J.A. Potter, D.A y McKinlay, J.B. 1991. Bringing social structure back into clinical decisión making. Social Science \& Medicine, 32, pp. 853-866. 
Counte, M y Meurer, S. 2001. Issues in the assesment of continuous Quality improvement implementation in health care organizations. International Journal for Quality in Health Care,13, (3) pp. 197-207.

Dejean, F. Gond, J.P. Leca, B. 2004. Measuring the unmeasured: An institutional entrepreneur strategy in an emerging industry. Human Relations, 57 (6) pp. 740764.

Doménech, M y Tirado, F. 2008. El problema de la materialidad en los estudios de la ciencia y la tecnología. Universidad Autónoma de Barcelona. (en prensa).

Donabedian, A. 1988. The quality of care. How can it be assesed. JAMA 260. pp. 17431748.

Donabedian, A. 1992. The seven pillars of quality. Arch. Pathol. Lab. Med, 114. pp. 1115-1118.

(EC). European Comission. 2001. Promoting a European Framework for Corporate Social Responsability. Brussel. p. 28.

Elkington, J. 1999. Cannibals with Forks: The Triple Bottom Line of 21st Century Business. Capstone Publishing Ltd. Oxford.

Erikson, PA. 1996. Occupational Health and Safety. Academic Press. San Diego. California.

Fisher, S y Todd, A.D (eds). 1983. The Social Organization of Doctor-Patient Communication. Center for Applied Linguistics, Washington, DC.

Franco-Giraldo, A y Álvarez-Dardet, C. 2008. Derechos humanos, una oportunidad para las políticas públicas en salud. Gaceta Sanitaria 22 (3), pp. 280-286.

Fransen, L.W. y Kolk, A. 2007. Global rule-setting for business. A critical analysis of mulit-stakeholder standards. Organizations, 14 (5), pp. 667-684.

GRI. Global Reporting Initiative. 2013. Guía G4 para la elaboración de memorias de sostenibilidad. Disponible en: www.globalreporting.org [Consultado, 20 febrero $\underline{2015]}$

González, N. Quintana, JM. Lacalle, JR. Chic, S. Maroto, D. 2009. Evaluación del uso apropiado de procedimientos sanitarios mediante el método RAND: revisión de 
su aplicación en la literatura biomédica (1999-2004). Gaceta Sanitaria 23 (3), pp 232-237.

Graña, F. 2005. ¿Democratizar la democracia? Las nuevas formas del diálogo social. Boletín Cinterfor - OIT (2a época)156, pp. 125-148.

Grau, M. Iñiguez-Rueda, L y Subirats, J. 2008. Un enfoque socio-técnico en el análisis de políticas públicas: un estudio de caso. Política y Sociedad, 45 (3) pp. 199217.

GRI. Global Reporting Initiative. www.globalreporting.org

Habich, R. Noll, H.H. 1994. Soziale Indikatorem und Sozialberichterstattung; internationale Erfahrungen und Stand der Forschung. Berne. Switzerland: Swiss. Federal Statistical Office.

Hahn, R. 2013. ISO 26000 and the Standardization of Strategic management Processes for Sustainability and Corporate Social Responsability. Business Strategy and the environment, 22. pp. 442-455.

Harteloh, P.P.M. 2003. Quality systems in health care: a sociotechnical approach. Health Policy, 64, pp. 391-398.

Hernández, I. y Lumbreras, B. 2014. Crisis e independencia de las políticas de salud pública. Informe SESPAS. Gaceta Sanitaria, 28 (S1) pp. 24-30.

Hernández, D. Delgado, I. Pérez, C. Hoyos, A. Gutiérrez, D. Gamba, M. 2104. Modificación de comportamientos en salud mediante la construcción de capacidades y la participación social. Revista Cubana de Salud Pública. 40 (2) pp, 258-267.

Irvine, D. 1990. Managing for quality in general practice. London: Kings Fund Centre.

ISO 26000:2010. Guía ISO de Responsabilidad Social.

Disponible en: http://www.iso.org/iso/home/standards/iso26000.htm

Jonker, J. 2000. Organizations as responsable contributors to society: linking quality, sustainabiity and accountability. Total Quality Management 11 (4/5/6). pp. 741 746.

Kickert, W.J.M. Klun, E y Koppenjan, J.F. Ed. 1998. Managing Complex Networks. Sage. Londres. 
Koskela, M. 2014. Occupational health and safety in Corporate social Responsability reports. Safety Science, 68 pp. 294-308.

Kurman, F. Duarte, V. L. Pacheco, W. 2012. Sustainable Development induction in organizations: a convergence analysis of ISO standards management tool's parameters. IOS Press. Work 41. pp. 2736-2743.

Lass, W. Reusswig, F. 2002. Social monitoring: meaning and methods for an integrated management in biosphere reserves. Biosphere Reserve Integrated Monitoring Series, 82 (1). pp 93-110.

Latour, B. 2005. Reassembling the social: an introduction to actor-network theory. Osford University Press. Nueva York.

Leach-Kemon, K. Chou, D.P. Schneider, M.T. Tardif, A. et al. 2012. The global financial crisis has led to a slowdown in growth of funding to improve health in many developing countries. Health Affairs. 31 (1) pp. 228-235.

Lynn, M.R. 1986. Determination and quantification of content validity. Nursing Research, 35 (6) pp. 382-385.

Maas, S y Reniers, G. 2014. Development of a CSR model for practice: connecting five inherent áreas of Sustainable business. Journal of Cleaner Production, 64, pp. 104-114.

Mackey, Tim K. Liang, Bryan A. 2013. A United Nations Global Health Panel for Global Health Governance. Social Science \& Medicine, 76, pp. 12-15.

Mann, JM. 1997. Health and Human Rights: if not know, When? Extracto publicado en American Journal of Public Health. 2006 (96) 11.

Mantilla, B. Oviedo, M. Hernández, A. Zoraida, N. 2013. Educación para la salud: una experiencia con población indígena del departamento de Chocó. Hacia la Promoción de la Salud. 18 (2) pp 96-109.

Marks, S. 2008. Health, Development and Human Rigths. Palgrave Macmillan.

Disponible en:

http://cdn1.sph.harvard.edu/wpcontent/uploads/sites/580/2012/10/marks_chapt 7 for_gatt_boggio_health_and_dev.pdf

[Consultado, 8 diciembre 2014] 
Marks, L. Cave, S. Hunter, D.J. 2010. Public health governance: views of key stakeholders. Public Health, 124, pp. 55-59.

Meier, B.M. Onzivu, W. 2014. The evolution of human Rights in World Health Organization Policy and the future of human Rights through global health governance. Public Health 128, pp. 179-187.

Meneu, R. Ortún, V. 2011. Transparencia y buen gobierno en sanidad. También para salir de la crisis. Gaceta Sanitaria 25 (4) 333-338.

Mikkelsen-López, I. Wyss, K. De Savingy, D. 2001. An approach to addressing governance from a health system framework perspective. BMC International Health and Human Rights. 11 (13).

Montero, MJ. Araque, R. Rey, JM. 2009. Occupational health and safety in the framework of Corporate social responsability. Safety Science 47 pp. 1440-1445.

Morales, P. 2000. Medición de actitudes en psicología y educación; construcción de escalas y problemas metodológicos. Universidad Pontificia Comillas. pp 46.

Muñoz-Torres, MJ. Fernández-Izquierdo, MA. Rivera-Lirio, J. León-Soriano, R. Escrig-Olmedo. E. Ferrero-Ferrero, I. 2012. Materiality Analysis for CSR Reporting in Spanish SMEs. International Journal of Management, Knowledge and Learning, 1 (2), pp. 231-250.

Niskala, M. Pajunen, T. Tarna-Mani, K. 2009. Yhteiskuntavastun raportointi; Raportointi-ja laskentaperiaatteet (Corporate Social Responsability reporting; Reporting and accounting principles) KHT-media. Helsinki.

OMS. 2008. Derechos humanos, salud y estrategias de reducción de la pobreza. Serie de publicaciones sobre salud y derechos humanos. 5 .

Reese, CD. 2003. Occupational Health and Safety Management. Lewis Publisher. New York.

Pega, F. Valentine, N.B. Matheson, D. Rasanathan, K. 2014. Public social monitoring reports and their effect on a Policy programme aimed at addressing the social determinants of health to improve health equity in New Zeland. Social Science and Medicine, 101, pp. 61-69. 
Ranangen, H. Zobel, T. 2014. Exploring the path from management systems to stakeholder management in the Swedish mining industry. Journal of Cleaner Production, 84, pp. 128-141.

Russo, F. 2014. What is the CSR`s Focus in Healthcare? Journal of Business Ethics. Published online. DOI 10.1007/s10551-014-2430-2

Schell, S. Luke, D. Schooley, M. Elliot, M. Herbers, S. Mueller, N. Bunger, A. 2013. Public health program capacity for sustainability: a new framework. Implementation Science 8:15.

Smith, P. Anell, A. Busse, R. Crivelli, L. Healy, J. Lindahl, A.K. Westert, G. Kene, T. 2012. Leadership and governance in seven developed health systems. Health Policy 106, pp. 37-49.

Schneider, B. 1980. The service organization: Climate is crucial. Organizational Dynamics. 9, pp. 52-55.

Sridhar, D y Batniji, R. 2008. Misfinancing global health: a case for transparency in disbursements and decisión making. The Lancet, 372, (9644), pp. 1185-1191.

Steffen, G.E. 1988. Quality medical care: A definition. JAMA, 260. pp 56-61.

Stiglitz, J. Sen, A. Fitoussi, J. 2009. Changing trends in indigenous inequalities in mortality; lessons from New Zeland. International Journal of Epidemiology, 38 (6), pp. 1711-1722.

Strauss, A, et al. 1985. Social Organization of Medical Work. University of Chicago Press. Chicago.

Stroetmann, K. 2013. Achieving the integrated and Smart health and wellbeing paradigm: A call for policy research and action on governance and business models.

Tarlov, A.R. Ware, J.E. Greenfield, S. Nelson, E.C. Perrin, E y Zubkoff, M. 1989. The medical outcomes study: An application of methods for monitoring the results of medical care. JAMA, 262. pp. 925-930.

Taylor, A.L. Alfuen, T. Hougendobler, D. Tanaka, S. Buse, K. 2014. Leveraging nonbinding instruments for global health governance: reflections from the Global AIDS Reporting Nechanism for WHO reform. Public Health. 
Tirado, MC. Cambio climático y salud. Informe SESPAS 2010. Gaceta Sanitaria, 24 (suplemento) pp. 74-84.

Trochim, K. 2007. VMK: Concept Mapping for Planning and Evaluation. Thousand Oaks: Sage.

Van Olmen, J. Marchal, B. Van Damme, W. Kegels, G. Hill, PS. 2012. Health systems frameworks in their political context: framing divergent agendas. BMC Public Health. 12 (774).

Vveinhardt, J. Gulbovaité, E. 2015. Expert Evaluation of Diagnostic Instrument for Personal and Organizational Value Congruence. Journal of Business Ethics. Publicado online. (doi:10.1007/s10551-014-2527-7).

VV.AA. Recursos Mundiales. 1998. La guía global del medio ambiente. Ministerio de Medio Ambiente. Instituto de Recursos Mundiales, 22.

WHO. 2010. Guidelines for indoor air quality: selected pollutants. World Health Organization.

Young, A. 1981. The creation of medical knowledge: some problems in interpretation. Social Science \& Medicine 15B, pp. 379-386. 